\title{
Biobased composites from agro-industrial wastes and by-products
}

\author{
Florencia Ortega ${ }^{1} \cdot$ Florencia Versino $^{1}$ - Olivia Valeria López $^{2} \cdot$ María Alejandra García $^{1}$
}

Received: 5 July 2021 / Accepted: 14 October 2021 / Published online: 25 November 2021

(c) Qatar University and Springer Nature Switzerland AG 2021

\begin{abstract}
The greater awareness of non-renewable natural resources preservation needs has led to the development of more ecological high-performance polymeric materials with new functionalities. In this regard, biobased composites are considered interesting options, especially those obtained from agro-industrial wastes and by-products. These are low-cost raw materials derived from renewable sources, which are mostly biodegradable and would otherwise typically be discarded. In this review, recent and innovative academic studies on composites obtained from biopolymers, natural fillers and active agents, as well as green-synthesized nanoparticles are presented. An in-depth discussion of biobased composites structures, properties, manufacture, and life-cycle assessment (LCA) is provided along with a wide up-to-date overview of the most recent works in the field with appropriate references. Potential uses of biobased composites from agri-food residues such as active and intelligent food packaging, agricultural inputs, tissue engineering, among others are described, considering that the specific characteristics of these materials should match the proposed application.
\end{abstract}

Keywords Sustainability $\cdot$ Biomass $\cdot$ Composite materials $\cdot$ By-products $\cdot$ Agri-food waste $\cdot$ Biodegradable

\section{Introduction}

Climate change due to greenhouse gases emissions (GGEs) is only one of the several problems derived from an unsustainable linear economy: such as hiking raw materials prices, increasing products demand, resources depletion, irreversible environmental damage, and waste accumulation. Thus, a new regenerative economic view based on a balance between economy, environment, and society aims at a circular production/consumption system seeking to maximize resources use and avoid or, at least, minimize environmental impact [1]. A circular approach implies the substitution of fossil fuels as an energy source and petroleum-based products, such as plastics, for sustainable energy systems (i.e., solar, eolic, biofuels, etc.) and renewable feedstock (mainly biobased products); the development of easily recyclable or

María Alejandra García

magarcia@quimica.unlp.edu.ar

1 Centro de Investigación y Desarrollo en Criotecnología de Alimentos (CIDCA), UNLP-CONICET-CICPBA, 47 y 116 (1900), La Plata, Argentina

2 Planta Piloto de Ingeniería Química (PLAPIQUI), UNS-CONICET, Camino La Carrindanga km.7 (8000), Bahía Blanca, Argentina biodegradable products; optimization of waste management systems; and the design of products from residues.

Most petroleum-based plastics are highly resistant to degradation in nature, being able to persist for hundreds of years in the environment [2]. Even though they are potentially recyclable, only about $20 \%$ of all the plastic produced globally is properly recycled or reused [3]. Even with efficient waste management and recollection systems, the recovered polymers are often shipped to countries with low environmental regulations and control [4]. These, along with the continuous increase in total plastic production and consumption have led to severe plastic pollution, especially in the marine environment. Plastic littering in the oceans represent a hazard to marine fauna, directly damaging their habitat, constituting dangerous traps, and tampering with their food chain. Microplastic, plastic broken into small pieces by erosion, is ingested by marine mammals, reptiles, birds, and fish which can be mortal and affects seafood safety, hence human health [5]. Besides, plastic accumulated in coastal regions degrade their natural attraction having a further impact on tourism and local economies based on this activity. Therefore, biobased and biodegradable plastics have gained interest as potential substitutes for conventional polymers with a growing market and a global production accounting for 
about one percent of the over 368 tons of plastic that are nowadays annually produced [6]. Given their biodegradability, these biobased materials offer new end-of-life routes such as organic recycling through aerobic or anaerobic degradation, agricultural mulching, solubilization, or biodegradation in the environment, resulting in fewer wastes accumulation and soil contamination [1].

Given this context, a transition towards sustainable biobased productions is sought. Generally, biomass is recognized as a sustainable alternative to fossil fuels due to its abundant availability, carbon neutrality, and low sulfur content. However, if not based on a sustainable approach biofuels production entails extensive land use, soil acidification, and eutrophication among other environmental impacts related to intensive agro-industry such as competition amid food and energy crop growing and limited net GGE reductions [7]. In this regard, biodegradable and biobased plastics face similar challenges as alternatives to conventional plastics. Therefore, more sustainable biofuels and biobased products, such as food and pharmaceutical ingredients; fine, specialty, and commodity chemicals; polymers; and fibers have been developed from non-food crops, agricultural wastes, and forest residues to be coproduced in biorefineries [8]. Particularly, the use of agri-food waste has enormous potential in sustainable bioeconomy or green economies considering the food manufacturing industry [9]. In traditional agricultural settings, production residues are usually burnt or landfilled, which results in a noticeable $\mathrm{CO}_{2}$ generation [10]. Other typical agri-food waste management implies its use as animal feed or fertilizer supply, composting, and anaerobic digestion, yet recovery and valorization capacity of these residues remain quite limited [11]. Considering that five percent of global GGEs originate from organic waste decay and that agri-food residues contain macromolecules, such as carbohydrates, proteins, and lipids, as well as active compounds and pigments, strategies to obtain higher value-added materials from agri-food wastes and by-products are both urgent and conceivable $[9,12]$. Numerous researches have been done and reviewed in this regard, from agro-industrial waste and by-products as feedstock for biofuels and bioplastic synthesis [8,13-15], direct biopolymers, and active compounds extraction from agri-food residues $[9,16,17]$, are reinforcing materials for composite materials [10,18-24]. Therefore, the present review focuses on revising and comparing the existing studies on fully biobased composite and nanocomposite materials, considering different processing technologies, and analyzing the potential uses of the developed materials. Current limitations on fully biobased products design and market as well as LCAs availability are discussed, aiming to give a relatively broad outlook on the state of the art and future perspectives on the field of sustainable biocomposite materials.

\section{Potential agro-industrial wastes and by-products for biobased composites}

\subsection{Bioplastics}

Plastic material is defined as bioplastic if it is either biobased, biodegradable, or features both properties. The term biobased implies that its components are mainly derived from biomass, while biodegradation is a chemical process by which a material is converted into water, carbon dioxide, and compost by the action of naturally available microorganisms under normal environmental conditions. For a polymer to be categorized as biodegradable bioplastic should as well meet the following criteria [25]:

- Chemical characteristics: at least $50 \%$ of its final composition should be necessarily organic matter.

- Biodegradation: it should degrade by a minimum of $90 \%$ of its weight/volume within 6 months under-stimulated composting conditions.

- Ecotoxicity: non-degradable residuals after biodegradation for 6 months should not be a potential threat to plant's growth.

- Disintegration: components' microscopic fragments should be undetectable $(<2 \mathrm{~mm})$ at least within 2 months under controlled composting conditions.

Bioplastics (both biodegradable and nonbiodegradable) can then be classified into 4 main groups: directly extracted from biomass, synthesized from a biobased monomer, synthesized from petrochemicals, and produced by microorganisms (Figure 1). They comprise a whole family of materials with different properties and applications and are nowadays ecological alternatives for many conventional plastics. The latest market data compiled by European Bioplastics in cooperation with the novaInstitute reported that the global bioplastics production capacities are set to increase from 2.11 million tons to approximately 2.87 million tons between 2020 and 2025, of which biodegradable and biobased bioplastics accounts for over $50 \%$ of the market [6]. In agreement with Siakeng et al. [26]: the biodegradable character creates a positive impact in society and also attracts researchers and industries. Therefore, this work focuses on those bioplastics that are essentially biodegradable and extracted directly from biomass or obtained by microbial fermentation of biomass.

\subsubsection{Biopolymers from biomass}

Polysaccharides are the most abundant macromolecules in nature, being many of them suitable raw materials for bioplastics. They are nontoxic and widely available since 
Fig. 1 Bioplastics classification according to production process and origin with some examples

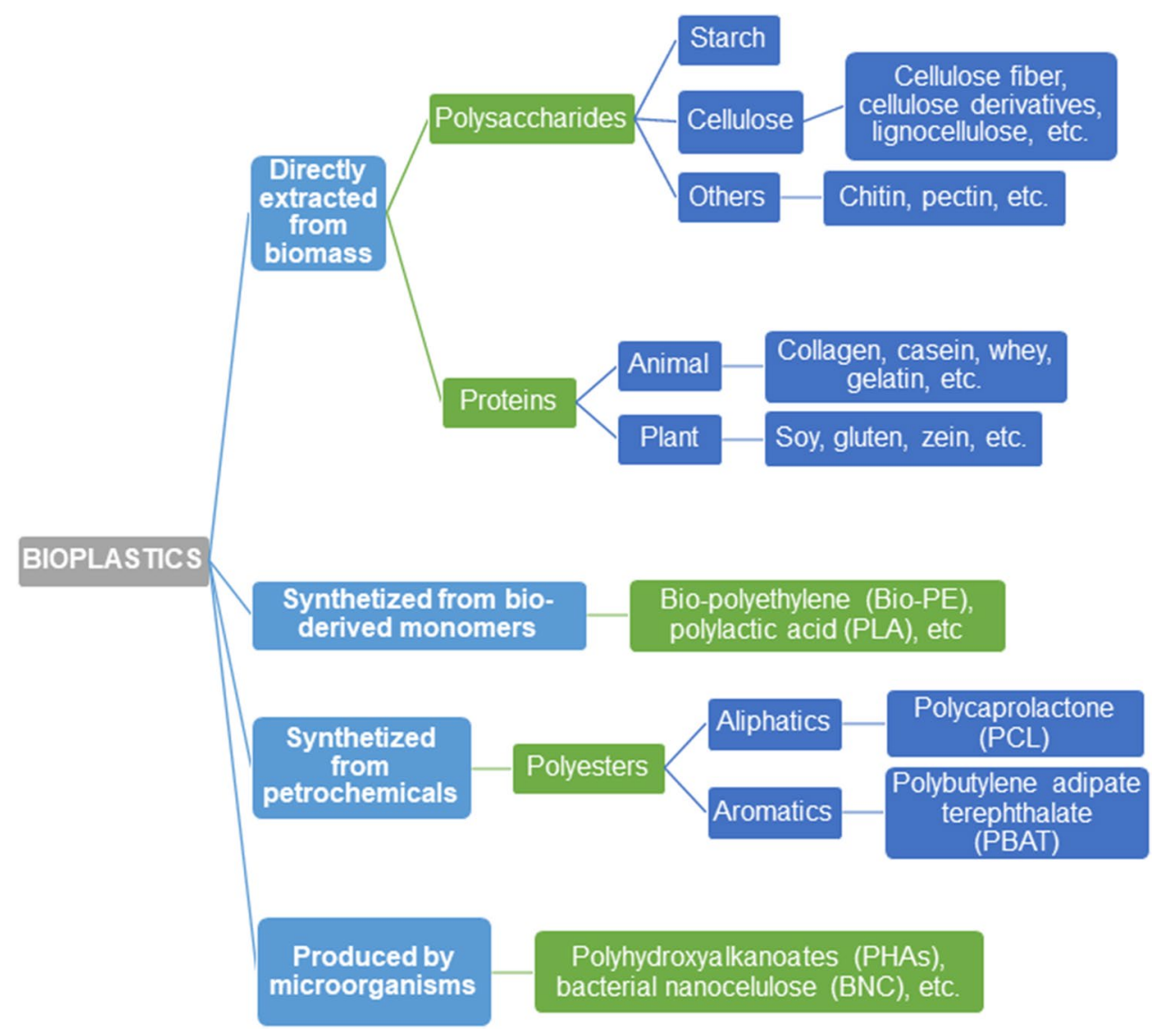

they can be obtained from many different sources such as plants, microorganisms, algae, and animals. Due to their physicochemical properties, many of them are susceptible to physical and chemical modifications leading to enhanced properties with various applications as biomaterials [27].

In particular, cellulose is a widely available polysaccharide derived from renewable resources [28]. It is generally synthesized by plants, but it is also produced by some bacteria. Plant-derived cellulose is usually found mixed with hemicellulose, lignin, pectin, and other substances, while bacterial cellulose is quite pure and has much higher water content and tensile strength owing to its longer polymer chains. The most used cellulose derivatives are methylcellulose (MC), hydroxypropyl methylcellulose (HPMC), and carboxymethyl cellulose (CMC) [29]. Above all, CMC has been reported to have excellent film-forming properties by thermal gelatinization with water-soluble polymers [30]. Moreover, nanocellulose or nanocrystalline cellulose is a versatile material with great mechanical and chemical resistance that is becoming increasingly valued for several applications, from packaging to electronics, yet limited by availability and cost [31-33].

Most plants produce starch as energy storage; thus, this polysaccharide can be extracted from rice, cassava, corn, wheat, and potatoes, among others. Starch is a carbohydrate that contains a great amount of glucose units combined through glycosidic links, however functional and structural dissimilarities are present among different botanical species [34]. Starch differ in type and content of two constitutive D-glucose macromolecules: amylose, linear, and helicoidal polymer; and amylopectin, with a branched structure [35]. The amylose content may vary from 20 to $25 \%$ in cereal starches, 15 to $30 \%$ in roots and tuber starches, and up to $40 \%$ in fruit starches, while the amylopectin content varies from 75 to $80 \%$ by weight. Even though starch has proven thermoplastic properties, its efficiency as a raw material for bioplastics depends upon its specific structure and composition [36]. Thermoplastic starch is obtained by the starch granule disruption in the presence of plasticizers. Extrusion processing employing low moisture content, high temperature, and pressure melts the starch granules into a single continuous phase component that can later be mixed with other components to form a film [25].

Pectin is an important natural polymer with diverse industrial applications. It is present in various fruits and vegetables such as berries, apples, and oranges and is extracted mainly from the processing residues of these agricultural products $[37,38]$. Pectin has attracted great interest because of its distinctive characteristics: it has the ability to freeze in the presence of acids and sugars, presents high viscosity

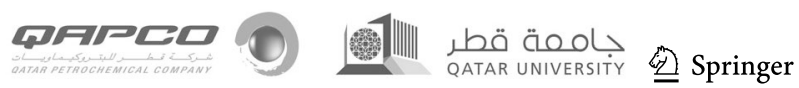


and aqueous-absorbent gel properties, and it is easily soluble in water but is insoluble in ethanol [39]. Therefore, it shows great potential for the development of biobased membranes, films, and edible coatings in the food packaging field [40, 41]. Pectin films are effective in the protection of low moisture food [42], while pectin coating are used to preserve fresh fruits and vegetables [38]. Moreover, cross-linking of pectin films with polyvalent cations, such as calcium, enhance their mechanical properties [43].

Likewise, being the second-most abundant biopolymer in the world (after cellulose), chitin is a promising raw material for bioplastics. It is the main structural component of the fungi cell wall and can be also found in shells of oceandwelling crustaceans such as crab and shrimp. Chitosan is obtained from the chemical modification of chitin, extracted from fungi and shells, after numerous chemical treatments. Soluble in weak acid solutions, chitosan can be dried to a solid plastic film and strengthened by soaking in alkaline solutions with promising uses for packaging and medical applications [44-49]. In addition, near 150,000 tons of chitin-rich waste is annually produced by the seafood industry worldwide [50]. These residues have a high environmental impact, little commercial uses, and high waste-disposal cost, thus extracting a high-added-value bioplastic from this waste creates an excellent cost-effective and more sustainable opportunity for the seafood industry.

Regarding marine origin biopolymers, carrageenan and alginate are worth mentioning as anionic polysaccharides found in the outer cell wall of red and brown algae. Alginates have been used for encapsulation of chemical and biological compounds with a wide range of applications in agriculture, food technologies, pharmaceutical cosmetics, chemical engineering, environmental engineering, paper and textile industry, and many others due to their nontoxicity, biocompatibility, and the ability to cross-link with cations [51-55].

Furthermore, many proteins from vegetable and animal sources can be used as the raw material for developing bioplastics materials. Wheat gluten, for instance, a by-product from the bio-ethanol industry, is relatively inexpensive, abundant, and basically used as animal feed but is thermoplastic in nature and presents interesting film formation capacity, gas barrier, mechanical and biodegradation properties that have risen the interest in its use in the packaging industry [56]. Wheat gluten-based biocomposites and nanocomposites with improved barrier and mechanical properties particularly suitable for packaging have been reported [57, 58].

\subsubsection{Polymers from microorganisms}

Microorganisms are a source of biopolymers using agricultural wastes as growth media. Although currently more expensive, bacteria have the potential of yielding bioplastics having properties comparable to those of conventional polymers that can be further modified by changing the growing medium and conditions of the bacteria. Bioplastics from the microbial production process have been optimized with a wide range of end products showing diverse properties [25]. Numerous of these microbiologically synthesize biopolymers have gained acceptability in food and other industrial applications among which polyhydroxyalkanoates (PHAs) have attracted particular interest. PHAs are polyesters of hydroxy acids naturally synthesized by bacteria as carbon reserves. These biopolymers are accumulated as cytoplasmic inclusions in certain bacteria during unbalanced growth conditions, usually characterized by an excess in feed supply and the lack of one or more essential nutrients [59]. PHAs are synthesized by different groups of bacteria from cheap renewable resources, yet in order to effectively exploit the commercial production of these biopolymers, it is important to select a bacterial strain having the highest PHAs yields growing on inexpensive carbon sources with efficient fermentation and requiring simple recovery processes.

More than 150 different PHA monomers have been identified, which renders them the largest group of natural polyesters [60]. For instance, poly(3-hydroxybutyrate) (PHB), poly(3-hydroxyvalerate) (PHV), and their copolymer poly(3-hydroxybutyrate-co-3-hydroxyvalerate) (PHBV) are typical examples of short-chain-length PHAs. Particularly, PHB is the most popular and promising PHA as an alternative biomaterial, since it has similar properties to conventional polyesters such as PE and polypropylene (PP) [61]. Its application includes packaging materials, bags, containers, sutures, targeted tissue repair, and regeneration devices, cardiovascular stents, polymer-based depots for controlled drug release or implants, and disposable items like singleuse cups and diapers [62]. Despite its biobased nature, biodegradability, and versatility, the high production cost of PHB is the main obstacle for its commercialization, being this at least three times higher than the conventional plastics such as PP and PE and similar to biopolymers like PLA [14]. Such high costs are mainly attributed to expensive substrates and processing [63]. Therefore, the use of cheaper feedstocks is a key factor towards reducing PHB production costs. Food wastes [64], wastes from beer breweries [65], cheese whey [66], olive mill wastewater [67], and hydrolyzed corn starch [68] are some resources that have been investigated for sustainable PHB production.

In the last decades, bacterial nanocellulose (BNC) has gained increasing interest because of its remarkable physical and chemical properties, including green technology processing, low production costs, elevated mechanical properties, hydrophilicity, and excellent biocompatibility and biodegradability [69]. Certain gram-negative non-pathogenic bacteria genera were reported to produce nanocellulose 
extracellularly [70]. It should be noted that despite sharing a common backbone there are marked differences between plant and bacterial cellulose. Plant fibers are composed of lignin, hemicelluloses, pectin, and only $40-70 \%$ of cellulose [71]. In contrast, bacterial cellulose is made up of pure cellulose nanofibers, displaying high purity and strength, without requiring subsequent refining treatments. BNC ultrafine structure presents higher crystallinity and polymerization degree, greater liquid absorption capacity, larger specific surface area, and better mechanical properties making it a superior choice to plant-sourced cellulose in many applications, especially in packaging [72] and biotechnological industry [73].

\subsubsection{Polymers synthesized for monomers derived from biomass}

Among bioplastics biobased nonbiodegradable polymers as bio-PP or bio-PE account for $41.8 \%$ of the current global bioplastics production [6]. Meanwhile, along with starchbased bioplastics, PLA is one of the most largely produced biodegradable biobased polymers ( $18.7 \%$ of the total annual bioplastic production in 2020). This versatile compostable biopolymer is synthesized from lactic acid, a naturally occurring organic acid easily produced by chemical synthesis or fermentation. Similar to other bioplastics, one of the main obstacles in PLA commercial use is their cost, thus the use of blends with cheaper biodegradable biobased polymers (i.e., starch) and its biocomposites with low-cost natural fillers has been studied and reported [74, 75]. PLAbased packaging can now be purchased almost everywhere, from food containers, disposable cutlery to suture thread and 3D printing filaments. Consequently, research on enhanced PLA biocomposite for such applications is still under study [74, 76-81]. Due to its biocompatibility, biodegradability, nontoxicity, and high strength, it has been studied for innovative biomedical and pharmaceutical applications, as drug delivery systems, wound dressing, and scaffolds for cellular growth [82, 83].

\subsection{Reinforcing materials}

In spite of their renewable and biodegradable character, the mechanical resistance, permeability and thermal stability of biopolymers tend to be relatively low for some applications [84-86]. Consequently, the best approach to improve their properties and commercial importance is to incorporate reinforcing agents [86-90]. The resulting materials known as environment-friendly polymer composites, biopolymer composites, or biocomposites, have a wide range of nextgeneration applications in medicine, electronics, construction, packaging, and automotive sectors [91]. Composites can be defined as materials that are formed by two or more constituents which have separate phases and compositions conforming to micro- or nano-structures. The composite properties are strongly dependent on the matrix (continuous phase) and filler (discontinuous phase) interfacial adhesion, as well as the reinforcement composition, size, shape, and content [90]. The smaller the filler particle size, the greater the efficiency for the formation of composites [89]. Biopolymer composites are synthesized using numerous methods, being in-situ reaction, solution casting method, and melt mixing technique the most employed. Diverse types of fillers can be used that, as suggested by Kumar et al. [92], can be divided following several criteria as shown in Figure 2.

In this work, the first classification according to fillers' origin and composition was considered. Distinctively, organic fillers derive from living organisms and are usually carbon-based compounds, while inorganic fillers are salt, metal, and elemental compound obtained from inert things. A further description of nanosized fillers $(<100 \mathrm{~nm})$ obtained by sustainable technology was included due to their key importance in high-performance eco-friendly biocomposite applications.

\subsubsection{Organic fillers}

Most of the organic fillers used in green composites (both biobased and non-biobased) are derived from renewable sources and are generally cellulose-rich materials. Natural cellulosic fibers, such as hemp, sisal, jute, kenaf, flax, and bamboo, among other plant tissue fibers, have been extensively used as filler of polymer composite materials as substitutes for glass-fiber mainly due to their lower density and cost, their renewable character and because they are less abrasive to processing equipment [85, 93]. Green composite materials have been extensively studied and applied in the transport and construction industries, from windows frames and insulation panels to railroad sleepers and automotive parts, and various other low-cost and mild-mechanical-demanding applications such as gardening items, agriculture mulch, and packaging [22, 94-99]. Therefore, interest in renewable and biodegradable fillers has grown as new sustainable materials are sought, specifically since these organic fillers can be obtained from agro-industrial or wood byproducts and residues [23, 88, 98, 100-102]. In this regard, fillers with diverse mechanical and surface properties, chemical composition, size, and form have been studied. Besides, conventional fibers from plant leaves and stems that are cultivated for their fibers, other such as wheat husk [103], rice straw [104], sugarcane bagasse [105], malt bagasse [106], banana leaves, and peel fibers [17, 77, 107] are by-products of agri-food production that, among others, have been studied as biocomposite fillers [18, 108-110]. Furthermore, starch from roots and tubers bagasse and peel have also been reported [19, 98, 101, 111-113], as well

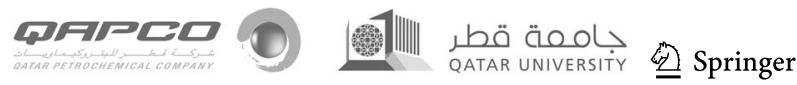


Fig. 2 Biopolymer fillers sorting according to three different criteria with some examples

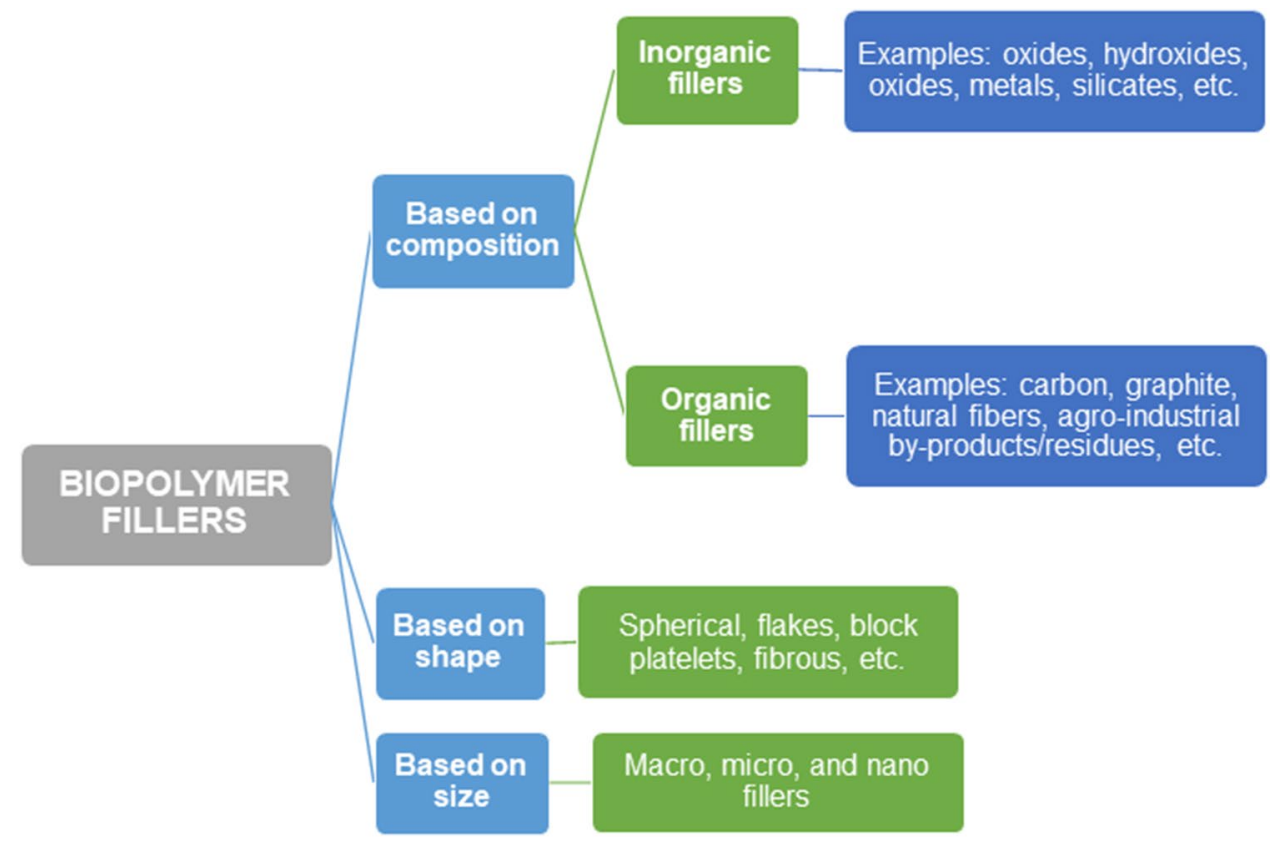

as algae, microalgae, and their byproducts [83, 114-117]. Recently, grasses such as Sabai grass (Eulaliopsis binata), an undervalued abundant grass in Asia [118], Cogon grass (Imperata cylindrica), one of the ten most aggressive weeds in the world [119], and Napier (Pennisetum purpureum schum) grass [120] have been considered as composite fillers with promising results. Novel green biocomposites have been lately developed from coffee silverskin and starch-rich potato washing slurries [121] or tea leaves from tea brewing wastes [122]. Oil industry by-products, as for instance sesame, rapeseed, peanut, and sunflower oil cakes have also been investigated as fillers for biocomposite films and foams [21, 123-127].

Increasing fiber contents tend to promote stiffer materials with higher impact strength yet diminishing their flexibility. Nevertheless, properties are dependent on filler source and content, surface treatments, particle size distribution, and processing conditions [88, 100, 101, 128-130]. In general, plant tissue fibers are composed of cellulose, hemicellulose, and lignin and their reinforcing efficiency depend on the cellulose nature and crystallinity and its alignment in the cell walls: high cellulose content and low microfibril angle (MFA, defined as the angle microfibrils make with respect to the fiber axis) are desirable [131, 132]. Yet, natural fibers have low thermal stability (approximately up to $200{ }^{\circ} \mathrm{C}$ ) which limits the processing conditions and the recyclability of biocomposites [85]. Nonetheless, as reported by Ramamoorthy et al. [133] and Chaitanya et al. [74], fiber thermal stability can be enhanced in composite materials as the polymer matrix protects the fiber from degrading. Chemical, physical, and biological pretreatments of the fibers have been firstly proposed to improve filler-polymer interaction in hydrophobic polymer matrices, though such treatments also result in cleaner surfaces, higher moisture content, and thermal stability [134-140]. Notwithstanding, various factors should be assessed in choosing fillers treatments as for enhancing biocomposites properties without compromising their sustainable character: energy and resources consumption and processing cost (especially in the case of complex techniques that result impractical for industrial applications), effluents characteristics and volume generated, reagents toxicity in long term exposures (for work safety) and life cycle environmental impact of the process. Still, one of the major problems in the use of plant-based fillers is their properties fluctuation with botanical source, cultivation region (with different climate conditions and soil composition), and harvest season, which can be somewhat tackled by mixing batches of sources or types of fibers [131].

Other organic fillers are extracted from wastes. Figure 3 illustrates the main sources of organic fillers with some examples for each. Cellulose micro and nanofibers have been isolated by a series of alkali, acid, and mechanical treatments that breakdown the original plant tissue from various sources: soybean hulls [141], sugarcane and cassava bagasse [142-145], and corncob and pinewood [146], among others [120, 147, 148]. Similarly, lignin can be extracted for lignocellulose byproducts and waste [149]. Keratin and chitin, which are extracted from animal feed waste such as chicken wings or shrimp shells are also employed as composites fillers [22, 150-153]. Furthermore, biochar or activated carbon can be obtained from various biomass sources through pyrolytic processes $[154,155]$. Both present high adsorption capacity, resulting in special interest in water and air decontamination. 


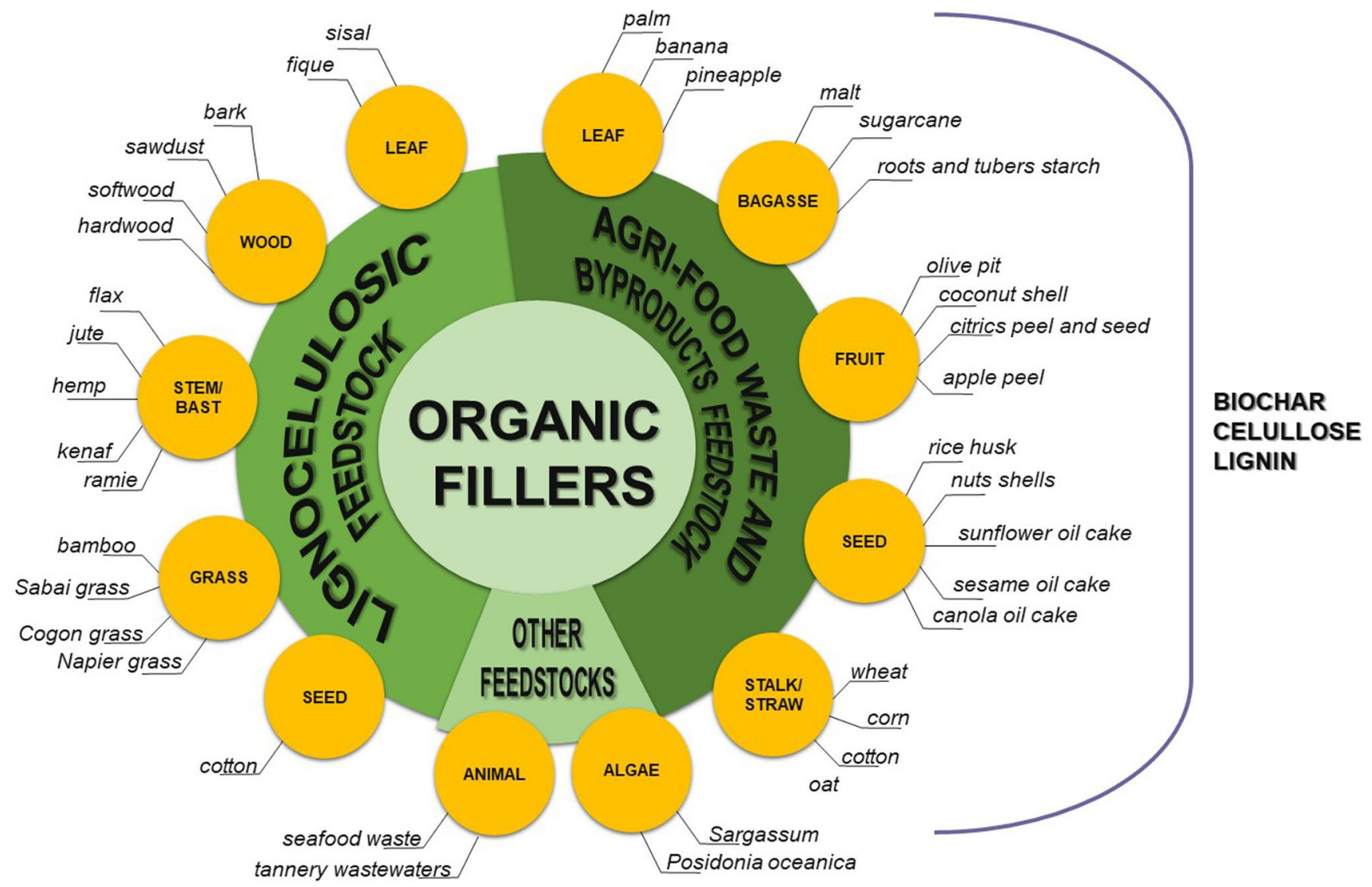

Fig. 3 Organic fillers main sources and some examples for each

\subsubsection{Inorganic fillers}

Mineral or metallic fillers are considered inorganic fillers: clay and nanoclay, silver nanoparticles (AgNPs), and calcium carbonate $\left(\mathrm{CaCO}_{3}\right)$ are among the most common inorganic reinforcement agents of biocomposites.

Due to its great natural abundance, clay is the most frequently used inorganic filler in the composite field. These are phyllosilicate minerals usually obtained from the chemical weathering of other silicate minerals on earth [156, 157]. Clay has a good intercalation property and can swell with the absorption of water [158]. Clay can be classified into a variety of groups including kaolinite, montmorillonite, illite, chlorite, and fibrous silicate [90]. Bentonites consist mainly of montmorillonite and can be used as adsorbents, ion exchangers, wine clarification agents, and catalysts. Besides due to their eco-friendly character, availability, and reusability have also been studied as reinforcing agents of polymeric matrices $[159,160]$. For their applications, the pillaring process is commonly used to modify the structural, thermal, and surface properties of bentonites. In this regard, Ninago et al. [161] proposed an environmentally friendly method to obtain Al-pillared clays by using microwave irradiation.
Among minerals, calcium carbonate $\left(\mathrm{CaCO}_{3}\right)$ is a widely inorganic material used as a viscosity modifier in many industries, which is normally obtained from carbonatitelava, stalactites, stalagmites, skeletons, or shells of some animals. It is an inorganic filler with various potential applications owing to its low-cost, abundance, and safe character [162]. Meanwhile, talc also qualifies as a good reinforcement agent because of its platy nature, presenting micron-sized length and width and nanometric thicknesses, as well as a high aspect ratio (particle diameter/thickness 20:1)[163].

Moreover, granite sand (GS) is an industrial waste derived from the granite polishing industry that can cause health problems and air pollution due to its powder form. Therefore, it is highly desirable to find uses in an effective manner to minimize these damages, reducing as well the need for new dump lands for these wastes [164]. Granite sand is a mixture of different minerals composed of muscovite, orthoclase, quartz, and biotite, among others. Particularly, muscovite is a laminar silicate of the micas-clays family and its structure facilitates the intercalation of organic-inorganic species between mineral slabs, which makes muscovite an excellent filler for polymeric materials [165]. Passaretti et al. [166] employed GS particles as fillers of thermoplastic corn 
starch films, demonstrating the potentiality of this mineral for this application.

Figure 4 shows a schematic representation of the processing of biocomposite materials with inorganic fillers as well as some examples of SEM micrographs of different inorganic fillers.

\subsubsection{Nanoparticles: green synthesis}

Nano-sized particles are characterized by their high surfaceto-volume ratio, which confers exceptional features on them. They are synthesized through physical, chemical, or biological methods, that are classified into top-down and bottom-up synthesis regarding whether the reagents are inorganic or are generated from the break-down of a macroscopic material by some external agent (Figure 5). Several physical and chemical methods like hydrothermal, sol-gel synthesis, laser ablation, or lithography, among others, require special equipment and skilled labor [167-169]. In addition, some of these techniques involve the use of toxic reagents that pose health and environmental hazards [168, 170]. For instance, silver nanoparticles (AgNPs) can be obtained by the reduction of a silver salt using strong reducers such as sodium borohydride, which is an extremely irritant and corrosive agent with high flammability risk [171]. Nowadays, green chemistry aims at the total or partial elimination of chemical waste and the implementation of nontoxic reagents, environmentally acceptable solvents and renewable materials, obtaining products with high thermal stability, low volatility, and cost-effective production [172-176]. Not only do these eco-friendly techniques reduce the use of hazardous substances, but also employ natural renewable compounds like polysaccharides, proteins, or those derived from vegetable extracts (mainly leaves, roots, and flowers) and microorganisms like bacteria, fungi, and algae, as reducing or capping agents [177-180]. Therefore, the three main concepts of nanoparticles green synthesis are the choice of the solvent (preferably water); the use of an ecological reducing agent, GRAS (substances generally recognized as safe), or natural reagents; and a nontoxic material for nanoparticles stabilization (i.e., biopolymers). Products of natural origin contain in their structure phenolic compounds, reducing sugar and nitrogen compounds that can reduce metal cations to generate nanoparticles and, in certain cases, can also act as stabilizers (Figure 5). In turn, the implementation of these compounds is also advantageous from the economic point
Fig. 4 Schematic representation of the processing of biocomposite materials with inorganic fillers as well as some examples of SEM micrographs of different inorganic fillers
Biodegradable polymer

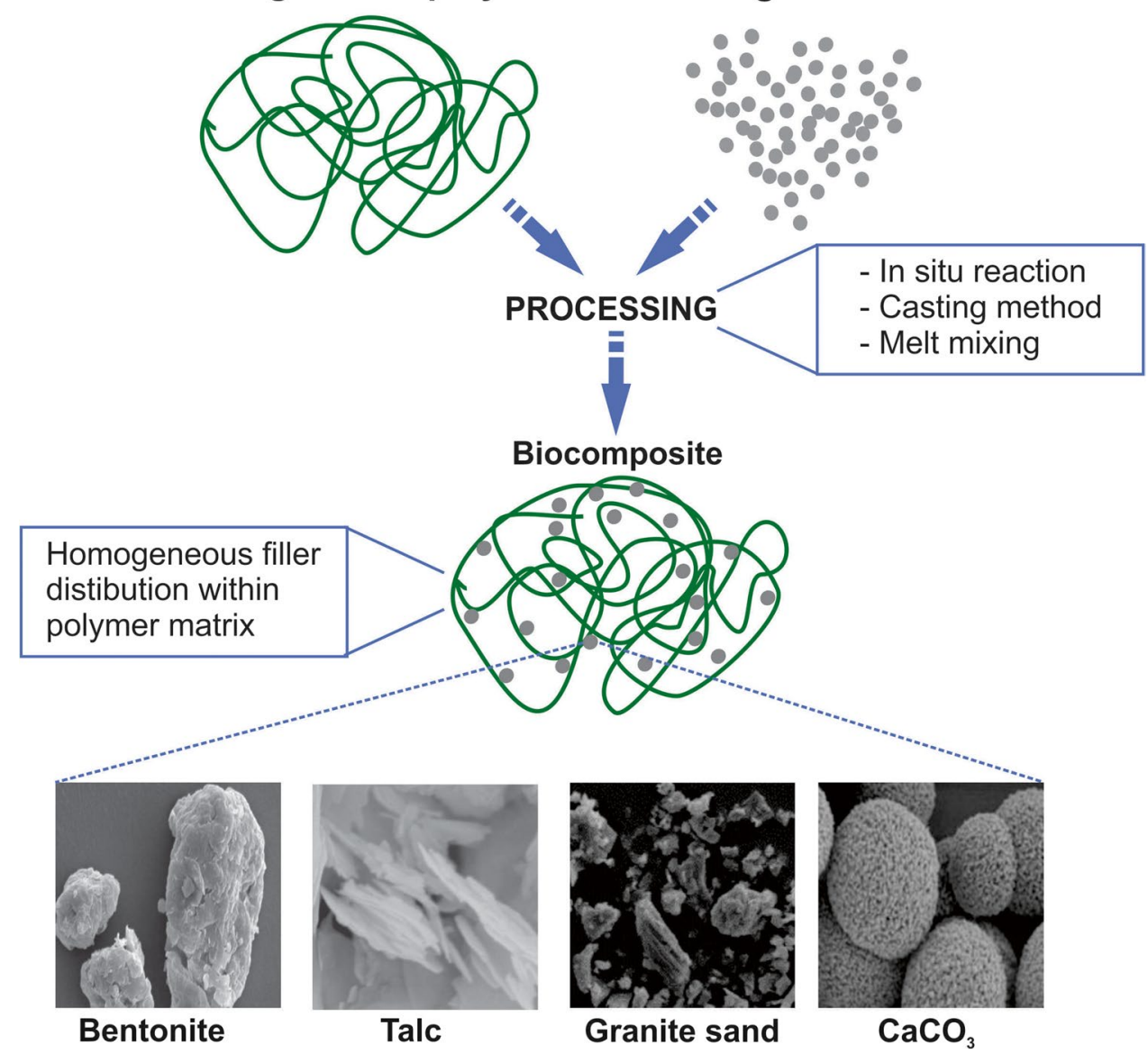

Inorganic fillers 


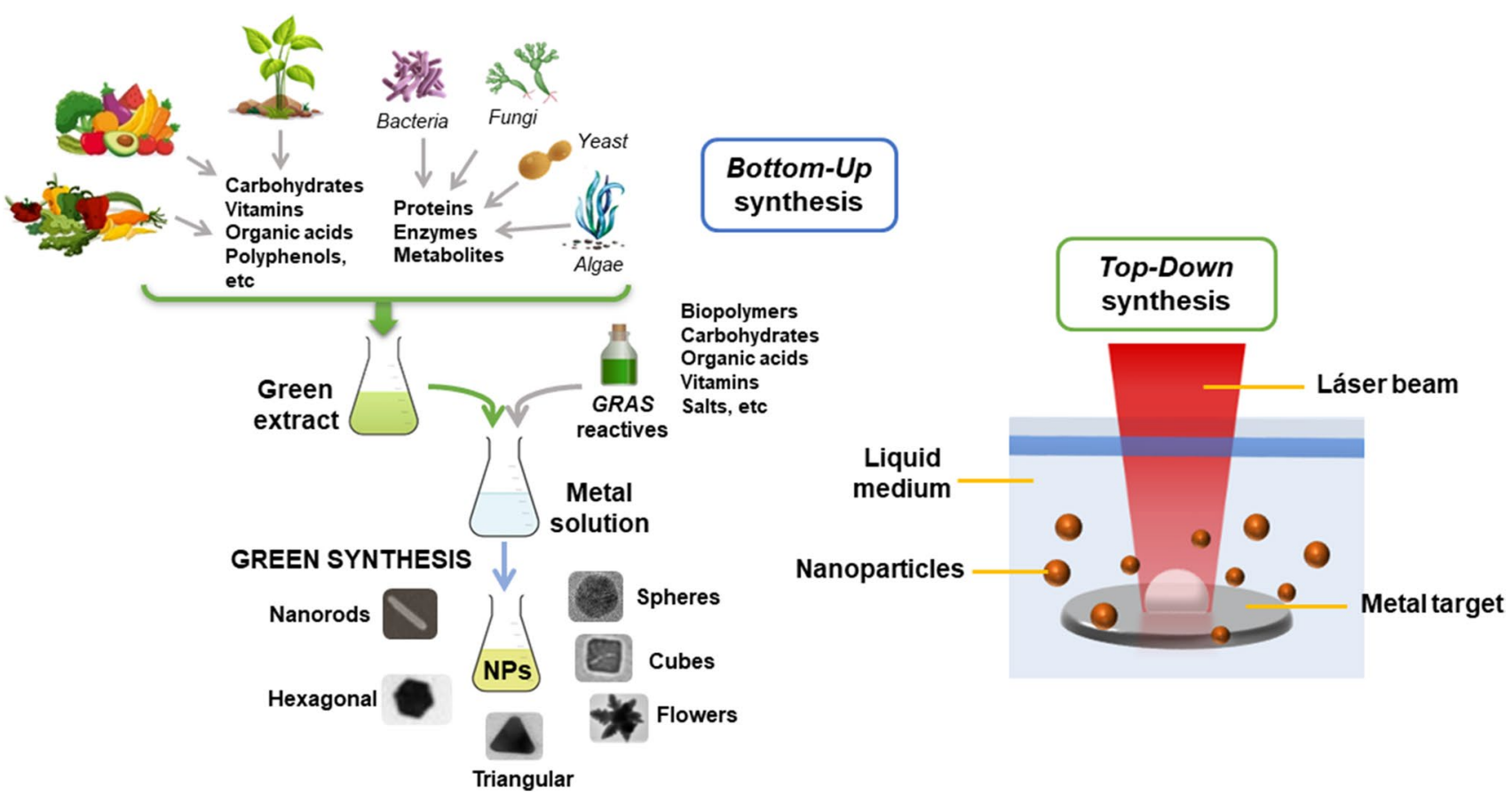

Fig. 5 Nanoparticles top-down and bottom-up synthesis

of view since they do not require high temperatures conditions and reduce energy consumption. Table 1 summarizes common metal and metal oxide nanoparticles obtained by green synthesis techniques.

The electrical conductivity, high stability, and especially the antimicrobial activity of AgNPs have prompted numerous investigations $[212,213]$. They can be synthesized by chemical reduction $[212,214,215]$, laser ablation [211, 216, 217], electrical and photochemical reduction[218]. Chemical reduction of a silver salt, mostly with organic reagents, is the most widely used and profitable method for large-scale synthesis [219]. Besides, nanoparticles morphology and size can be controlled by chemical synthesis depending on the capping agent and stabilizer. Several authors have reported that spherical and small AgNPs obtained by a completely green chemical process show good antimicrobial properties even when they were used in low concentrations [212, 214, 215, 220]. Ortega et al. [221] have successfully coupled the AgNPs synthesis with cornstarch-based filmogenic suspensions to develop nanocomposite films. Thus, a simple and nontoxic method was proposed to obtain silver nanoparticles where maltose is used a reducing agent, corn starch as a stabilizer, and ultrapure water as a solvent. Proposing the use of corn starch as stabilizers allows the synthesis of AgNPs to be coupled to the filmogenic suspension and thus obtain nanocomposite films in just a few steps, optimizing both processing time and energy, and reagents consumption. Processes coupling requires a prior fine-tuning of the reagent concentrations and reaction times to obtain the AgNPs in the filmogenic suspension [185, 186]. The AgNPs formation is evidenced by the characteristic surface plasmon resonance (SPR) between 420 and $445 \mathrm{~nm}$ [222]. Several authors have synthesized AgNPs with lemon juice, which was spherical with diameters around $20 \mathrm{~nm}$ as observed by high-resolution transmission electron microscopy (HR-TEM), exhibiting negative charge considering their $\mathrm{Z}$ potential measurements [185, 213, 218, 223].

Likewise, $\mathrm{ZnO}$ nanoparticles have arisen great interest in sensing applications, since they exhibit high electron mobility, large exciton binding energy, wide bandgap, and high optical transmittance [168]. They can be synthesized with different morphologies, such as spheres, discs, ribbons, flowers, or bars [224]. ZnO nanorods stand out as reinforcement of active packaging materials due to their excellent mechanical performance and their marked antimicrobial activity [225]. They can be prepared by different methods, being the chemical reactions in solution preferred in terms of costs, simplicity, efficiency, and energy consumption [226]. Hydrothermal growth in aqueous solution is a widely used methodology in the literature for obtaining $\mathrm{ZnO}$ nanorods. This method uses an aqueous solution of $\mathrm{Zn}\left(\mathrm{NO}_{3}\right)_{2}$ containing hexamethylenetetramine (HMTA) which hydrolyzes and produces a basic environment necessary for the formation of $\mathrm{Zn}(\mathrm{OH})_{2}$ and stabilizes $\mathrm{Zn}^{+2}$. In general, seeds of $\mathrm{ZnO}$ are incorporated for the hydrothermal growth of $\mathrm{ZnO}$ nanorods to improve the morphology and orientation of the bars [227]. The $\mathrm{ZnO}$ seeds are synthesized through a simple and low-cost sol-gel process in a nonaqueous solution of zinc 


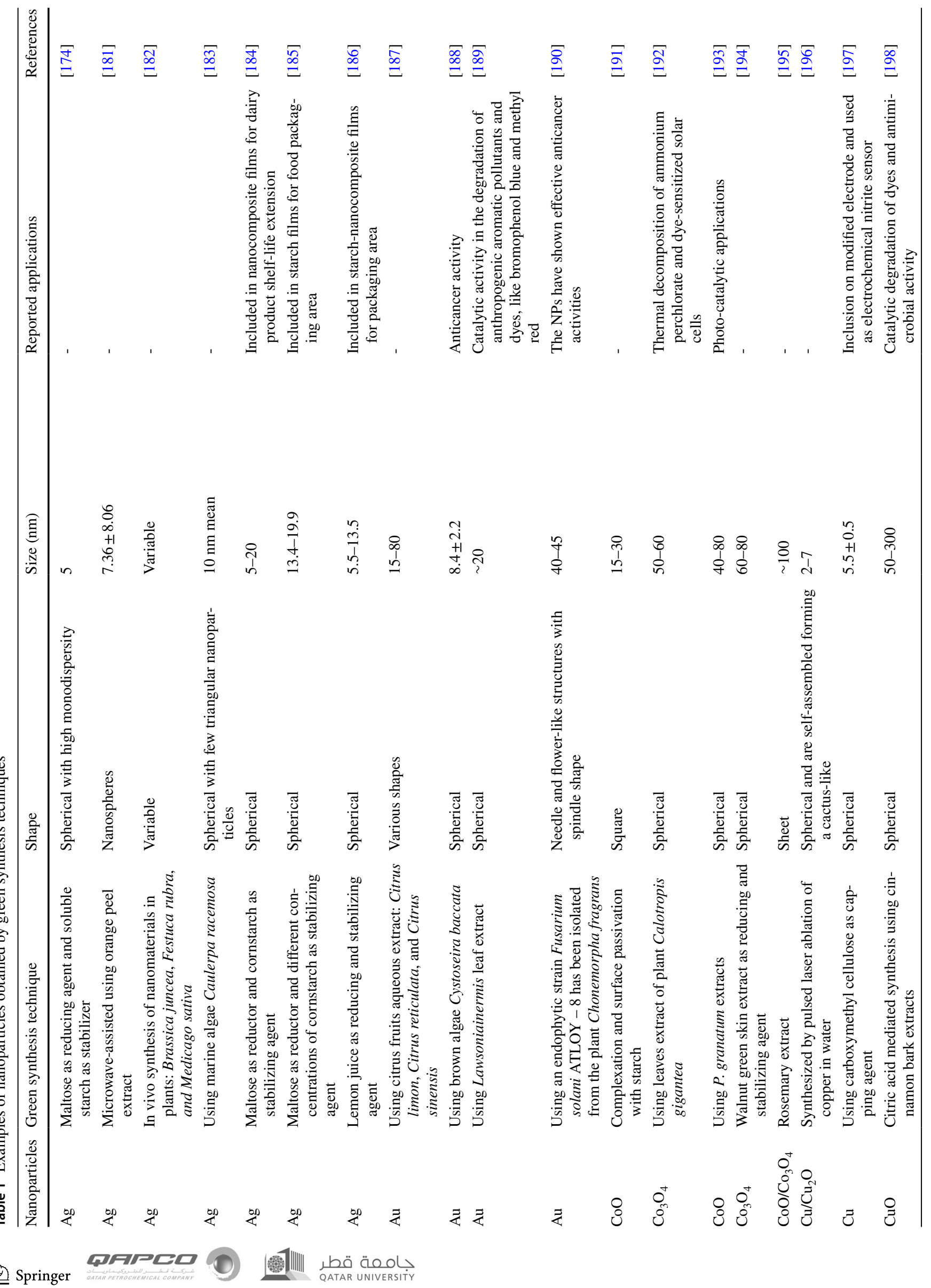




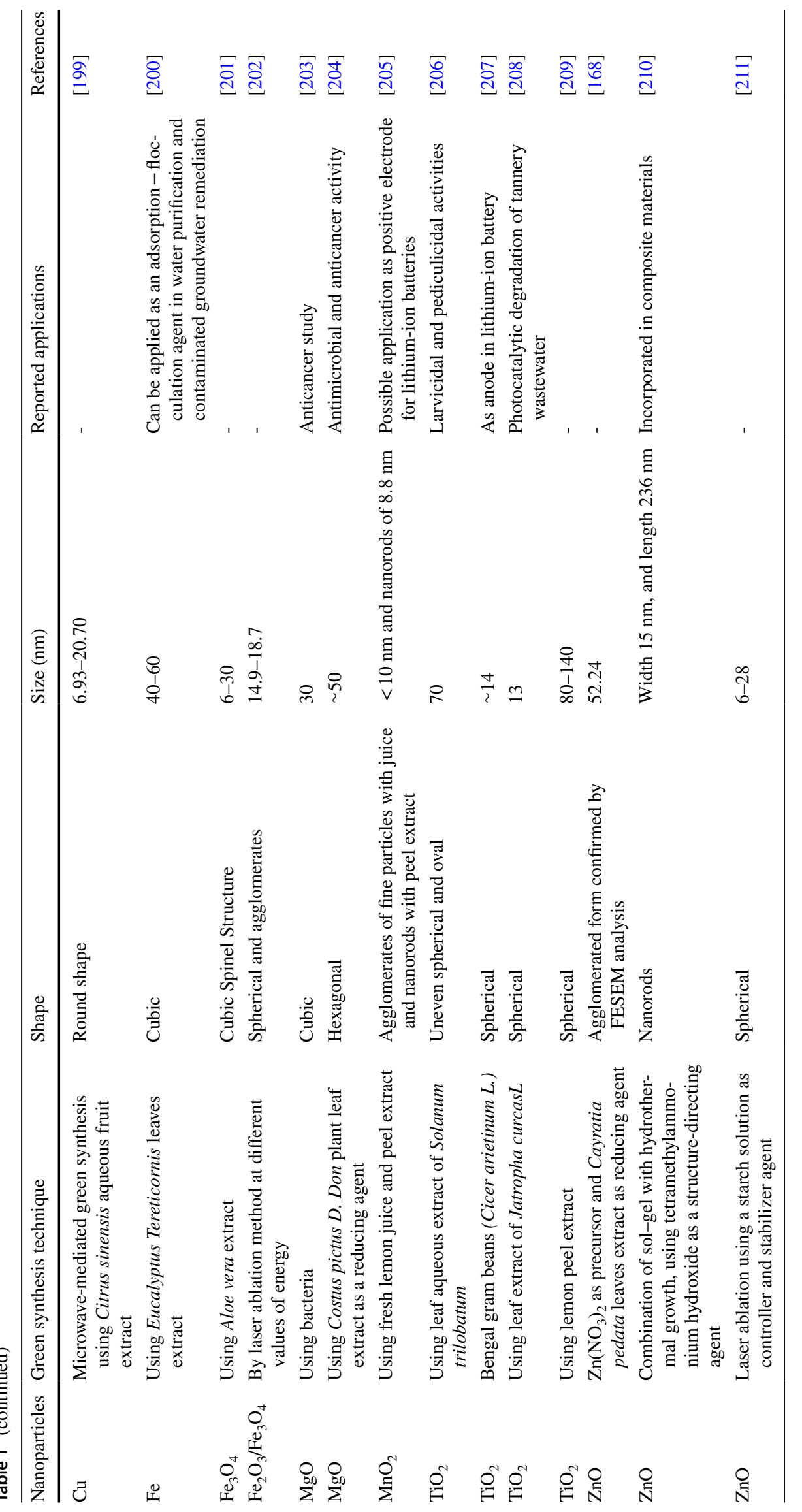


acetate as a precursor. The precursor hydrolyzes by heating and forms acetate and $\mathrm{Zn}$ ion that binds to the hydroxyl groups $(-\mathrm{OH})$ present in the solution resulting in $\mathrm{ZnO}$ formation [228]. At this point, the concentration of hydroxyl groups in the solution determines the size of the nanoparticles obtained and, in general, is adjusted by incorporating $\mathrm{NaOH}$ or $\mathrm{KOH}$ [229]. Similarly, the chemical reduction of Zn solution using natural compounds derived from different plant extracts has been reported [168].

Several other nanoparticles with exciting and innovative applications like sensors, biomedical, energy storage, and packaging applications have been studied and synthesized by green technologies as shown in Table 1.

The mechanisms involved in the synthesis of nanoparticles have been extensively reviewed by Polte et al. [230]. Ortega et al. [186] synthesized silver nanoparticles using the active compounds of lemon juice $\left(\mathrm{AgNP}_{\mathrm{L}}\right)$ and proposed a four-step growth mechanism for this process. First, the chemical reduction of the Ag salt occurs by the reducers present in lemon juice (mainly ascorbic acid and citric acid, in addition to other components such as reducing sugars, polyphenols, and flavonoids). Polydisperse particles smaller than $1 \mathrm{~nm}$ are then formed by coalescence. The third step, which can last between 5 and 60 min depending on the synthesis temperature, corresponds to a metastable state where the particles reach a mean radius of $1 \mathrm{~nm}$. Finally, the coalescence of the formed particles occurs until colloidal stability is sufficient to prevent aggregation. Ortega et al. [186] reported that the optimized conditions for the synthesis of $\operatorname{AgNP}_{\mathrm{L}}$ were $30 \mathrm{~min}$ at $90{ }^{\circ} \mathrm{C}$, leading to a $5.5 \mathrm{~nm}$ nanoparticle with associated stability $(\zeta=-29.5 \mathrm{mV})$ that was maintained for up to 90 days. Yet studies on the stability of nanoparticles during storage are scarce and are strongly recommended for future research in the field [171, 231].

\section{Films and foams from biobased composites}

\subsection{Biocomposite films}

Biocomposite films are based on different biopolymer matrices and fillers and can be obtained by diverse processing methods. As an example of the enormous amount of biocomposite films that have been studied to date some of the most relevant developments in the last 10 years from different biopolymers will be mentioned.

Cellulose is the most abundant biopolymer, and it is widely employed for sustainable biocomposite materials because of its renewable character, biodegradability, and other specific properties. It can be converted to different structures with a variety of physical properties, depending on the origin of the cellulose and the method of production
[120]. Cellulose microfibers (CMFs) can be obtained by refining dilute cellulose suspensions under high-pressure. Nanofibrillated cellulose (NFC), on the other hand, result from cellulose fibers disintegration using high pressure homogenizers combined with chemical or enzymatic treatments [232]. In addition, if the amorphous parts of the cellulose are removed, leaving single and well-defined crystals in a stable colloidal suspension, microcrystalline cellulose (MCC) can be obtained [233]. Thus, depending on cellulose structure and the desired properties of the final materials, this polysaccharide can be used as a biopolymeric matrix or biocomposite filler. In this respect, Kumar et al. [120] extracted cellulose fibrils (CFs) from Napier (Pennisetum purpureum schum) grass and used it as a filler of cellulose matrices. These cellulose-based composites obtained by casting, presented good thermal stability and higher tensile resistance than conventional HDPE and PP, deeming them appropriate for biodegradable packaging, wrapping, and mulching applications. Likewise, Spence et al. [234] worked on microfibrillated cellulose (MFCs) composite films containing kaolin clay and calcium carbonate obtained by casting. Even though the authors demonstrated that the addition of mineral fillers reduced films density and water vapor transmission rate (WVTR) and presented proper mechanical properties for packaging applications, their water barrier properties are low in comparison to petroleum-based plastics. Moreover, Trovatti et al. [235] studied the use of NFC as filler of bionanocomposite films with improved thermal and mechanical properties prepared by casting of water-based suspensions of pullulan: an extracellular homopolysaccharide made up of 1,6-linked maltotriose residues, produced by certain strains of the polymorphic fungus Aureobasidium pullulans. Thus, the authors assured that these novel bionanocomposites could be labeled as sustainable materials since they were prepared entirely from renewable resources and through a green approach. In another interesting work reported by Oun and Rhim [236], crystalline cellulose nanofibrils (CNF) were isolated from cotton linter pulp using an acid hydrolysis method and later used as filler of sodium carboxymethyl cellulose (CMC) composite the film's obtained by casting. It was demonstrated that CNF is highly compatible with the CMC and the presence of this filler affected films mechanical and water vapor barrier properties. The CMC/CNF composite films have a high potential to be used as edible coating or packaging films for the shelf-life extension of fresh and minimally processed fruits and vegetables. CNFs have been also used as fillers of starch-based biocomposite films [145, 237, 238]. The addition of CNFs obtained from different biomass sources resulted in increased tensile strength and elastic modulus and led to the reduction of elongation at break, water vapor permeability, and, 
in some cases, oxygen transmission rate. Furthermore, Farooq et al. [239] utilized a variety of softwood Kraft lignin morphologies to obtain strong and ductile CNF nanocomposite films with potential food packaging, water purification, and biomedical applications. In this work, two techniques were employed to obtain biocomposites: casting and thermocompression. The incorporation of lignin rendered tougher film structure, materials waterproof while exhibiting complementary UV shielding and radical scavenging capability.

Starch-based materials offer a very attractive low-cost base for new biodegradable polymers due to their abundance, annual renewability, and ability to be processed with conventional plastic processing equipment $[22,35$, 36]. The improvement of mechanical properties of starchbased materials is an ongoing challenge due to their poor mechanical performance, particularly tensile strength [240]. Among the various alternatives to improve these mechanical properties, blends, and composites have been proposed [22, 241-246]. Correspondingly, Ali et al. [241] developed fully biodegradable starch-based films by casting method based on modified (hydroxypropyl) cornstarch and two kinds of commercially available polysaccharidebased macro-crystals (cellulose and starch crystals). They demonstrated that the mechanical properties were modified by crystals addition, increasing the tensile strength and elastic modulus, and decreasing elongation at break. Besides, the biocomposites showed improved protection against UV radiation. Wang et al. [243] studied collagen composites with three different maize starches: waxy maize starch, normal starch, and high amylose starch, showing higher tensile strength and lower solubility in water than collagen film, and increased thermal stability and crystallinity. Noteworthily, Stasi et al. [246] suggested a novel and cost-effective reutilization of carbon waste ashes as a reinforcing agent of biocomposite films based on thermoplastic starch for agricultural applications. Carbon-based ashes produced by pyrolysis of lignocellulosic wastes were added to glycerol and maize native starch in different quantities, which were meltprocessed and molded. The authors reported that ash content decreased both moisture sorption and degradation of starch biocomposites. Moreover, Yin et al. [247] proposed to improve the functional properties of starch-based films incorporating chitin obtained from shrimp shell powder into corn starch matrix. Before blending, maleic anhydride was introduced as a cross-linker and composite films were obtained by casting-evaporation. The obtained starch-based nano-biocomposite films presented superior mechanical properties, higher surface hydrophobicity, and enhanced barrier properties, in addition to antibacterial properties against Escherichia coli and Staphylococcus aureus.
Soy protein isolate (SPI) is another biobased polymer with good film-forming ability that can be produced by casting, extrusion, or injection molding [248-251]. Since SPI films have low strength and absorb a high amount of moisture which limits their applications, reinforcing filler has been proposed [252-255]. Accordingly, Martelli-Tosi et al. [254] investigated the potential use of soybean straw as reinforcing filler in SPI films. Both raw soybean straw and samples treated with alkali $(\mathrm{NaOH} 5$ and $17.5 \%)$ and bleached with hydrogen peroxide $\left(\mathrm{H}_{2} \mathrm{O}_{2}\right)$ or sodium hypochlorite $(\mathrm{NaOCl})$ was studied. Films added with treated soybean straw presented higher mechanical resistance, lower elongation at break, and lower solubility in water; while the addition of non-treated soybean straw had no significant effect on SPI film properties. Alternatively, Zhao et al. [255] developed a series of epichlorohydrin-crosslinked hydroxypropyl chitosan/SPI films with different soy protein contents. The authors demonstrated that these materials were tunable in terms of their surface structure and mechanical properties by changing the SPI content. Biocomposites exhibited good cytocompatibility and hemocompatibility, improved wound contraction rates, and showed great promotion of granulation tissue regeneration and collagen deposition, which are excellent results for skin tissue engineering.

Among the biodegradable polymers, PHB is the principal and the most widely used type of the PHA, with high potentiality for replacing fossil-based synthetic packaging [256]. Even though this biopolymer displays thermophysical and mechanical characteristics similar to polystyrene and isotactic polypropylene, it presents a narrow processing window which limits its applicability [257]. Therefore, the development of PHB composites has been proposed as a solution. PHB biocomposites employing a wide range of fillers, such as cellulose nanocrystals [258], graphene [259], agave fiber [260], chitosan, and catechin [110] have been developed over the last few years. An interesting work carried out by Araque et al. [261] focused on the development of PHB and hollow glass microspheres and composite films. These materials were obtained through melt intercalation, an innovative technique with low environmental impact because it does not require solvents use. Besides, Seggiani et al. [116] studied PHAs based biocomposites with fibers from Posidonia oceanica (PO) to assess their processability by extrusion, mechanical properties, and potential biodegradability in a natural marine environment. These composites provide an interesting valorization route for PO fibrous wastes largely accumulated on coastal beaches and can be suitable to manufacture items usable in marine environments, such as in natural engineering interventions for restoration or protection of coastal habitats.

The processing methods strongly affect the properties of the biocomposite materials [262], thus a description of the most widely used methods to obtain biopolymeric films are

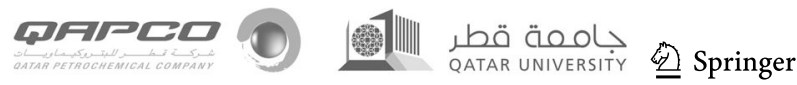


given, mentioning the advantages and disadvantages of each of them:

Solution casting: this is the simplest and most frequently used method at a laboratory scale for biocomposite films. The casting technique consists in spreading a film-forming solution or suspension on small plexiglass or plates, in which the film thickness is controlled by the mass of suspension poured onto the plate [263]. The drying process of these films usually takes place at room temperature or in an oven with air circulation [45, 120, 264]. Polymers that are soluble in water are mostly treated with this technique and, as stressed by Bondeson and Oksman [265], the differences in hydrophobicity or the hydrophilicity of the filler and that of the matrix require the use of a suitable solvent. Besides, the solvent concentration can be decided according to the required characteristics and viscosity of the solution. The biopolymers composites obtained through this technique usually show good properties, though constituents distribution throughout the film is strongly dependent on the biopolymer and filler ratio in the solution [266]. Finally, even though this method has been extensively used for research on films based on starch and protein, the difficulty in scaling up production volumes and the long drying times, make this technique impracticable on an industrial scale [267].

Tape-casting: films and coatings can also be prepared by the tape-casting technique at a larger scale than those usually reported by literature using the classical casting technique. In the tape-casting process, a suspension is placed in a reservoir with a blade, which height can be adjusted with micrometric screws [268]. The suspension is later dried on the same support, resulting in a film that can be removed from the surface. Depending on the film's characteristics, it can be rolled, cut, drilled, stamped, or laminated. The spreading of the film-forming solution (or suspension) can be done on larger supports or on a continuous carrier tape. The formed film is dried on the support, by heat conduction, circulation of hot air (heat convection), and infrared heating, resulting in a reduction of its thickness.

Extrusion: melt compounding or extrusion, is a conventional method widely used in the polymer industry and compound composites where the material is shaped through a die. Using extrusion to produce biopolymerbased composites could reduce manufacturing costs and render them more cost-competitive [265]. Extruders can be categorized on the number of screws in single, twin, and multiple screw extruders, further on the rotation mode of the screws can be classified in a single direction or in the opposite direction (corotating or counterrotating) or a mixture of both for a multiple screw extruder [262]. It is important to highlight that biopolymers processing by extrusion requires the use of additives, such as plasticizers and antioxidants to thermo-plasticize the polymer mix and avoid its degradation. However, it is well-known that extrusion processing these kinds of materials is not simple; hence optimization of the operating conditions (screw speed, configuration, and processing temperature) for each composite is necessary.

Blowing: blowing is a process that involves using air or nitrogen to inflate a tube of the melt as it comes out from the die. The blown film usually grows in a vertically upward direction. The die most often has a circular (annular) geometry, which is the simplest and most convenient solution even though the resulting film is less homogeneous. The thin bubble is then drawn by a series of nip rollers, flattened, and wound up in a reel. Both drawing and blowing orient the polymer molecular chains in a preferred manner. Depending on whether drawing or blowing prevailed the final film will be stronger in the longitudinal or transverse direction, respectively [269].

The inherent properties of biocomposite films are relevant for their applications. As it was stressed by Haniffa et al. [270], mechanical and thermal properties are regarded as the most relevant properties of biocomposite films. However, the physical and chemical characteristics of the main components can significantly alter these properties. The thermal, mechanical, barrier, and other relevant properties of diverse biocomposite films are included in Table 2. As it can be observed, the properties of these materials depend on many factors, being the most relevant: the type of polymer matrix, the filler type and concentration, and the selected processing method and conditions. Consequently, when comparing properties and characteristics of different films based on the same biopolymer and filler, it is necessary to consider the filler concentration and size, as well as processing technique and conditions.

\subsection{Active biobased composite and nanocomposites}

Active containers, usually used in food packaging, are those containing some substance capable of preserving the organoleptic or sensory characteristics of a product to ensure its quality. Of special interest are those active packages that contain natural antioxidants and antimicrobials that not only extend the shelf-life of packaged products by preventing rancidity reactions but also prevent the growth of foodborne pathogens [278]. Biodegradable and biobased polymers are preferred in the development of active materials for single used food packaging due to their low environmental impact 


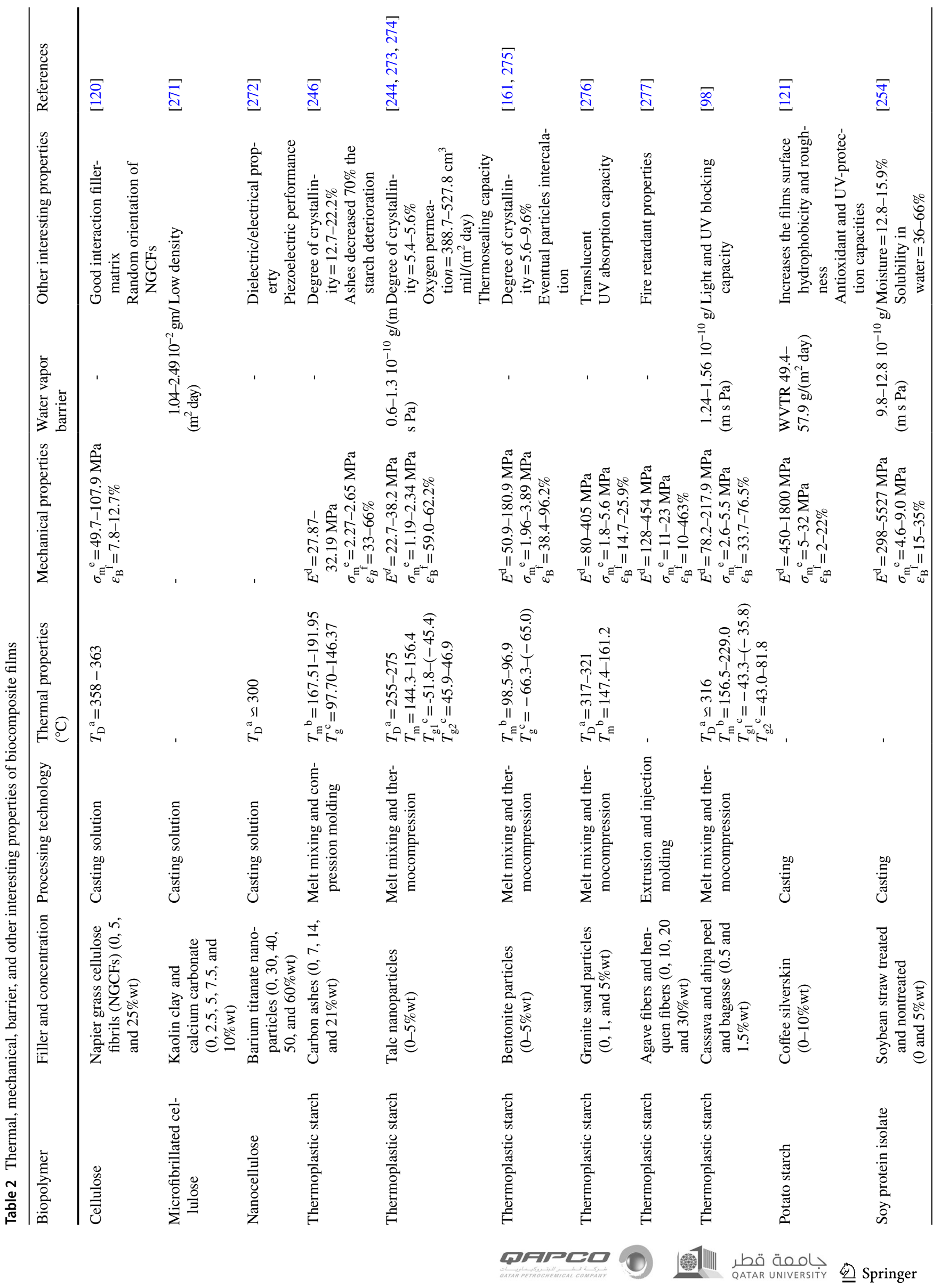




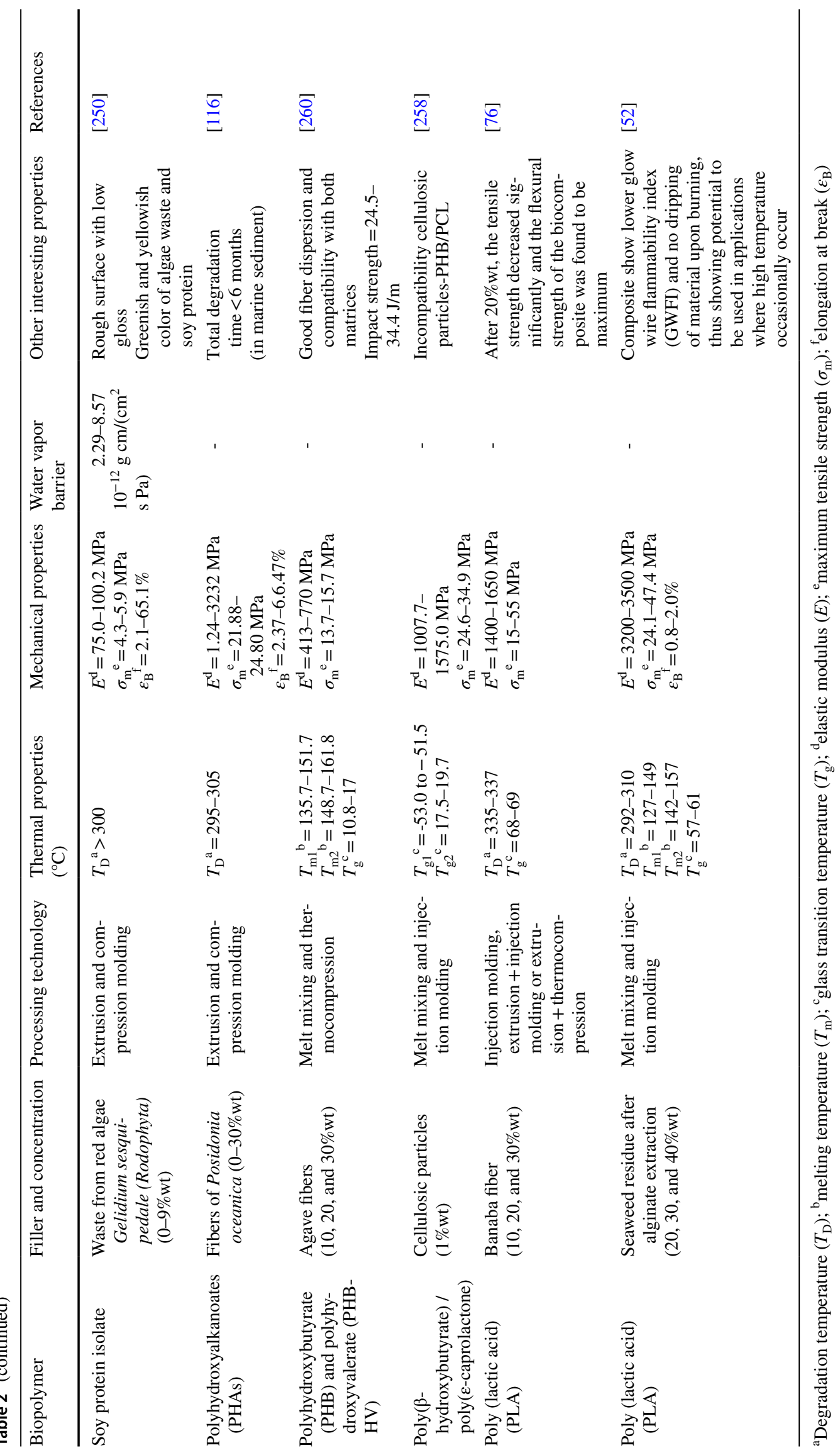


[221, 275, 279, 280]. Among the available natural polymers and compounds, some can be obtained from agri-food industrial waste and their use would add value to these residues and keep them in circulation, one of the premises of circular economy. A clear example is the use of chitosan, a biodegradable polymer derived from chitin with antimicrobial activity that is obtained from the fishing industry waste such as crustacean exoskeletons [281]. Likewise, byproducts and wastes from fruit and vegetables processing are an important source of compounds with high nutritional and functional value such as vitamins, minerals, antioxidants, and antimicrobial compounds, though are often discarded or derived for animal feed [282]. Essential oils (EOs) that can be obtained from these sources have been widely studied as additives for the development of active food packaging, mainly due to their antioxidant and antimicrobial capacity and their GRAS (Generally Recognized As Safe) character [283, 284]. Therefore, the use of active compounds derived from agricultural by-products not only contributes to the recovery of these compounds with specific activities but also generates added value for them. EOs are mainly phenolic compounds derived from plant secondary metabolites with antimicrobial capacity and several therapeutic and healthpromoting attributes. Several authors have reported that the addition of EOs can significantly affect the microstructure, mechanical and barrier properties of the material depending on how they are incorporated into the polymeric matrix [284-287]. The most commonly reported EOs incorporated in biodegradable matrices are rosemary, tea tree, cinnamon, oregano, clove, and thyme [86, 288-292]. For instance, Bof et al. [16] have developed and characterized active biodegradable films based on corn starch and chitosan $(\mathrm{CS}: \mathrm{CH})$ with the addition of lemon essential oil (LEO) and grapefruit seed extracts (GSE). The inclusion of these active compounds, which are by-products of residues derived from citrus processing, did not affect the mechanical properties of the material and provided antimicrobial capacity by contact. Similarly, Kanmani and Rhim [293] developed antimicrobial active films with GSE on carrageenan matrix, with additional UV barrier capacity, particularly important for UVsensitive food packaging. Further interesting biocomposites materials with EOs were reviewed in Table 3.

On the other hand, several investigations in recent years have focused on studying the effects of the incorporation of metal or metal oxides nanoparticles in biodegradable matrices [304, 305]. Starch-based and nanoclay biocomposites have been the most studied [212, 220, 306-308], although other biopolymer matrices have been used, such as chitosan [309], agar [310, 311], proteins [312, 313], or their combination [298, 314]. Usually, this strategy manages to improve the mechanical properties and susceptibility to the water of the system and, if the nanoparticles have antimicrobial activity the composite material also acquires this property. For instance, Abreu et al. [220] incorporated silver nanoparticles into wheat starch films obtained by solvent evaporation (casting). The materials obtained presented lower hydrophilicity and bacteriostatic activity against Staphylococcus aureus and Escherichia coli. Likewise, Ortega et al. [221] showed that the incorporation of AgNPs in cornstarch-based films decreased the solubility of the material and improved the mechanical properties by increasing Young's modulus and tensile stress values without decreasing deformation at the break. Similar effects have been reported by Malathi and Singh [315] by $\mathrm{TiO}_{2}$ nanoparticles addition into rice starch films. In this case, the authors showed that the nanocomposite material presented a better water vapor barrier, enhanced mechanical properties, and bacteriostatic activity against Escherichia coli. The incorporation of $\mathrm{ZnO}$ nanoparticles has also proven to be an interesting strategy for improving the properties and adding bactericidal activity to starch films. In this regard, Mirjalili et al. [316] showed that starch-based films containing $\mathrm{ZnO}$ nanoparticles have better mechanical properties and antimicrobial activity against Escherichia coli and Staphylococcus aureus. Likewise, Nafchi et al. [225] reported that the incorporation of $\mathrm{ZnO}$ nanobars reduces hydrophilicity, improves mechanical properties, and provides antimicrobial activity against Escherichia coli to sago starch films. Yet, Guz et al. [210] demonstrated that the properties of starch films containing $\mathrm{ZnO}$ nanobars depend strongly on their size.

Nanoparticles and EOs biocomposites have also been studied with other innovative applications, such as wound dressing [45, 317]. Table 3 summarizes different types of nanoparticles included in nanocomposite formulations, being AgNPs the most commonly used for food packaging applications since they effectively reinforce biopolymer matrices and provide antimicrobial capacity over a broad spectrum of bacteria, virus, and fungi [185, 186, 221, 318]. Although numerous nanocomposites or active systems have been studied, the available literature refers mainly to materials manufactured with the solvent evaporation methodology, which is difficult to scale up. The development of biodegradable nanocomposite materials through scalable technologies is essential for the industrial implementation of such systems. Even though extrusion is a continuous and scalable processing technology, the study of the effect of extrusion on nanoparticles or bioactive molecules is still required. In this regard, it is necessary to analyze the mixing and distribution of the components within the matrix, the resulting interactions, and their effect on the material properties, as well as the possible degradation of the additives during the manufacturing process. Recent studies have successfully extruded biocomposites of thermoplastic starch with nanoparticles and EOs [294, 319].

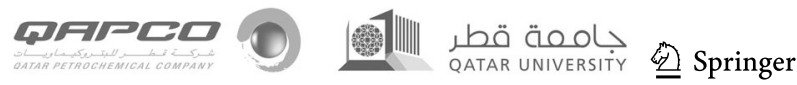




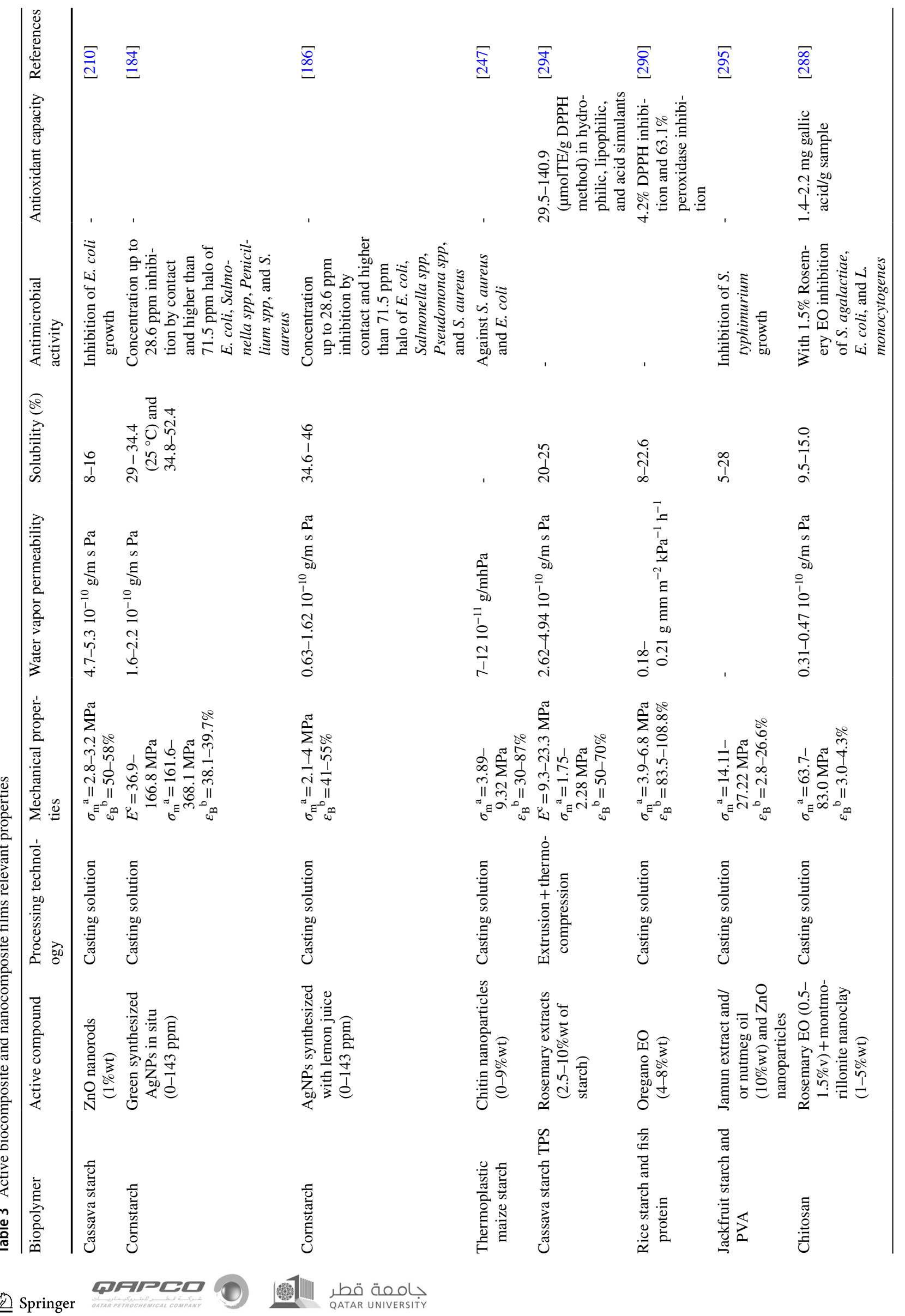




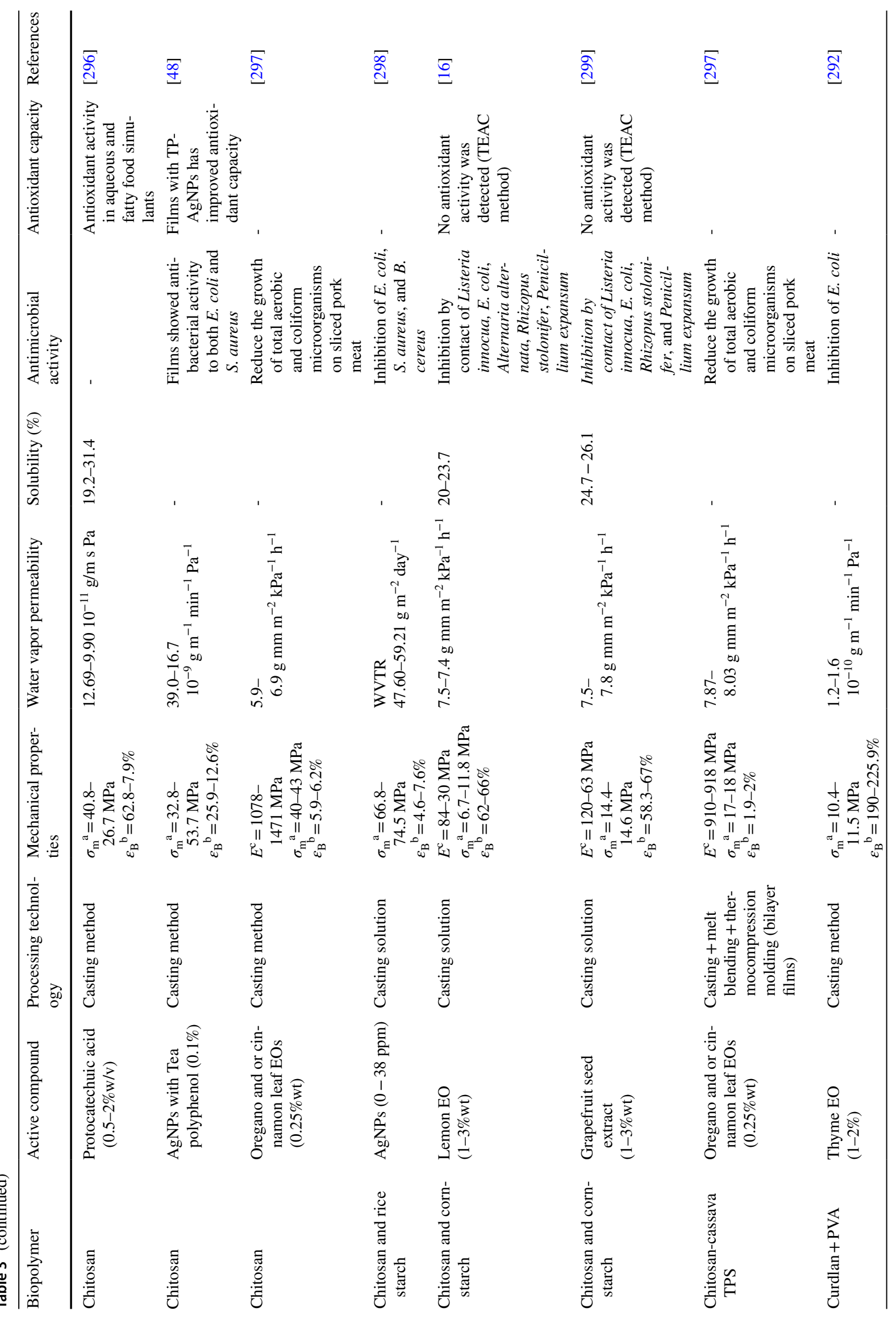

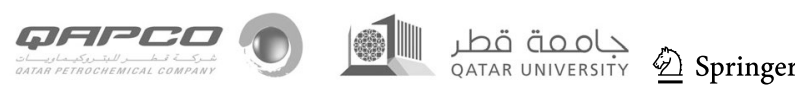




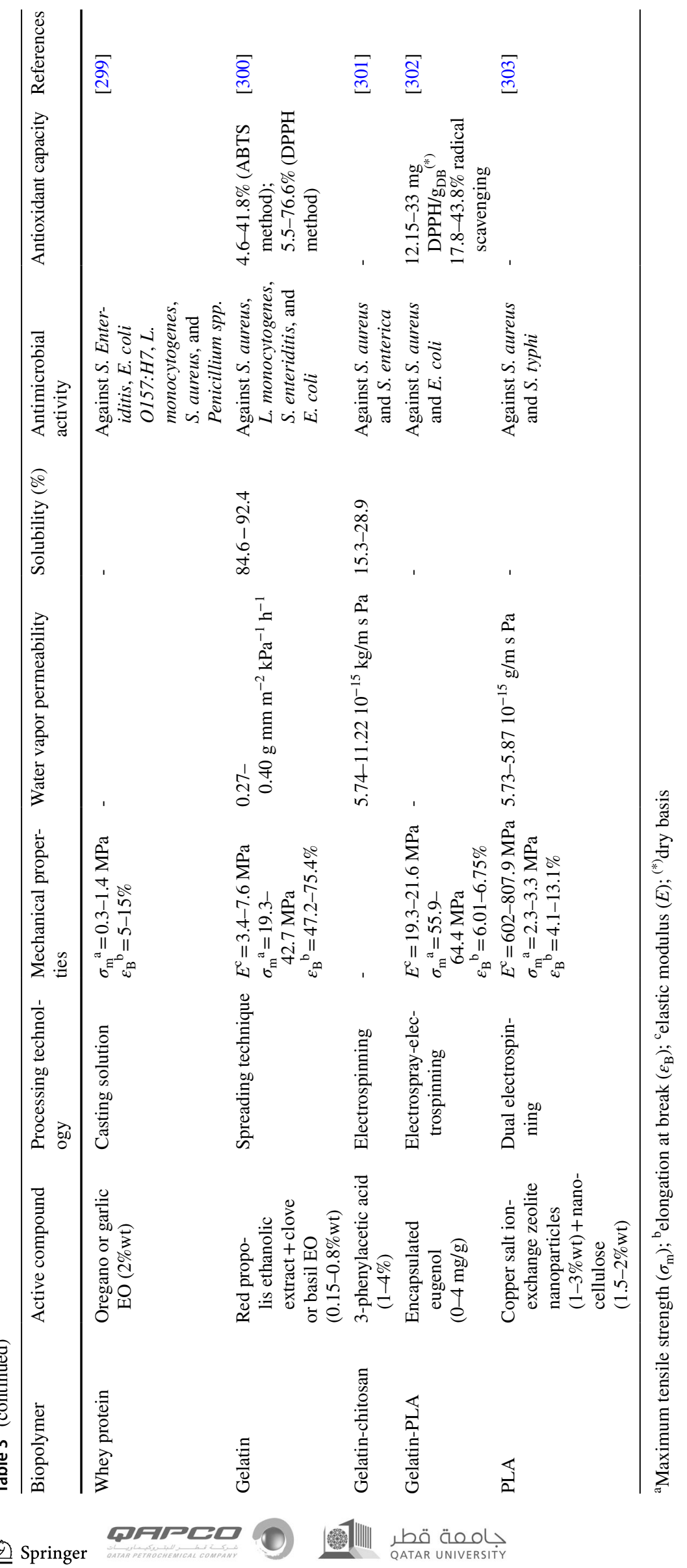


Particularly, since many biopolymers are hydrophilic, the naturally hydrophobic EOs must be compatibilized with the polymeric matrix generally by the addition of surfactant agents. The most widely used technique for this purpose includes the formation of an emulsion or a nanoemulsion to ensure the homogeneous distribution of the active compound in the matrix. Moreover, given the volatile nature of EOs, the processing conditions must be optimized to minimize activity loss. Consequently, when extrusion processing is desired EOs need to be protected from the drastic treatment conditions for which purpose encapsulation is a useful tool [320]. Alternatively, Li et al. [302] have efficiently encapsulated eugenol (83.4 to $92.7 \mathrm{~g} / 100 \mathrm{~g}$ ) in PLA and gelatin nanofibers obtained by electrospinning. Electrospinning has also been used by Scaffaro et al. [321] to modulate EO migration from solvent casting films in a multilayer composite material. Active laminates were formulated with a PLA film containing carvacrol (14\%wt) obtained by solvent casting and one or two fibrous layers of PLA applied by electrospinning. These fibrous layers modulated the carvacrol release kinetics, which proved to progressively reduce the burst delivery at an early stage of immersion, therefore increasing the delivery device lifespan from 288 to $795 \mathrm{~h}$.

Inactive and nanocomposite materials, the study of the microstructure helps to understand the interrelation of the structure with the properties that determine the performance of the material, in addition to being able to infer the effectiveness of the filler inclusion within the matrix. In general, when homogeneous surfaces without pores or cracks as well as compact cross-sections are visualized by SEM the included active compounds or nanoparticles are compatible with the polymeric matrix, which also leads to its reinforcement. These observations agree with the reported mechanical behavior of the nanoreinforced materials listed in Table 3. Correspondingly, Bof et al. [16] stressed that the presence of discontinuities in the matrix of cornstarch/ chitosan composite films with lemon EO (visualized as oil microdroplets by SEM) was indicative of the lack of miscibility of the active compound with the polymer and lead to poor gas barrier properties. A similar trend was found by other authors working on biodegradable films containing different EOs such as orange peel, tea-tree, and ginger oil, among others [286, 287, 322]. Consequently, the compatibility of the active agent with the matrix determines how efficiently the former is incorporated into the polymer network and therefore the film microstructure characteristics. In this regard, ATR-FTIR spectroscopy is a useful technique that has been widely employed to study the interaction among the composite constituents. In the same work, Bof et al. [16] found by FTIR analyses that hydrogen bonding occurs in the corn starch and chitosan blend films containing grapefruit seed extract as filler, leading to a more compact and denser film structure. Similarly, Sharifi and Pirsa [320] working on black mulberry fruit pulp pectin films studied the effect of both chlorophyll encapsulated with carboxymethylcellulose and silica nanoparticles addition. SEM analysis indicated that both active components act as fillers of the pectin structure. Moreover, their high compatibility was demonstrated through FTIR studies since spectra confirmed electrostatic interactions between pectin chains with encapsulated chlorophylls and silica nanoparticles. Besides, thermogravimetric analysis (TGA) results revealed that the simultaneous addition of these active compounds increases the thermal stability of the film [16, 46, 247].

Biodegradable films formulated with polymers derived from biomass are, in general, hydrophilic in nature due to the presence of a large number of hydroxyl groups in their structures. These biomaterials are susceptible to humidity: water causes a weakening of the intra- and intermolecular bonds (plasticizing effect) which leads to an increase in the WVP of this type of polymers [323]. Given the hydrophobic character of EOs, it is expected that their inclusion in a polymeric matrix formulated with biopolymers improves their water susceptibility, measured by WVP, water absorption capacity, swelling, contact angle, solubility, and moisture content. This trend has been widely reported in the literature and is summarized in Table 3. However, as already mentioned, the microstructure of the biocomposite is decisive, especially regarding barrier properties.

In general, the addition of nanoparticles exerts a reinforcement effect on biopolymeric matrices, which has been evidenced in the improved mechanical properties (enhancement of mainly tensile strength and elastic modulus) as well as barrier properties (Table 3). Ortega et al. [221], for example, stressed that AgNPs incorporation in cornstarch-based films maintained the material UV-barrier capacity while decreasing WVP with higher AgNPs concentration.

EOs incorporation usually confers both antioxidant and antimicrobial properties. In this regard, Varghese et al. [282] have reviewed the effect of EOs on the physical properties of biopolymer films highlighting the migration release of the active compounds to different food surfaces or simulant media as well as their action mechanisms. Their antioxidant capacity can be evaluated by diverse complementary techniques such as DPPH, ABTS, FRAP, ORAC, and total phenolic compounds content. The addition of some nanoparticles also provides antimicrobial properties to the materials, such as in the case of silver, zinc, copper, and chitin, among others. The antimicrobial capacity is evaluated over common foodborne microorganisms frequently by the agar disc diffusion method. It has been observed that, even though nanocomposite films generally exhibit inhibition by contact, the observation of an inhibition halo depends on the nanoparticle concentration (Table 3). For instance, nanocomposite corn starch films containing AgNPs concentrations greater than $71.5 \mathrm{ppm}$ inhibit the growth of $E$. coli

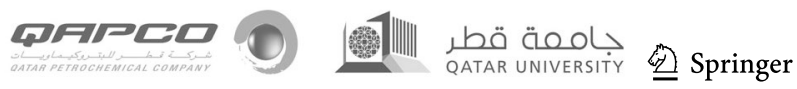


ATCC and Salmonella spp. and exhibit the corresponding halo [221]. Several examples of different biopolymer matrices containing different active compounds and processed by casting, thermocompression, extrusion, or spread-coating are included in Table 3, considering also the effect of different processing methodologies as well as the protection of these active compounds by encapsulation or electrospinning.

Several studies have been carried out on active composites biodegradation kinetic though the comparison of results depends on the conditions of assay. Rech et al. [324] evaluated the biodegradation of eugenol-loaded PHB films obtained by casting and buried for 60 days in agricultural, sandy, and landfill soil. The soil acidity, phosphorus availability, moisture level, and polymer crystallinity were key factors in explaining the differences in microbial growth and biodegradation rates. PHB films buried in agricultural soil presented a higher rate of biodegradation, which may be associated with the high fungi load and higher soil-phosphorus availability. Likewise, Castro-Aguirre et al. [325] evaluated the effect of bioaugmentation on the biotic and abiotic degradation of PLA and PLA bionanocomposites (BNCs) in simulated composting conditions. Bioaugmentation with Geobacillus increased the evolution of $\mathrm{CO}_{2}$ and accelerated the biodegradation phase of PLA and BNCs in compost environments. Finally, it is important to remark that the evaluation of the ecotoxicological impact on the composting soil is necessary. In this regard, Salehpour et al. [326] analyzed the effect of PVA films containing cellulose nanofibers on municipal solid waste composting quality after film biodegradation. An ecotoxicological test revealed that nanocomposite films did not generate any negative effects on germination or development of the studied vegetal species (cress and spinach).

\subsection{Sustainable composite foams}

Foam-like polymer materials, such as expanded polystyrene (EPS) and polyurethanes (PUs), are greatly desired for their lightweight and insulation properties. Due to their nonrenewable resource basis and high resistance to abiotic and biotic degradation, biobased alternatives are under study. In this regard, innovative more sustainable PU foams have been developed using biobased polyols and recycled polymers [327, 328], tannins extracted from lignocellulosic wood by-products [329-335], and other biopolyols obtained from agri-food waste and by-products such as crops straws [336] and citric peels [337]. Among fully biobased composite foams studied as an alternative to PU insulation materials, the alginate and orange peel biocomposite foams developed by Vincent et al. [338] also present fire-retardant properties, an important safety feature for building materials. Owing to their mechanical performance, easy confirmation and biocompatibility PUs are also attractive for tissue regenerating scaffolds. Yet, because of their heterogeneous structure and the nature of their building blocks PUs, are quite resistant to biodegradation even in the absence of stabilizing additives [339], therefore new fully biodegradable scaffolds have been developed for biomedical applications [340-343]. Different natural fillers are used as reinforcement of biobased PUs, some of which can be obtained from agri-food waste [344-346].

Expanded polystyrene (EPS), on the other hand, has been broadly used in packaging such as disposable food containers and protective packagings for products susceptible to mechanical damage, due to its low-density, moisture resistance, thermal insulation, and low-cost. In addition, other characteristics such as high durability, acoustic insulation, and strength have proven EPS useful for building and construction [347, 348]. In addition, compared to other conventional food packaging materials, EPS shows $7-28 \%$ lower environmental impact than aluminum containers and 25\% less than disposable polypropylene (PP) ones, even when reusable PP containers are considered [349]. Given its versatility and performance, EPS demand has had a marked increase with the consequent increase in the amount of waste generated of this nonbiodegradable synthetic polymer [347]. Besides, EPS is difficult to collect inadequate conditions for recycling, since large plastic waste volumes are generated and washing water is needed. Moreover, even though closedloop recycling systems show better performance in greenhouse gases emission (GGE) and energy consumption, as well as lower landfilling, optimized recycling technologies, and waste management systems are needed to reduce the large water volume consumption and scrap generation or sorted materials that cannot be reused $[350,351]$. To reduce EPS waste accumulation, its use as composite filler or raw material for building and construction materials, such as bricks [352, 353], thermal or acoustic insulation materials [347, 354-356], and as an absorbent substrate for gaseous pollutants removal [357] has been studied.

Furthermore, biodegradable biobased foams are being investigated as substitutes for EPS, especially for disposable packaging applications. In this regard, a study by Razza et al. [358] indicated that a 50\% reduction in non-renewable energy resources consumption and $60 \%$ lower GGE could be achieved with starch-based prototype packaging materials obtained by microwave technology in comparison to benchmark EPS cushioning packing. Various bioplasticsbased foams from starch to PLA and their mixture have been reported [21, 79, 106, 126, 359-371]. These materials should be cheap, lightweight to minimize transportation environmental impact as well as compressible, and strong enough to prevent physical damage to the product. In general, foams based on biopolymers such as polysaccharides or proteins are susceptible to moisture sorption and its consequent effect on permeability and mechanical properties. 
Thus, biocomposites and nanocomposites are proposed to enhance their water and mechanical resistance $[21,79,106$, 361, 362, 372, 373]. Most of the studied fillers are derived from agri-food waste and by-products, aiming to reduce materials cost and reinforce their sustainable character without compromising their biodegradability. Bergel et al. [371] found that contents up to $20 \% \mathrm{wt}$. of the modified starches reduced water absorption and increased impact resistance. Similarly, Guan et al. developed composite acetylated starchbased foams with corncob fiber and cellulose [374] or with PLA [375]. Crosslinked starch foams presented promising results, with higher thermal stability, and lower water sorption and improved flexion properties [368, 376]. A composite blend of starch with plant proteins, kraft fibers, palm oil, or chitosan studied by Kaisangsri et al. showed enhanced mechanical performances [366, 377]. Furthermore, biodegradable hydrophobic coatings have been also studied as a promising alternative to improve biocomposite foam's water resistance [364, 369, 370, 378].

Several technologies have been studied to obtain biobased foams, from extrusion-cooking (a method commonly used in the food industry) for loose-fill cushioning materials [367] to thermoforming for containers production [126, 360, 363]. Soykeabkaew et al. [379] summarized a wide range of processing techniques for starch-based foams, among which the most common are extrusion, baking (thermoforming), microwave, freeze-drying/solvent exchange, and supercritical fluid extrusion. The same process technologies are used for other biobased foams [373, 380-383].

During thermoforming, the porous structure of the foam is formed by insufflation of gas in the molten polymer blend, which expands as pressure is reduced, or by gas formation within the batter due to the use of chemical blowing agents that produce gas by thermal decomposition or chemical reaction. Carbon dioxide is currently the most widely used gas for physical blowing of polymer foams as an eco-friendlier alternative to hydrochlorofluorocarbons (HCFCs), due to its low toxicity, high stability, and low-cost [384]. Some foams are obtained by air diffusion into the battery by whipping before curing [385]. Supercritical inert gases, like carbon dioxide and nitrogen, are used as more environmentally friendly alternatives to blowing foams [373, 381, 386-388]. Yet these blowing agents require specific and expensive equipment to work under high-pressure conditions, thus chemical blowing agents that are easily incorporated during mixing in the polymer matrix are sometimes preferred [384]. The latter leads to highly diffusing gas molecules $\left(\mathrm{CO}_{2}, \mathrm{~N}_{2}\right.$, and $\left.\mathrm{H}_{2}\right)$ resulting in open-cell structures that limit the foam's fields of application. Sodium bicarbonate is another well-known low-cost chemical blowing agents, commonly used with citric acid being both safe for food contact usage [389]. Urea was also studied as a blowing agent in biocomposite starch foams considering both its plasticizing and cross-linking properties in starch matrices [126]. A vast variety of chemical blowing agents have been reviewed by Coste et al. [384], yet the authors highlighted that unreacted blowing agent and by-products can compromise the material's properties and toxicity due to migration throughout their life cycle. Consequently, various parameters and reaction conditions should be determined for each blowing agent/polymer system to meet the final material requirements with no side effects. As regards, biopolymeric composite foams water vapor is mainly used as a blowing agent $[21,24,390]$. Water-based polymer and filler batters are prepared and baked at $140-220^{\circ} \mathrm{C}$ where water vaporizes inflating the batter as it dehydrates and solidifies forming the foam's cells.

In thermoforming processing, either thermoplastic polymer pellets are used $[365,383,391]$ or biopolymers waterbased batters are prepared and poured onto the preheated mold [21, 126, 359, 390, 392-394]. In this regard, molding time, temperature, and pressure must be optimized according to the batter formulation [126]. Additives such as magnesium stearate as a release agent, guar gum as solids suspension stabilizer and glycerol as plasticizer have been reported [106].

A key problem for natural biopolymers foams, mainly starch-based materials is their water susceptibility; therefore several strategies have been studied to overcome this limitation. Biocomposite foams with several fillers have been studied to reduce water uptake $[21,124,140,280$, $359,361,379,395]$. Moreover, despite of the increase in process complexity and cost, the use of coating with other biodegradable bioplastics, such as PLA, or natural waxes has also been reported as a promising alternative to enhance the water-resistance of starch-based biocomposite foams [78, 364, 370, 393].

Biobased foams obtained by microwave from extruded biobased thermoplastic were studied by various authors [358, 383, 396-399]. Besides, Razza et al. [358] indicated that biodegradable and biobased foams expanded by microwave technology resulted in more sustainable materials than EPS benchmark material. Alternatively, noteworthy starch and alginate with micro-fibrous clay composite foams with fire retardant properties were developed via lyophilization by Darder et al. [400]. Nonetheless, the industry-scale design of these processing technologies is needed for future research, with a particular focus on process energy consumption optimization.

Unlike biocomposite films, foam's properties depend not only on its components (polymer, filler, plasticizer, and other additives) intrinsic characteristics and interaction within the composite structure but unequivocally due to the type, number, and size distribution of pores of the foam. Foam structures are cataloged as open or closed-cell types depending on whether pores are interconnected or isolated keeping the

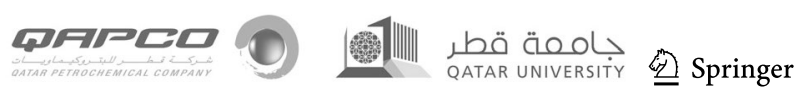


gas or air trapped inside the foam, respectively. Therefore, open-cell systems are more permeable to gases and usually less rigid, resulting in less attractiveness for specific building and insulation and sound-canceling requirements. Generally, more homogenous and smaller cell size structures derive in higher density materials with higher compressive strength [362, 364, 383, 401].

Comparatively, mechanical resistance to compression and flexion is usually increased with filler content in biocomposite foams as shown in Table 4, though optimal filler content depends on its nature and size. Water uptake, on the other hand, is strongly dependent on filler nature. For instance, Machado et al. [359] observed a marked increase in foams contact angle with peanut skin in starch-based foams, indicating an increase in the material's hydrophobicity. Similar results were shown by sesame oil cake residue on starch foams [21], yet others such as sunflower oil cake residual particles presented the opposite effect [126]. Similarly, the biodegradability of foam biocomposites tends to be favored by natural fillers content, some evidencing higher biodegradation rates than others according to assay conditions [21, 126, 395].

A wide range of biocomposite foams have been developed and studied over the last decades with diverse potential applications. Nevertheless, to reinforce their sustainable character further investigations on the use of renewable waste products as raw materials, cost-effective and lowenergy-consuming processing technologies and innocuous foaming agents are needed [85].

\section{Applications of biobased composites}

\subsection{Active and intelligent food packaging}

Active and intelligent packaging materials protect and preserve food ensuring its microbiological, organoleptic, and nutritional quality until it reaches the final consumer. Unlike traditional materials, active and intelligent packaging is polymeric matrices that serve as vehicles for a wide variety of additives such as antimicrobials, antioxidants, gas absorbers, and $\mathrm{pH}$ indicators among others, depending on the primary mode of deterioration of the food that limits its shelf life (Figure 6). Intelligent food packaging systems are small, simple, and inexpensive real-time indicators of food quality or storage conditions. In this regard, Firouz et al. [407] have critically reviewed intelligent and active packaging in the food industry; meanwhile, Yang et al. [408] have summarized the advanced applications of chitosan-based hydrogels as both, biosensors, and intelligent food packaging systems. Table 5 summarizes different types of intelligent systems and active packaging used in the food industry.
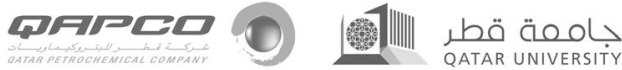

In the last 10 years, there has been an overwhelming advance in the development of nanocomposites, especially those with antimicrobial activity. These materials have been studied as active packaging for application in the food industry in order to eliminate or at least reduce the growth of pathogens responsible for foodborne diseases [304, 305, 310]. The most common developments include formulations containing AgNPs and $\mathrm{ZnO}$ based on starch, chitosan, gelatin, PVA, and starch among others [48, 295, 318, 430].

Ortega et al. [221] studied the effectiveness of nanocomposite starch-based films containing 143 ppm of AgNPs synthesized within the filmogenic suspension as active film packaging for a dairy product. These active films were able to extend the shelf-life of fresh cheese samples for 21 days. Regarding nanocomposite materials in contact with food, studies are necessary to evaluate not only the cytotoxicity of the nanoparticles themselves but also their migration to the food matrix. In this regard, tests are performed using different food simulants. Abreu et al. [220] carried out a contact test to determine if the nanostructured starch films comply with current European regulations without detecting a significant migration of Ag. Furthermore, Metak et al. [431], working on polyethylene containers with $1 \%$ AgNPs inclusion, did not detect Ag migration to the matrix or organoleptic changes in the packaged products. As regards the cytotoxicity of the silver nanoparticles, Bacchetta et al. [432] studied the effects of waterborne AgNPs on juvenile fish Piaractus mesopotamicus and analyzed toxicological endpoints such as metal burdens, oxidative stress, and genotoxicity. DNA damage in fish erythrocytes was observed after $24 \mathrm{~h}$ exposition at $25 \mu \mathrm{g} / \mathrm{l}$ AgNP. Bidian et al. [433] demonstrated that if AgNPs (0.8-1.5 mg/kg) were administered to offspring rats during pregnancy, they could cross the placental and testicular barriers and induced oxidative stress, DNA damage, and autophagy as mechanisms of cell toxicity. However, more research is still needed on this topic.

On the other hand, no migration of montmorillonite (MMT) nanoparticles from soybean protein matrices towards tuna fish muscle was detected through atomic absorption spectroscopy but MMT presence enhance the antimicrobial capacity of clove EO included in the formulation [291].

\subsection{Biobased composites as fertilizer delivery and their applications as agricultural inputs}

Biodegradable plastic mulch films have been developed and studied to reduce plastic waste generated from plastic mulch films disposal after crop harvest. Since the recovered films are usually greatly contaminated with soil and organic residues, their recyclability is difficult and not cost-efficient [434, 435]. The main reason is that mulch, especially thin mulch, cannot be picked up completely and that recollection is highly time and manpower-consuming [435]. Moreover, 


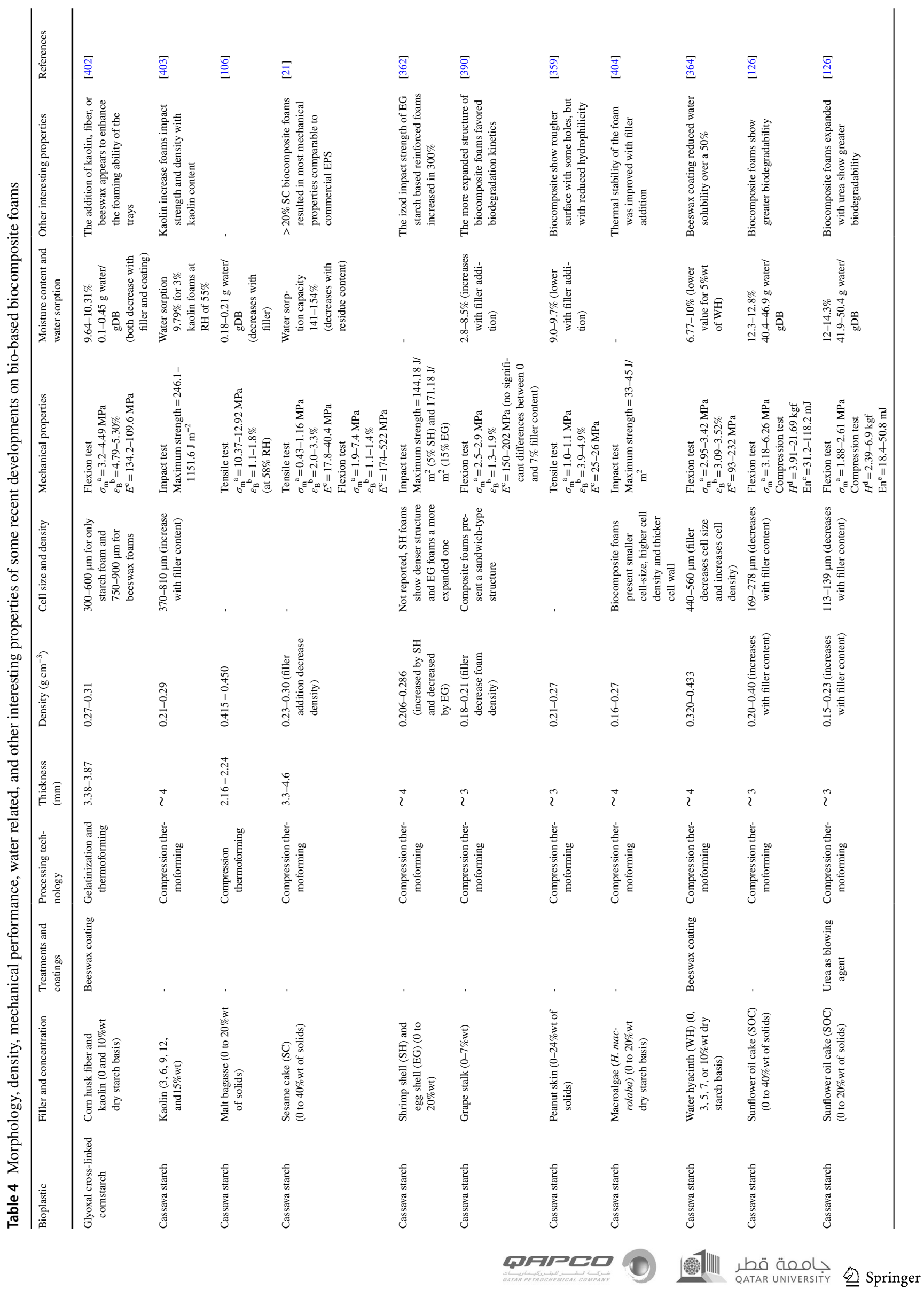




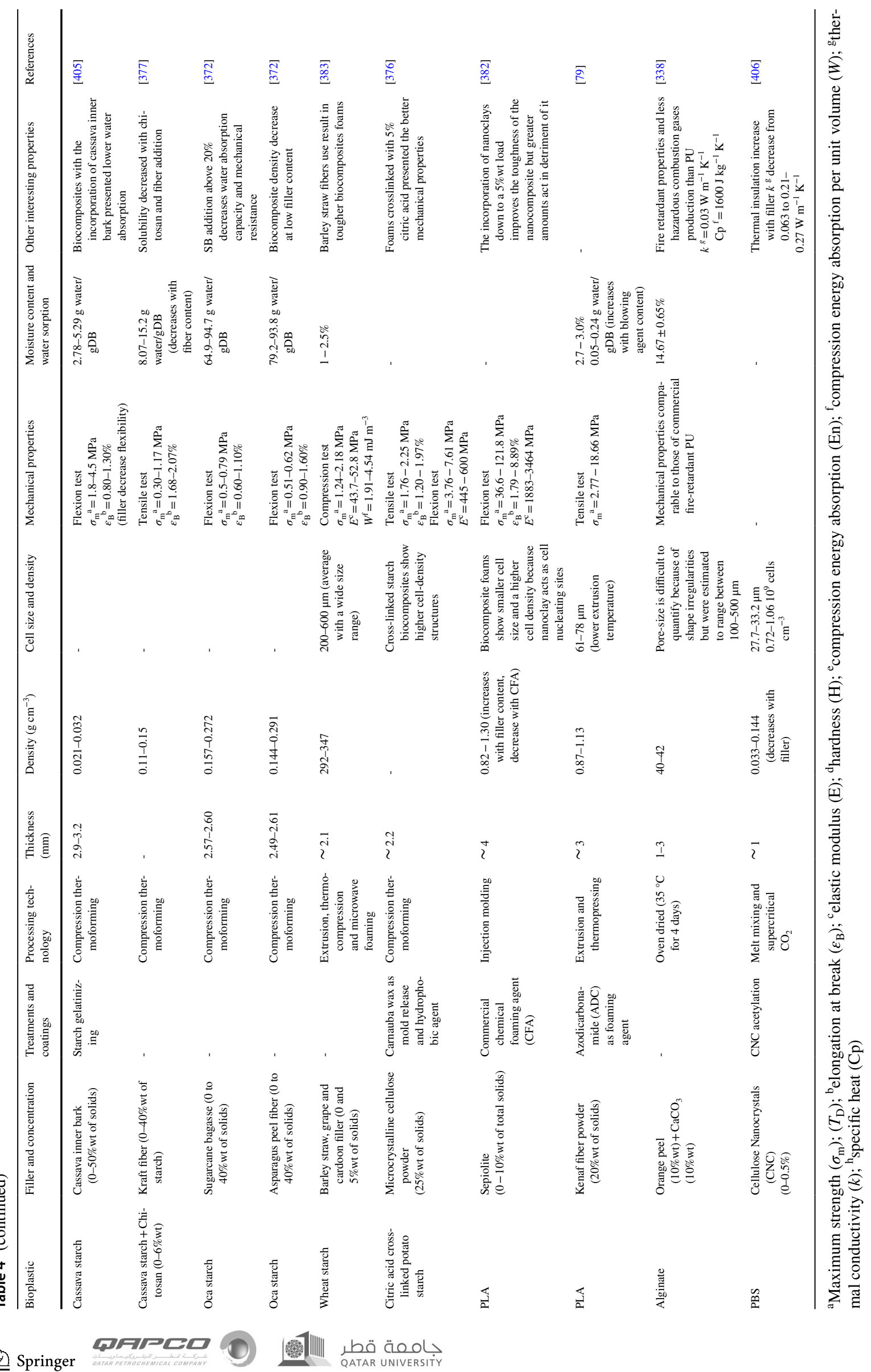


the different aging degrees of the recycled polymer films conversely affect the regenerated product properties [436]. Therefore, most collected films end up in landfills or are used for energy recovery, few countries, such as Germany, France, and Canada, have established recycling systems for plastic mulch waste [437]. In addition, large amounts of residual plastic waste may remain on the field leading to polluted soils with diminished porosity, moisture content, and increasing bulk density which affects quality, health, and fertility, as has been evidenced in Xinjiang Autonomous Region (China) where residual plastic films can reach 200 $\mathrm{kg} / \mathrm{ha}$, known as "white pollution" [1, 435, 438]. Moreover, these plastic residues enter the soil ecosystem by different routes depending on water flow, insects' ingestion and egestion, root plant growth, and weathering in the soil leading to microplastic that can enter deep aquifers and hence the aquatic food chain [439]. Even though its long-term sustainability is arguable, soil covering is an established agronomical technique intended to increase yield and quality of the production by conservation of soil temperature and moisture, as well as weed growth control [434, 440]. Consequently, as food demand increases, plastic films consumption grows annually, with an estimated 1.4 million ton global market used to cover around $80,000 \mathrm{~km}^{2}$ (equivalent to $0.6 \%$ ) of the global arable land [1].

The latter has derived considerable research, development and commercialization of novel biodegradable, and biobased mulch films, that at the end of their lifetime degrade and mineralize in soil avoiding recollection and acting as in situ soil fertilizer [1, 246, 441, 442]. Various oil-based and biobased biodegradable polymer films and their blends and copolymers have been studied as mulch films [120, 435, 443-445]. Field studies have also been performed on commercial biodegradable bioplastics $[434,436]$, yet biodegradation rate is clearly dependent not only on bioplastic nature but also on climate conditions and soil characteristics. The EN 17033:2018, a new European Norm concerning "Plastics - Biodegradable mulch films for use in agriculture and horticulture - Requirements and test methods", sets the standard methods necessary to determine biodegradability, performance, and environmental impact of biobased mulch films [1]. Additionally, additives liberation control and ecotoxicity testing after full biodegradation are also needed to ensure no further environmental impact $[1,446]$.

Biodegradable mulches can be obtained by thermo-plasticizing, casting, or spraying using renewable and biodegradable biopolymers such as starch, cellulose, chitosan, alginate, and glucomannan [442]. A wide range of studies on this type of mulching system is listed in Table 5. Natural fillers from renewable sources were incorporated into composite mulching films and coating to improve their mechanical performance, decrease water sensitivity, and/or confer better UV-light barrier properties for soil temperature

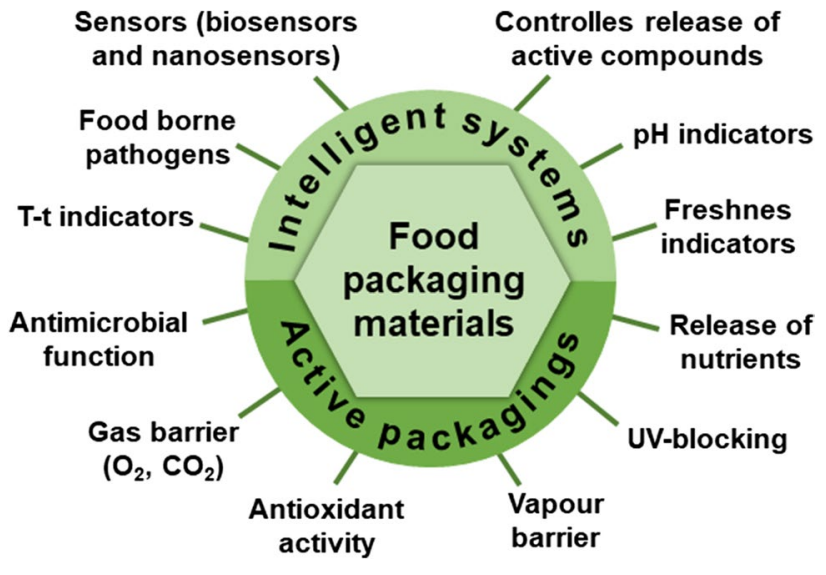

Fig. 6 Active and intelligent food packaging materials properties

conservation [420, 442, 447, 448]. The most recent works focus on spraying water solutions onto soil forming a biodegradable mulching coating directly in the field, using mainly biopolymers obtained from marine and agricultural waste and byproducts [419, 420, 442, 447, 449-453].

Likewise, excessive fertilization and run-off are known to pollute surface and groundwaters leading to eutrophication of lakes and rivers that, in turn, result in the deterioration of aquatic ecosystems due to algae bloom, oxygen loss, aquatic wildlife mortality, and the consequent biodiversity loss [454]. These, among other serious environmental issues derived from current agriculture practices, generated interest in new methods using innovative technologies to ensure high yields and quality of agricultural products while minimizing agrochemicals use. On the one hand, the study, extraction, and use of natural pesticides and herbicides derived from renewable sources have been promoted $[455,456]$. On the other hand, in view of cleaner and more sustainable agriculture practices, the use of biodegradable composite fertilizers controlled-release systems has been considered to achieve more efficient use of nutrients, for increased productivity yields with lower cost and environmental impact. Many works have focused on urea dosage by its inclusion in biodegradable films and composites or encapsulation (see Table 5). Similarly, other elemental nutrients for crop production could be encapsulated with bioplastics and introduced as filler of biocomposite materials for fertilizers-controlled release, though further investigations are needed in this respect.

\subsection{Biomedical applications}

Nowadays, biopolymer composites are widely employed in biomedical applications such as tissue engineering and wound healing. According to Al-Enizi et al. [457], polymerbased nanofibrous materials are used in tissue engineering

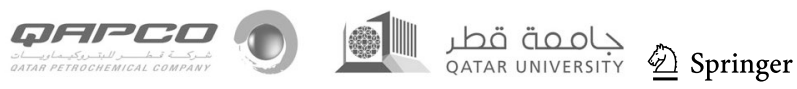




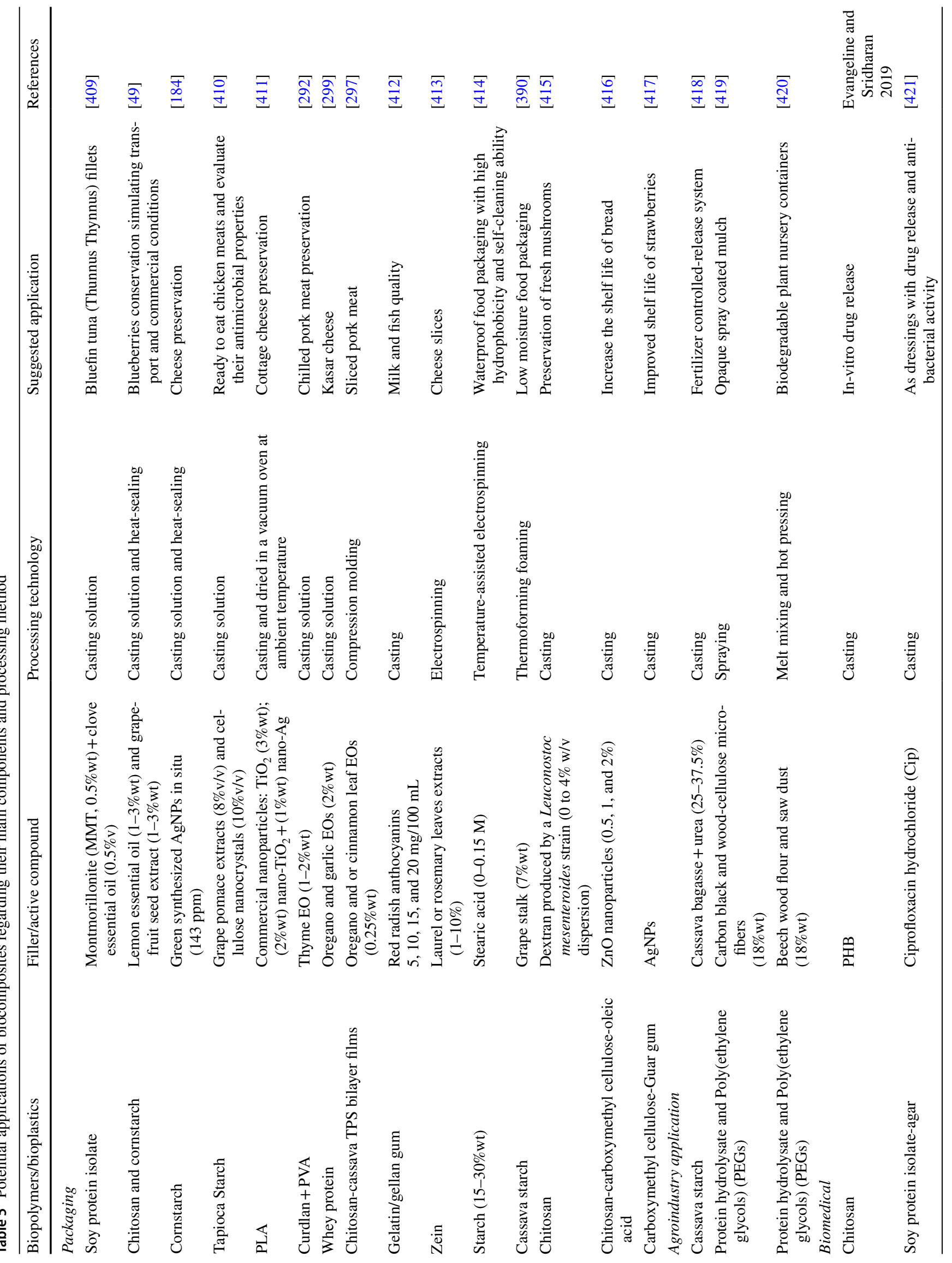




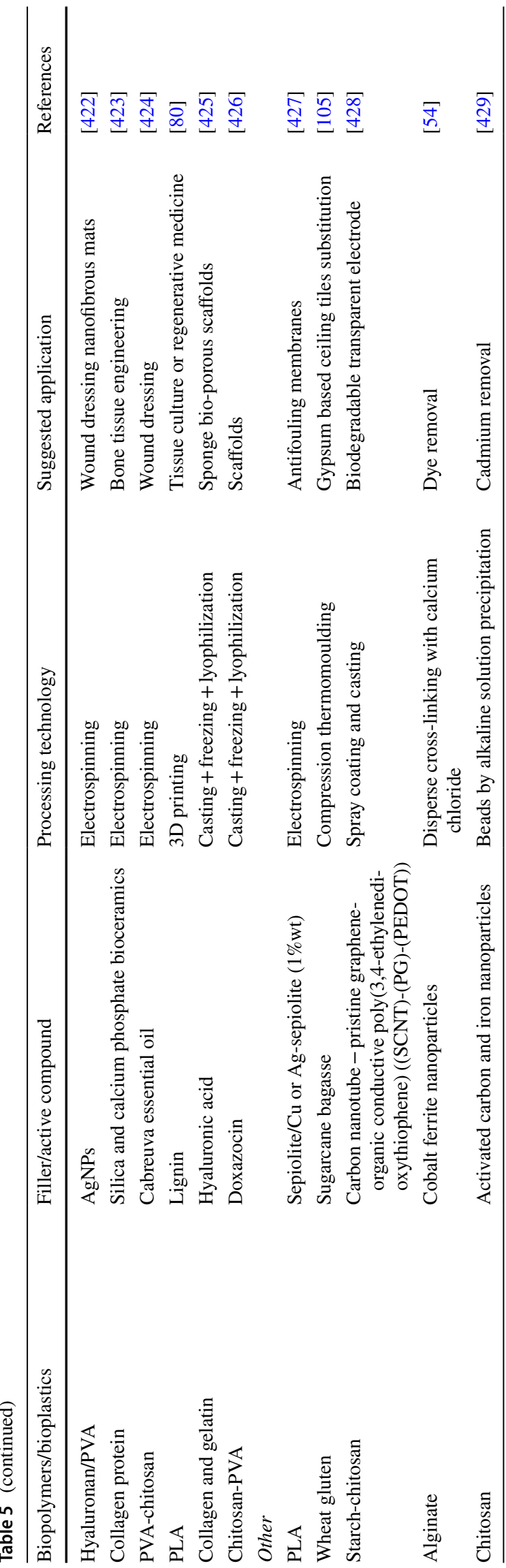

(bones, blood vessels, and oral tissues) and wound dressing. Synthetic biodegradable and natural polymers offer advantages over the conventional materials employed for medical devices because of their biocompatibility, biodegradability, lower antigenicity, and renewability [458]. The development of biomaterials based on biodegradable polymers has driven a new generation of materials for tissue regeneration and wound healing, which is in line with nanotechnology-based engineering strategies. In this sense, Hamdan et al. [459] stressed that numerous engineered nanotechnologies have been proposed demonstrating unique properties and multiple functions that address specific problems associated with wound repair mechanisms. The versatility of biopolymers enables to develop of diverse biomedical devices such as scaffold and wound dressings with high performance, biomimetic properties, and several other tailored characteristics which offer multiple applications. Correspondingly, Sahana and Rekha [458] assure that the technological advances in material science, regenerative medicine, nanotechnology, and bioengineering aid to improve the functional and structural characteristics of biodegradable polymers to suit the current wound care demands such as tissue repair, restoration of lost tissue integrity, and scarless healing.

Wound dressing protects the wound from microorganism deposition and dehydration and must improve the healing process by interacting with the wound through the release of bioactive molecules while maintaining the necessary favorable conditions for the re-establishment of the skin integrity and homeostasis [460]. In addition, wound dressing must ensure complete skin recovery with the best functional and cosmetic results [461]. Biopolymer-based wound healing materials can absorb tissue exudates, prevent wound dehydration and allow oxygen to permeate the wound, and can also be loaded with bioactive substances to be delivered into the wound [462]. As reported by Kalashnikova et al. [463], there are two main categories of biomaterials used in wound healing: materials that exhibit intrinsic properties beneficial for wound treatment, and materials employed as delivery vehicles for therapeutic agents. Various innovative biocomposites films and hydrogels with controlled drug or active compound release have been reported for wound dressing [47, 255, 424, 464, 465]. Collagen, cellulose, chitosan, alginate, hyaluronan, fucoidan, and carrageen are the most widely used biopolymers to develop wound dressing materials. These present either antimicrobial, anti-inflammatory, water retention, proliferative, angiogenic, or other targeted actions on specific cells, hence playing a key role in the healing process [458]. A very interesting and comprehensive review of collagen and collagen-based wound dressings published by Brett [466], remarks that wound dressings based on this biopolymer are cost-effective and present high water holding capacity, mechanical resistance, and flexibility. Collagen-based wound dressings can be obtained for diverse

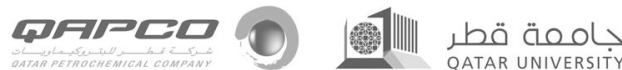


wound types and degrees, such as bedsores, minor burns, foot ulcers, large open cuts, chronic wounds, low to heavy exudation wounds, and surgical wounds. Likewise, Keshk [467] reviewed several industrial applications of bacterial cellulose, including wound healing. Wound dressings for burns, chronic wounds, plastic/reconstructive surgeries can be developed from this biopolymer due to its antibacterial capacity [458]. Alginate has been also widely studied in this regard, either alone or in combination with other biomaterials or biomolecules. In the review by Varaprasad et al. [462] about alginate-based composite materials for wound dressing application, the importance of alginates and the roles of their derivatives in wound dressing biomaterials, besides numerous studies on recent alginate-based wound dressing materials. Alginates and their derivatives present homeostatic character, which is relevant to treat draining wounds, pressure ulcers, dermal wounds, surgical incisions, or dehisced wounds, as well as infected and postoperative wounds. In the case of hyaluronate-based wound dressings, these are characterized for their flexibility, high biocompatibility, and bacteriostatic character [468]. This kind of biomedical devices is very useful to treat chronic wounds as well as partial and full-thickness wounds. Regarding chitosan, its antimicrobial capacity is the more relevant property to develop wound dressing for acute wounds and pressure ulcers as was reported by Dai et al. [469]. In addition to these widely studied and reported biopolymers, there are several similar biomolecules of therapeutic interest such as; fucoidan, carrageenan, and glucans that have been less explored [458].

The concept of tissue engineering aims to the self-regeneration of damaged tissues with the support of a scaffold that acts as a guide and support for new cell growth [470]. Biocompatible and biocomposite scaffolds aid the fast integration of tissues, their biocompatibility allows human cells to organize and grow around the polymer. Initially, the scaffold was merely designed to give support to the cell, but nowadays scaffolds may be loaded with biological factors to facilitate cells growth [471]. Tissue engineering also contemplates the development of artificial tissues that are physiologically functional; hence technological advances in this area continuously occur. In this regard, Gauvin et al. [472] stressed that studies about cell-seeded scaffolds have accomplished novelty materials and processing methods leading to well-engineered biocompatible systems. Another technological advance in tissue engineering is the use of nanostructured biomaterials such as nanoparticles and nanocomposites, as well as organic-inorganic hybrid polymers to develop scaffolds for organs regeneration. According to Iqbal et al. [473] and Khan et al. [474], diverse synthetic and natural polymers and their composite materials have been used to fabricate scaffolds for bone tissue engineering, nerve regeneration, controlled drug release, tooth structure regeneration, guided tissue regeneration (GTR), reinforcement of dental composite, bone and cartilage regeneration. Electrospinning, foaming, and 3D printing have been studied for biocomposites scaffolds, being PLA the most used bioplastic for these applications [80, 423, 475]. Regarding micro-fabrication technologies, Iqbal et al. [473] mentioned that lithography, bioprinting, micromolding, or photolithography are now becoming more routine and are emerging as powerful tools for the manufacture of biomaterials and tissue-engineered constructs. These authors also stressed that the use of these micro and nanotechnologies not only replicates cell-scale complexities by providing the cells with a microenvironment that mimics the native structure but also allows obtaining 3D architectures.

A few further examples of biomedical applications of biocomposite with raw materials from agri-food by-products are shown in Table 5.

\subsection{Other innovative biobased composites applications}

Numerous novel and groundbreaking applications have been reported for biobased composites and nanocomposites using by-products from the agri-food industry and green synthesized nanoparticles. Various applications have been proposed for copper nanoparticles from the field of electronics, catalysis, and industrial wastewater treatment [476]. Its use has also been proposed for cloth treatment since these nanoparticles have a high disinfectant capacity. In the context of the COVID-19 pandemic, this property is more than relevant and would improve the safety of both health personnel and patients, considering personal and medical hygiene clothing. In this regard, an Argentine company jointly with CONICET has developed AtomProtect ${ }^{\circledR}$, a chinstrap made with a cloth treated with a polymeric solution containing $\mathrm{Cu}$ and Ag nanoparticles, which retains its sanitizing properties even after 15 washes [477].

Moreover, several recent works have been reported on the use of biobased biocomposites and nanocomposites for water treatment and pollutants removal [54, 55, 239, 427, 429, 478]. Such research is of primal importance to ensure clean water sustainability. For instance, Jayalakshmi and Jeyanthi [54] studied cobalt ferrite-alginate nanocomposite synthesized for highly polluting dye removal from watercourses. In addition, Dasari et al. [427] developed a biocide PLA-based nanocomposite membrane for drinking water purification. With a different approach, Goldhahn et al. [479] developed wood and gelatin tunable biocomposite membranes for water decontamination from various pollutants. Furthermore, the use of nanomaterials in the fabrication of superhydrophobic membranes for water desalination via membrane distillation has been deeply revised by Gontarek-Castro et al. [480] and Castro-Muñoz [481]. 
Over the last few decades, different biopolymers have been employed in membrane preparation for pervaporation (PV) applications that are currently used in the preparation of mixed matrix membranes (MMMs), a new-generation membrane for purification applications of great interest to chemical engineering processes. These MMS have been proved effective for ethanol recovery and dehydration [482, 483], EOs and aroma compound recovery [484, 485], azeotropic separation of organic mixtures [486], among others. In this respect, membranes based on chitosan, cellulose acetate, sodium alginate, PLA, and PVA have served as support materials for membranes for pervaporation, alone or including different types of nanoparticles such as $\mathrm{Au}, \mathrm{Cu}$, and $\mathrm{Ag}$ as well as zeolites and carbon nanotubes [482, 483, 487, 488]. In addition, Castro-Muñoz and coworkers have extensively reviewed the use of MMMs for PV, emphasizing that specific components transport and selectivity enhancement through the incorporation of inorganic materials into different polymeric membranes, mentioning key principles that conditioned the filler selection for a synergistic effect [482].

Furthermore, biobased foam with natural fillers have proven thermal and acoustic insulation properties which are attractive for construction and building [331, 333, 338, 391, 406, 489]. Several studies on biocomposites using byproducts and wastes were revised and detailed in Section 3.2. Besides, biomass by-products and waste have been studied for construction panels and materials. For example, sustainable wood panels from wood industry by-products and ecofriendly adhesives from cassava starch were developed by Monroy et al. [490, 491] as an alternative to synthetic adhesives in medium-density fiberboard (MDF) manufacture. Likewise, Guna et al. [105] studied sugarcane bagassegluten composites as a potential substitute for gypsum based ceiling tiles.

Finally, biobased composites and nanocomposite materials show promising use of inflexible and biodegradable electronics and energy storage systems [492-495]. In this regard, Thiangtham et al. [496] designed biocomposite membranes based on MCC extracted from sugarcane bagasse added into PLA/PBS matrices.

\section{Life cycle assessment of single use biobased composites}

Within the context of circular economy, aiming to preserve the value of products, materials, and resources for as long as possible minimizing or eliminating, if possible, their environmental impact, biobased materials have become key players, especially owing to their renewable character. Yet, despite their renewability, biobased composite materials sustainability is not granted and depends on various factors, from raw materials source to produced materials end of life.
In general, life cycle assessments (LCAs) of biobased plastic materials have indicated significantly lower greenhouse gases GHG emissions than the fossil oil counterparts [497]. Differences are mostly attributed to plants $\mathrm{CO}_{2}$ absorption in photosynthesis before harvest or felling, considering that biobased materials are either composted or burned at the end of their life cycle resulting in $\mathrm{CO}_{2}$ emission with a netzero carbon balance [498]. Besides, biobased materials use intrinsically implies a reduction in non-renewable energy resources due to the raw material source shift. Razza et al. [358] demonstrated that despite their greater density, starchbased expanded packaging could have a $50 \%$ cut in fossil fuels use, a $60 \%$ decrease in greenhouse gas emission, a $90 \%$ reduction in volatile organic compounds (VOCs) emissions, and a $15 \%$ of landfilling, considering a current standard of $40 \%$ of organic recycling rate compared to EPS packaging.

The major LCA-reported impact of biobased plastics is the source and production of the raw materials. Food crop feedstocks are land extensive, therefore large new land areas shall be destined to crop production exclusively for bioplastics purposes. Such land-use changes imply deforestation for agricultural production, as have the conversion of rainforests to sugarcane plantations in Brazil or the Great Chaco (Argentina) deforestation for soy expansion, which comprise several direct and indirect environmental and social impacts within the raw materials production regions [499, 500]. Furthermore, land-use change is one of the primary global causes of increasing greenhouse gases emissions and soil degradation, biodiversity loss, and fresh-water scarcity [501]. In this regard, the use of agrifood waste and by-products for bioplastic and biocomposite production would decrease land-use requirements safeguarding its negative impacts. For instance, seed oil cakes, are byproducts of vegetable oil industries, are known for their high fiber, polysaccharides, and proteins content that can be extracted and that may represent a renewable source to produce innovative biobased materials [15]. In addition, current agricultural practices have a great impact on the LCA of biobased products, being sustainable practices needed to reduce eutrophication, prevent soil erosion, and protect biodiversity. Incidentally, an LCA study carried out by Vigil et al. [502] on active packaging for the fresh-cut vegetable industry, indicated that agricultural production of fresh lettuces is responsible for most impact factors, followed by packaging manufacturing. An alternative to tackle the latter, the use of fully renewably sourced electricity for packaging molding technology could reduce in over $50 \%$ the potential impact [358].

To close the loop in the plastic products industry, reusable product design and recycling systems have been established. Nonetheless, products that can be reuse is somehow limited and recycling is rarely total: mechanical recycling seldomly transforms products back into their original product system;

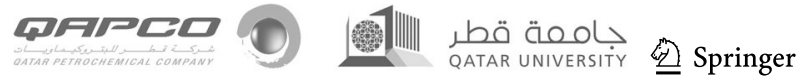


usually, the virgin polymer is needed for reprocessing; and a substantial volume of material is rejected and redirected to other waste management types, of which a percentage may even end up as ocean debris [503]. Biodegradable biobased plastics introduce another form of waste transformation intending to reduce plastic waste generation and increase the product's circularity by aerobic and anaerobic degradation. However, effective waste management systems are needed to prevent the incorrect disposal of bioplastic waste and its consequent accumulation in the environment as have been observed with conventional plastics use [1, 2]. Among biodegradable bioplastics, PHAs are both compostable and biodegradable in marine environments which may comparably reduce their environmental impact [4].

Lastly, the sustainability of biobased nanocomposites is also questioned in terms of the unknown hazards and toxicity [504]. Therefore, migration and cytotoxicity studies of nanofillers are currently being conducted [180, 432, 505, 506]. Furthermore, the use of hazardous chemicals in some biopolymers and biobased filler treatments must also be considered and reevaluated aiming to find greener alternatives [507].

\section{Final remarks on current limitations and future trends}

Over the last decade, a shift in the design dynamics of new materials has been observed, having a more specific approach born from the application requirements up. In this regard, composite materials offer a major advantage since their final properties can be tailored by selecting polymer matrix and filler type, their content ratio, and filler size distribution and morphology. Besides, the limitation of fossil resources and their consequent environmental impact has driven the search for alternative biomass-based polymeric materials and composites. Over 7000 research articles on biocomposites have been reported during the last 10 years with a growing tendency, which highlights the novelty and potential of these materials.

In addition, bio-sourced and biodegradable materials are key players towards a circular or sustainable economy. In recent years, the focus has been set on those materials with optimized end-of-life cycles considering reusability, recyclability, and biodegradability. However, structural changes and improvements are needed both in waste management systems as in production and retail allocation and distribution to achieve fully sustainable products and processes. Therefore, a tendency towards fully integrated production systems (i.e., biorefineries) in which different products from raw materials, by-products, and residues are entangled and nearby so as to reduce waste generation, transportation costs, and emissions. Nonetheless, to fully understand the role that bioplastics and biocomposites could play in a global economy, further reliable information on their sustainability is needed. Providing a basis to guide future technological developments. Research towards developing more ecologically responsible biocomposites not only needs to focus on properties optimization according to the application of the materials but also aim to minimize resource use through the selection of the process technologies and to avoid (if possible) environmental and health hazardous chemical reagents. In this regard, biomass production is crucial to the sustainability of these materials, thus the need for agricultural systems that are respectful for farmers, the environment, and the communities.

The major drawback of bioplastics and their products is that they are not economically competitive with commodity plastics. Therefore, as it was once for conventional plastic, the development of composite materials provides a lowercost alternative to pure components as well as providing enhanced and unique properties. Furthermore, fully renewable biobased composites materials can be produced from currently devalued raw materials, regarded as low-cost byproducts or wastes. This implies not only a potential drop in production cost of biobased material, but also a reduction in energy, water, and soil used in raw materials production and a further reduction in waste generation.

The numerous and innovative possible applications for biobased composites and nanocomposites that have been reviewed and reported demonstrate the potentiality of these materials. The nontoxic nature and biodegradability of these materials are key features for their use in active and intelligent food packaging that can be composted and functionalized biodegradable mulching plastic and fertilizerscontrolled release aiming for more environmentally friendly agricultural systems. Their water affinity and retention capacity are relevant for absorption systems for pollutants retention and membrane development for water purification treatments. Furthermore, these properties along with the biocompatibility have triggered the development of wound dressing, drug-delivery systems, and scaffolds for tissue engineering. Several other investigations have been done in insulation construction materials and flexible electronics and energy storage systems. The results shown are very promising, thus future research should examine strategically the scaled-up production and process optimization of these ecological materials to meet the market demands.

Acknowledgements This work was possible thanks to the financial support of the Agencia Nacional de Promoción Científica y Tecnológica (ANPCyT, Argentina) that has funded the following projects: PICT 2015-0921, PICT 2019-2827 and PICT 2018-3285, the project PGI 24/ZQ18 (Proyectos Grupos de Investigación) funden by the Universidad Nacional del Sur (UNS, Bahía Blanca, Argentina) and the Consejo Nacional de Investigaciones Científicas y Técnicas (CONICET, Argentina) 
Author contribution All authors contributed to the study conception and design, as well as literature search and data analysis. A first draft of the manuscript was jointly written and commented on previous versions of the manuscript by all authors. All authors read and approved the final manuscript.

Funding PICT 2015-0921, PICT 2019-2827 and PICT 2018-3285 (ANPCyT, Argentina); PGI 24/ZQ18 (UNS and CONICET, Argentina) and Florencia Ortega Doctoral Fellowship CONICET (CONICET, Argentina).

Data availability Data sharing is not applicable - no new data generated.

Code availability Not applicable.

\section{Declarations}

Conflict of interest The authors declare no competing interests.

\section{References}

1. F. Razza, C. Briani, T. Breton, D. Marazza, Metrics for quantifying the circularity of bioplastics: the case of bio-based and biodegradable mulch films. Resour. Conserv. Recycl. 159, 104753 (2020). https://doi.org/10.1016/j.resconrec.2020.104753

2. A. Abraham, H. Park, O. Choi, B.I. Sang, Anaerobic co-digestion of bioplastics as a sustainable mode of waste management with improved energy production - a review. Bioresour Technol 322, 124537 (2021). https://doi.org/10.1016/j.biortech.2020.124537

3. L.M. Blank, T. Narancic, J. Mampel et al., Biotechnological upcycling of plastic waste and other non-conventional feedstocks in a circular economy. Curr Opin Biotechnol 62, 212-219 (2020). https://doi.org/10.1016/j.copbio.2019.11.011

4. K. Dietrich, M.J. Dumont, L.F. Del Rio, V. Orsat, Producing PHAs in the bioeconomy - towards a sustainable bioplastic. Sustain Prod Consum 9, 58-70 (2017). https://doi.org/10.1016/j. spc.2016.09.001

5. D. Civancik-Uslu, R. Puig, M. Hauschild, P. Fullana-i-Palmer, Life cycle assessment of carrier bags and development of a littering indicator. Sci Total Environ 685, 621-630 (2019). https:// doi.org/10.1016/j.scitotenv.2019.05.372

6. European Bioplastics in cooperation with nova-Institute (2020) Bioplastics market development update 2020. In: Eur. Bioplastics Org. http://www.european-bioplastics.org/news/publications/\% 0AEuropean. Accessed 14 May 2021

7. M. Zhao, B. Li, J. Cai et al., One-step method to prepare starchbased superabsorbent polymer for slow release of fertilizer. Chem Eng J 153, 607-616 (2016). https://doi.org/10.1016/j.cej. 2016.10.101

8. J. Sadhukhan, E. Martinez-Hernandez, R.J. Murphy et al., Role of bioenergy, biorefinery and bioeconomy in sustainable development: strategic pathways for Malaysia. Renew Sustain Energy Rev 81, 1966-1987 (2018). https://doi.org/10.1016/j.rser.2017.06.007

9. G.A. Valencia, C.J. de Andrade, J.L. Ienczak et al., Valorization of agri-food wastes, in Bio-valorization of Waste: Trends and Perspectives. ed. by S. Shah, V. Venkatramanan, R. Prasad (Springer Nature Singapore Pte Ltd., Singapore, 2021), pp. 111-132

10. D.S. Gunarathne, I.A. Udugama, S. Jayawardena et al., Resource recovery from bio-based production processes in developing
Asia. Sustain Prod Consum 17, 196-214 (2019). https://doi.org/ 10.1016/j.spc.2018.11.008

11. S. Otles, C. Kartal, Food waste valorization, in Sustainable Food Systems from Agriculture to Industry. ed. by Galanakis CM (Academic Press, 2018), pp. 371-399

12. L. Six, F. Velghe, S. Verstichel, S. De Meester, Sustainability Considerations on the Valorization of Organic Waste, in Biotransformation of Agricultural Waste and By-Products. ed. by Poltronieri P, D’Urso OF (Elsevier, 2016), pp. 287-307

13. K. Jõgi, R. Bhat, Valorization of food processing wastes and by-products for bioplastic production. Sustain Chem Pharm 18, 1-10 (2020). https://doi.org/10.1016/j.scp.2020.100326

14. L. Kaur, R. Khajuria, L. Parihar, G. Dimpal Singh, Polyhydroxyalkanoates: biosynthesis to commercial production- A review. J Microbiol Biotechnol Food Sci 6, 1098-1106 (2017). https://doi. org/10.15414/jmbfs.2017.6.4.1098-1106

15. S.F. Mirpoor, C.V.L. Giosafatto, R. Porta, Biorefining of seed oil cakes as industrial co-streams for production of innovative bioplastics A review. Trends Food Sci Technol 109, 259-270 (2021). https://doi.org/10.1016/j.tifs.2021.01.014

16. M.J. Bof, A. Jiménez, D.E. Locaso et al., Grapefruit seed extract and lemon essential oil as active agents in corn starch-chitosan blend films. Food Bioprocess Technol 9, 2033-2045 (2016). https://doi.org/10.1007/s11947-016-1789-8

17. A. El Barnossi, F. Moussaid, A. Iraqi Housseini, Tangerine, banana and pomegranate peels valorisation for sustainable environment: a review. Biotechnol Rep 29, e00574 (2021). https:// doi.org/10.1016/j.btre.2020.e00574

18. D.C.M. Ferreira, G. Molina, F.M. Pelissari, Biodegradable trays based on cassava starch blended with agroindustrial residues. Compos Part B Eng 183, 107682 (2020). https://doi.org/10. 1016/j.compositesb.2019.107682

19. F. Versino, O.V. López, M.A. García, Sustainable use of cassava (Manihot esculenta) roots as raw material for biocomposites development. Ind. Crops. Prod. 65, 79-89 (2015). https://doi.org/ 10.1016/j.indcrop.2014.11.054

20. E. de Morais Teixeira, T.J. Bondancia, K.B.R. Teodoro et al., Sugarcane bagasse whiskers: extraction and characterizations. Ind Crops Prod 33, 63-66 (2011). https://doi.org/10.1016/j.indcr op.2010.08.009

21. C. Martins Machado, P. Benelli, I.C. Tessaro, Sesame cake incorporation on cassava starch foams for packaging use. Ind Crops Prod 102, 115-121 (2017). https://doi.org/10.1016/J.INDCROP. 2017.03.007

22. R. Bodirlau, C.A. Teaca, I. Spiridon, Influence of natural fillers on the properties of starch-based biocomposite films. Compos Part B Eng 44, 575-583 (2013). https://doi.org/10.1016/j.compo sitesb.2012.02.039

23. M. Phiriyawirut, P. Maniaw, Cellulose microfibril from banana peels as a nanoreinforcing fillers for zein films. Open J Polym Chem 02, 56-62 (2012). https://doi.org/10.4236/ojpchem.2012. 22007

24. A.E.S. Vercelheze, F.M. Fakhouri, L.H. Dall'Antônia et al., Properties of baked foams based on cassava starch, sugarcane bagasse fibers and montmorillonite. Carbohydr Polym 87, 1302-1310 (2012). https://doi.org/10.1016/j.carbpol.2011.09.016

25. S. Kumar, K. Thakur, Bioplastics - classification, production and their potential food applications. J Hill Agric 8, 118 (2017). https://doi.org/10.5958/2230-7338.2017.00024.6

26. R. Siakeng, M. Jawaid, H. Ariffin et al., Natural fiber reinforced polylactic acid composites: a review. Polym Compos 40, 446463 (2019). https://doi.org/10.1002/pc.24747

27. A.S.A. Mohammed, M. Naveed, N. Jost, Polysaccharides; classification, chemical properties, and future perspective applications in fields of pharmacology and biological medicine (a review of current applications and upcoming 
potentialities). J Polym Environ (2021). https://doi.org/10. 1007/s10924-021-02052-2

28. M. Misra, S. Vivekanandhan, A.K. Mohanty, J. Denault, Nanotechnologies for agricultural bioproducts, in Comprehensive Biotechnology, 3rd edn., ed. by M. Moo-Young (Pergamon, 2011), pp. 119-127

29. L. von Schantz, H. Schagerlöf, E.N. Karlsson, M. Ohlin, Characterization of the substitution pattern of cellulose derivatives using carbohydrate-binding modules. BMC Biotechnol. 14:113, 1-8 (2014). https://doi.org/10.1186/s12896-014-0113-9

30. H. Almasi, B. Ghanbarzadeh, A.A. Entezami, Physicochemical properties of starch-CMC-nanoclay biodegradable films. Int $\mathbf{J}$ Biol Macromol 46, 1-5 (2010). https://doi.org/10.1016/j.ijbio mac.2009.10.001

31. C. Brigham, Biopolymers: Biodegradable alternatives to Traditional Plastics, in Green Chemistry: An Inclusive Approach. ed. by Török B, Dransfield T (Elsevier, 2017), pp. 753-770

32. C. Molina-Ramírez, A. Cañas-Gutiérrez, C. Castro et al., Effect of production process scale-up on the characteristics and properties of bacterial nanocellulose obtained from overripe Banana culture medium. Carbohydr Polym 240, 116341 (2020). https:// doi.org/10.1016/j.carbpol.2020.116341

33. K. Shanmugam, H. Doosthosseini, S. Varanasi et al., Nanocellulose films as air and water vapour barriers: a recyclable and biodegradable alternative to polyolefin packaging. Sustain Mater Technol 22, e00115 (2019). https://doi.org/10.1016/j.susmat. 2019.e00115

34. M.A. Carpenter, M. Shaw, R.D. Cooper et al., Association mapping of starch chain length distribution and amylose content in pea (Pisum sativum L.) using carbohydrate metabolism candidate genes. BMC Plant Biol 17, 1-23 (2017). https://doi.org/10.1186/ s12870-017-1080-9

35. M.L. Sanyang, R.A. Ilyas, S.M. Sapuan, R. Jumaidin, Sugar palm starch-based composites for packaging applications, in Bionanocomposites for Packaging Applications. ed. by Jawaid M, Swain SK (Springer International Publishing, 2018), pp. 125-147

36. W. Liu, Z. Wang, J. Liu et al., Preparation, reinforcement and properties of thermoplastic starch film by film blowing. Food Hydrocoll 108, 106006 (2020). https://doi.org/10.1016/j.foodh yd.2020.106006

37. T.I.A. Gouveia, K. Biernacki, M.C.R. Castro et al., A new approach to develop biodegradable films based on thermoplastic pectin. Food Hydrocoll 97, 105175 (2019). https://doi.org/10. 1016/j.foodhyd.2019.105175

38. A. Valdés, N. Burgos, A. Jiménez, M.C. Garrigós, Natural pectin polysaccharides as edible coatings. Coatings 5, 865-886 (2015). https://doi.org/10.3390/coatings5040865

39. T.C.T. Troung, T. Kobayashi, Pectin bioplastic films regenerated from dragon fruit peels. Environ Sci 62, 18-22 (2020). https:// doi.org/10.31276/VJSTE.62(4).18-22

40. S. Šešlija, A. Nešić, M.L. Škorić et al., Pectin/Carboxymethylcellulose films as a potential food packaging material. Macromol Symp 378, 1-5 (2018). https://doi.org/10.1002/masy.201600163

41. T. Giancone, E. Torrieri, P.P. Di et al., Effect of surface density on the engineering properties of high methoxyl pectin-based edible films. Food Bioprocess Technol 4, 1228-1236 (2011). https://doi.org/10.1007/s11947-009-0208-9

42. L.S. Liu, C.K. Liu, M.L. Fishman, K.B. Hicks, Composite films from pectin and fish skin gelatin or soybean flour protein. J Agric Food Chem 55, 2349-2355 (2007). https://doi.org/10.1021/jf062612u

43. R.S.K. Sucheta, K. Chaturvedi, S.K. Yadav, Evaluation of structural integrity and functionality of commercial pectin based edible films incorporated with corn flour, beetroot, orange peel, muesli and rice flour. Food Hydrocoll 91, 127-135 (2019). https://doi.org/10.1016/j.foodhyd.2019.01.022
44. Z. Yu, Y. Ji, V. Bourg et al., Chitin- and cellulose-based sustainable barrier materials: a review. Emergent Mater 3, 919-936 (2020). https://doi.org/10.1007/s42247-020-00147-5

45. J. Lamarra, S. Rivero, A. Pinotti, Nanocomposite bilayers based on poly(vinyl alcohol) and chitosan functionalized with gallic acid. Int J Biol Macromol 146, 811-820 (2020). https://doi.org/ 10.1016/j.ijbiomac.2019.10.049

46. C. Valencia-Sullca, M. Vargas, L. Atarés, A. Chiralt, Thermoplastic cassava starch-chitosan bilayer films containing essential oils. Food Hydrocoll 75, 107-115 (2018). https://doi.org/10. 1016/j.foodhyd.2017.09.008

47. Y. Zhang, M. Jiang, Y. Zhang et al., Novel lignin-chitosan-PVA composite hydrogel for wound dressing. Mater Sci Eng C 104, 110002 (2019). https://doi.org/10.1016/j.msec.2019.110002

48. W. Zhang, W. Jiang, Antioxidant and antibacterial chitosan film with tea polyphenols-mediated green synthesis silver nanoparticle via a novel one-pot method. Int J Biol Macromol 155, 12521261 (2020). https://doi.org/10.1016/j.ijbiomac.2019.11.093

49. M.J. Bof, F.E. Laurent, F. Massolo et al., Bio-packaging material impact on blueberries quality attributes under transport and marketing conditions. Polymers 13:4, 481 (2021). https://doi.org/ 10.3390/polym 13040481

50. J.G. Fernandez, D.E. Ingber, Bioinspired chitinous material solutions for environmental sustainability and medicine. Adv Funct Mater 23, 4454-4466 (2013). https://doi.org/10.1002/adfm. 201300053

51. B. Wang, Y. Wan, Y. Zheng et al., Alginate-based composites for environmental applications: a critical review. Crit Rev Environ Sci Technol 49, 318-356 (2019). https://doi.org/10.1080/10643 389.2018.1547621

52. M. Bulota, T. Budtova, Valorisation of macroalgae industrial byproduct as filler in thermoplastic polymer composites. Compos Part A Appl Sci Manuf 90, 271-277 (2016). https://doi.org/10. 1016/j.compositesa.2016.07.010

53. O.V. López, M.D. Ninago, M.M.S. Lencina et al., Thermoplastic starch plasticized with alginate-glycerol mixtures: Melt-processing evaluation and film properties. Carbohydr Polym 126, 83-90 (2015). https://doi.org/10.1016/j.carbpol.2015.03.030

54. R. Jayalakshmi, J. Jeyanthi, Simultaneous removal of binary dye from textile effluent using cobalt ferrite-alginate nanocomposite: performance and mechanism. Microchem J 145, 791-800 (2019). https://doi.org/10.1016/j.microc.2018.11.047

55. V. Javanbakht, R. Shafiei, Preparation and performance of alginate/basil seed mucilage biocomposite for removal of eriochrome black $\mathrm{T}$ dye from aqueous solution. Int J Biol Macromol 152, 990-1001 (2020). https://doi.org/10.1016/j.ijbiomac.2019.10.185

56. I. Olabarrieta, M. Gällstedt, I. Ispizua et al., Properties of aged montmorillonite-wheat gluten composite films. J Agric Food Chem 54, 1283-1288 (2006). https://doi.org/10.1021/jf0522614

57. F. Muneer, E. Johansson, M.S. Hedenqvist et al., Preparation, properties, protein cross-linking and biodegradability of plasticizer-solvent free hemp fibre reinforced wheat gluten, glutenin, and gliadin composites. BioResources 9, 5246-5261 (2014). https://doi.org/10.15376/biores.9.3.5246-5261

58. R. Kuktaite, H. Türe, M.S. Hedenqvist et al., Gluten biopolymer and nanoclay-derived structures in wheat gluten-urea-clay composites: relation to barrier and mechanical properties. ACS Sustain Chem Eng 2, 1439-1445 (2014). https://doi.org/10.1021/ sc500017y

59. A. Kovalcik, S. Obruca, I. Fritz, I. Marova, Polyhydroxyalkanoates: their importance and future. BioResources 14, 24682471 (2019). https://doi.org/10.15376/biores.14.2.2468-2471

60. S. Ghysels, M.S.I. Mozumder, H. de Wever et al., Targeted poly(3-hydroxybutyrate-co-3-hydroxyvalerate) bioplastic production from carbon dioxide. Bioresour Technol 249, 858-868 (2018). https://doi.org/10.1016/j.biortech.2017.10.081 
61. L.J. Vandi, C.M. Chan, A. Werker et al., Wood-PHA composites: mapping opportunities. Polymers 10:7, 1-15 (2018). https://doi. org/10.3390/polym10070751

62. M. Koller, A review on established and emerging fermentation schemes for microbial production of polyhydroxyalkanoate (PHA) biopolyesters. Fermentation 4, 30 (2018). https://doi.org/ 10.3390/fermentation4020030

63. C. Kourmentza, J. Plácido, N. Venetsaneas et al., Recent advances and challenges towards sustainable polyhydroxyalkanoate (PHA) production. Bioengineering 4, 1-43 (2017). https://doi.org/10.3390/bioengineering 4020055

64. C. Nielsen, A. Rahman, A.U. Rehman et al., Food waste conversion to microbial polyhydroxyalkanoates. Microb Biotechnol 10, 1338-1352 (2017). https://doi.org/10.1111/1751-7915.12776

65. M. Amini, H. Yousefi-Massumabad, H. Younesi et al., Production of the polyhydroxyalkanoate biopolymer by Cupriavidusnecator using beer brewery wastewater containing maltose as a primary carbon source. J Environ Chem Eng 8, 103588 (2020). https://doi.org/10.1016/j.jece.2019.103588

66. J. Pais, L.S. Serafim, F. Freitas, M.A.M. Reis, Conversion of cheese whey into poly(3-hydroxybutyrate-co-3-hydroxyvalerate) by Haloferax mediterranei. N Biotechnol 33, 224-230 (2016). https://doi.org/10.1016/j.nbt.2015.06.001

67. D. Alsafadi, O. Al-Mashaqbeh, A one-stage cultivation process for the production of poly-3-(hydroxybutyrate-co-hydroxyvalerate) from olive mill wastewater by Haloferax mediterranei. $\mathrm{N}$ Biotechnol 34, 47-53 (2017). https://doi.org/10.1016/j.nbt.2016. 05.003

68. M. José Fabra, P. Pardo, M. Martínez-Sanz et al., Combining polyhydroxyalkanoates with nanokeratin to develop novel biopackaging structures. J Appl Polym Sci 133, 42695 (2016). https://doi.org/10.1002/app.42695

69. D. Abol-Fotouh, M.A. Hassan, H. Shokry et al., Bacterial nanocellulose from agro-industrial wastes: low-cost and enhanced production by Komagataeibacter saccharivorans MD1. Sci Rep 10, 1-14 (2020). https://doi.org/10.1038/s41598-020-60315-9

70. M. Gao, J. Li, Z. Bao et al., A natural in situ fabrication method of functional bacterial cellulose using a microorganism. Nat Commun 10, 1-10 (2019). https://doi.org/10.1038/ s41467-018-07879-3

71. B. Madsen, E.K. Gamstedt, Wood versus plant fibers: similarities and differences in composite applications. Adv Mater Sci Eng 2013, 1-15 (2013). https://doi.org/10.1155/2013/564346

72. W. Wang, Z. Yu, F.K. Alsammarraie et al., Properties and antimicrobial activity of polyvinyl alcohol-modified bacterial nanocellulose packaging films incorporated with silver nanoparticles. Food Hydrocoll 100, 105411 (2020). https://doi.org/10.1016/j. foodhyd.2019.105411

73. M.L. Cacicedo, M.C. Castro, I. Servetas et al., Progress in bacterial cellulose matrices for biotechnological applications. Bioresour Technol 213, 172-180 (2016). https://doi.org/10.1016/j. biortech.2016.02.071

74. S. Chaitanya, I. Singh, S.J. Il, Recyclability analysis of PLA/Sisal fiber biocomposites. Compos Part B Eng 173, 106895 (2019). https://doi.org/10.1016/j.compositesb.2019.05.106

75. K. Madhavan Nampoothiri, N.R. Nair, R.P. John, An overview of the recent developments in polylactide (PLA) research. Bioresour Technol 101, 8493-8501 (2010). https://doi.org/10.1016/j.biort ech.2010.05.092

76. U.K. Komal, M.K. Lila, I. Singh, PLA/banana fiber based sustainable biocomposites: a manufacturing perspective. Compos Part B Eng 180, 107535 (2020). https://doi.org/10.1016/j.compo sitesb.2019.107535

77. L.J. Rodríguez, S. Fabbri, C.E. Orrego, M. Owsianiak, Comparative life cycle assessment of coffee jar lids made from biocomposites containing poly(lactic acid) and banana fiber. $\mathbf{J}$
Environ Manag 266, 110493 (2020). https://doi.org/10.1016/j. jenvman.2020.110493

78. M.O. Reis, J.B. Olivato, A.P. Bilck et al., Biodegradable trays of thermoplastic starch/poly (lactic acid) coated with beeswax. Ind Crops Prod 112, 481-487 (2018). https://doi.org/10.1016/j. indcrop.2017.12.045

79. N.A.A. Hassan, S. Ahmad, R.S. Chen et al., Effect of processing temperature and foaming agent loading on properties of polylactic acid/kenaf fiber composite foam. Mater Today Proc 7, 601-606 (2019). https://doi.org/10.1016/j.matpr.2018.12. 013

80. J. Domínguez-Robles, N.K. Martin, M.L. Fong et al., Antioxidant PLA composites containing lignin for 3D printing applications: a potential material for healthcare applications. Pharmaceutics 11, 5-7 (2019). https://doi.org/10.3390/pharmaceutics 11040165

81. X. Xiao, V.S. Chevali, P. Song et al., Polylactide/hemp hurd biocomposites as sustainable 3D printing feedstock. Compos Sci Technol 184, 107887 (2019). https://doi.org/10.1016/j.comps citech.2019.107887

82. S. Liu, J. Yu, H. Li et al., Controllable drug release behavior of polylactic acid (PLA) surgical suture coating with ciprofloxacin (CPFX) - polycaprolactone (PCL)/polyglycolide (PGA). Polymers 12:2, 288 (2020). https://doi.org/10.3390/polym12020288

83. R. Scaffaro, F. Lopresti, L. Botta, PLA based biocomposites reinforced with Posidonia oceanica leaves. Compos Part B Eng 139, 1-11 (2018). https://doi.org/10.1016/j.compositesb.2017.11.048

84. R.A. Ilyas, S.M. Sapuan, M.R. Ishak, E.S. Zainudin, Development and characterization of sugar palm nanocrystalline cellulose reinforced sugar palm starch bionanocomposites. Carbohydr Polym 202, 186-202 (2018). https://doi.org/10.1016/j.carbpol. 2018.09.002

85. F. Versino, O.V. López, M.A. García, Green Biocomposites for Packaging Applications, in Biocomposite Materials Design and Mechanical Properties Characterization. ed. by M.T.H. Sultan, M.S.A. Majid, M.R.M.J. Azmi et al. (Springer Nature Singapore Pte Ltd., Singapore, 2021), pp. 1-30

86. N. Vahedikia, F. Garavand, B. Tajeddin et al., Biodegradable zein film composites reinforced with chitosan nanoparticles and cinnamon essential oil: physical, mechanical, structural and antimicrobial attributes. Colloids Surf B Biointerfaces 177, 25-32 (2019). https://doi.org/10.1016/j.colsurfb.2019.01.045

87. T. Abitbol, A. Rivkin, Y. Cao et al., Nanocellulose, a tiny fiber with huge applications. Curr Opin Biotechnol 39, 76-88 (2016). https://doi.org/10.1016/j.copbio.2016.01.002

88. L.A. Castillo, O.V. López, M.D. Ninago et al., Composites and Nanocomposites Based on Starches: Effect of Mineral and Organic Fillers on Processing, Structure, and Final Properties of Starch, in Starch-Based Materials in Food Packaging: Processing, Characterization and Applications. ed. by Villar MA, Barbosa SE, García MA, et al. (Academic Press, 2017), pp. 125-151

89. W.P.S.L. Wijesinghe, M.M.M.G.P.G. Mantilaka, K.A.A. Ruparathna et al., Filler Matrix Interfaces of Inorganic/Biopolymer Composites and their Applications, in Interfaces in Particle and Fibre Reinforced Composites: Current Perspectives on Polymer, Ceramic, Metal and Extracellular Matrices. ed. by Goh KL, M.K. A, Silva RT De, Thomas S (Elsevier Ltd, 2020), pp. 95-112

90. H.P.S. Abdul Khalil, E.W.N. Chong, F.A.T. Owolabi et al., Enhancement of basic properties of polysaccharide-based composites with organic and inorganic fillers: a review. J Appl Polym Sci 136, 47251 (2019). https://doi.org/10.1002/app.47251

91. K.K. Sadasivuni, P. Saha, J. Adhikari et al., Recent advances in mechanical properties of biopolymer composites: a review. Polym Compos 41, 32-59 (2020). https://doi.org/10.1002/pc. 25356

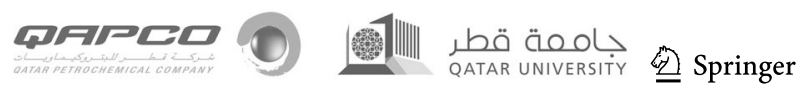


92. T. Senthil Muthu Kumar, K. Senthilkumar, M. Chandrasekar et al., Influence of Fillers on the Thermal and Mechanical Properties of Biocomposites: An Overview, in Biofibers and Biopolymers for Biocomposites. ed. by A. Khan, R.S. Mavinkere, S.A.A. Siengchin (Springer International Publishing, Cham, 2020), pp. 111-133

93. S.M. Sapuan, K.F. Tamrin, Y. Nukman et al., Multiple-objective optimization in precision cutting of cocoa fiber reinforced composites. Compr Mater Finish 1-3, 203-230 (2016). https:// doi.org/10.1016/B978-0-12-803581-8.09183-9

94. F.P. La Mantia, M. Morreale, Green composites: a brief review. Compos Part A Appl Sci Manuf 42, 579-588 (2011). https:// doi.org/10.1016/j.compositesa.2011.01.017

95. M.V. Madurwar, R.V. Ralegaonkar, S.A. Mandavgane, Application of agro-waste for sustainable construction materials: a review. Constr Build Mater 38, 872-878 (2013). https://doi. org/10.1016/J.CONBUILDMAT.2012.09.011

96. T. Gurunathan, S. Mohanty, S.K. Nayak, A review of the recent developments in biocomposites based on natural fibres and their application perspectives. Compos Part A 77, 1-25 (2015). https://doi.org/10.1016/j.compositesa.2015.06.007

97. P. Dey, S. Ray, An overview of the recent trends in manufacturing of green composites - considerations and challenges. Mater Today Proc 5, 19783-19789 (2018). https://doi.org/10.1016/j. matpr.2018.06.341

98. V. Florencia, O.V. López, M.A. García, Exploitation of byproducts from cassava and ahipa starch extraction as filler of thermoplastic corn starch. Compos Part B Eng 182, 107653 (2020). https://doi.org/10.1016/j.compositesb.2019.107653

99. P. Bhagabati, Biopolymers and biocomposites-mediated sustainable high-performance materials for automobile applications, in Micro and Nano Technologies. ed. by Mohammad F, Al-Lohedan HA, Jawaid MBT-SN and N from NS (Elsevier, 2020), pp. 197-216

100. S.M. Sapuan, M.R. Mansor, Concurrent engineering approach in the development of composite products: a review. Mater Des $\mathbf{5 8}$, 161-167 (2014). https://doi.org/10.1016/j.matdes.2014.01.059

101. O.V. López, F. Versino, M.A. Villar, M.A. García, Agro-industrial residue from starch extraction of Pachyrhizus ahipa as filler of thermoplastic corn starch films. Carbohydr. Polym. 134, 324332 (2015). https://doi.org/10.1016/j.carbpol.2015.07.081

102. R.B. Yusoff, H. Takagi, A.N. Nakagaito, Tensile and flexural properties of polylactic acid-based hybrid green composites reinforced by kenaf, bamboo and coir fibers. Ind Crops Prod 94, 562-573 (2016). https://doi.org/10.1016/j.indcrop.2016.09.017

103. Š Hýsek, M. Podlena, H. Bartsch et al., Effect of wheat husk surface pre-treatment on the properties of husk-based composite materials. Ind Crops Prod 125, 105-113 (2018). https://doi.org/ 10.1016/j.indcrop.2018.08.035

104. M. Bassyouni, S. Waheed Ul Hasan, The use of rice straw and husk fibers as reinforcements in composites. In Biofiber Reinforcements in Composite Materials. ed. by Faruk O, Sain M. (Woodhead Publishing, 2015), pp. 385-422

105. V. Guna, M. Ilangovan, C. Hu et al., Valorization of sugarcane bagasse by developing completely biodegradable composites for industrial applications. Ind Crops Prod 131, 25-31 (2019). https://doi.org/10.1016/j.indcrop.2019.01.011

106. L.R.P.F. Mello, S. Mali, Use of malt bagasse to produce biodegradable baked foams made from cassava starch. Ind Crops Prod 55, 187-193 (2014). https://doi.org/10.1016/J.INDCROP.2014. 02.015

107. A. Baharin, N.A. Fattah, A.A. Bakar, Z.M. Ariff, Production of laminated natural fibre board from banana tree wastes. 19, 999-1006 (2016). https://doi.org/10.1016/j.proche.2016.03.149

108. A. Haque, D. Mondal, I. Khan, et al., Fabrication of composites reinforced with lignocellulosic materials from agricultural biomass, in Lignocellulosic Fibre and Biomass-Based Composite Materials, ed. by Jawaid M, Tahir PM, Saba N (Woodhead Publishing, 2017), pp. 179-191. https://doi.org/10.1016/B978-0-08100959-8.00010-X

109. J.L. Guimarães, E. Frollini, C.G. da Silva et al., Characterization of banana, sugarcane bagasse and sponge gourd fibers of Brazil. Ind Crops Prod 30, 407-415 (2009). https://doi.org/10.1016/j. indcrop.2009.07.013

110. M.P. Arrieta, J. López, D. López et al., Effect of chitosan and catechin addition on the structural, thermal, mechanical and disintegration properties of plasticized electrospun PLA-PHB biocomposites. Polym Degrad Stab 132, 145-156 (2016). https:// doi.org/10.1016/j.polymdegradstab.2016.02.027

111. A. Edhirej, S.M. Sapuan, M. Jawaid, et al., Effect of cassava peel and cassava bagasse natural fillers on mechanical properties of thermoplastic cassava starch: comparative study. AIP Conference Proceedings 1901:1, 010002 (2017). https://doi.org/10.1063/1. 5010532

112. A. Edhirej, S.M. Sapuan, M. Jawaid, N.I. Zahari, Preparation and characterization of cassava bagasse reinforced thermoplastic cassava starch. Fibers Polym 18, 162-171 (2017). https://doi.org/ 10.1007/s12221-017-6251-7

113. G.R. de Carvalho, G.S. Marques, L.M. de Matos Jorge, R.M.M. Jorge, Cassava bagasse as a reinforcement agent in the polymeric blend of biodegradable films. J Appl Polym Sci 136, 1-7 (2019). https://doi.org/10.1002/app.47224

114. K.J. Sim, S.O. Han, Y.B. Seo, Dynamic mechanical and thermal properties of red algae fiber reinforced poly(lactic acid) biocomposites. Macromol Res 18, 489-495 (2010). https://doi.org/10. 1007/s13233-010-0503-3

115. B. Ferrero, T. Boronat, R. Moriana et al., Green composites based on wheat gluten matrix and Posidonia Oceanica waste fibers as reinforcements. Polym Compos 34, 1663-1669 (2013). https:// doi.org/10.1002/pc.22567

116. M. Seggiani, P. Cinelli, N. Mallegni et al., New bio-composites based on polyhydroxyalkanoates and posidonia oceanica fibres for applications in a marine environment. Materials (Basel) 10, 326 (2017). https://doi.org/10.3390/ma10040326

117. E. Chiellini, P. Cinelli, V.I. Ilieva et al., Hybrid composites based on fibres of marine origin. Int J Mater Prod Technol 36, 47 (2009). https://doi.org/10.1504/ijmpt.2009.027819

118. V. Guna, M. Ilangovan, K. Adithya et al., Biofibers and biocomposites from sabai grass: A unique renewable resource. Carbohydr Polym 218, 243-249 (2019). https://doi.org/10.1016/j.carbp ol.2019.04.085

119. R. Jumaidin, M.A.A. Khiruddin, Z. Asyul Sutan Saidi et al., Effect of cogon grass fibre on the thermal, mechanical and biodegradation properties of thermoplastic cassava starch biocomposite. Int J Biol Macromol 146, 746-755 (2020). https://doi.org/ 10.1016/j.ijbiomac.2019.11.011

120. T. Senthil Muthu Kumar, N. Rajini, K. Obi Reddy et al., Allcellulose composite films with cellulose matrix and Napier grass cellulose fibril fillers. Int J Biol Macromol 112, 1310-1315 (2018). https://doi.org/10.1016/j.ijbiomac.2018.01.167

121. G. Oliveira, I. Gonçalves, A. Barra, et al., Coffee silverskin and starch-rich potato washing slurries as raw materials for elastic, antioxidant, and UV-protective biobased films. Food Res. Int. 138:Part A, 109733 (2020). https://doi.org/10.1016/j.foodr es.2020.109733

122. M. Liu, M. Arshadi, F. Javi et al., Green and facile preparation of hydrophobic bioplastics from tea waste. J Clean Prod 276, 123353 (2020). https://doi.org/10.1016/j.jclepro.2020.123353

123. K.R. Sumesh, K. Kanthavel, V. Kavimani, Peanut oil cakederived cellulose fiber: Extraction, application of mechanical and thermal properties in pineapple/flax natural fiber composites. Int 
J Biol Macromol 150, 775-785 (2020). https://doi.org/10.1016/j. ijbiomac.2020.02.118

124. P. Evon, J. Vinet, L. Labonne, L. Rigal, Influence of thermopressing conditions on the mechanical properties of biodegradable fiberboards made from a deoiled sunflower cake. Ind Crops Prod 65, 117-126 (2015). https://doi.org/10.1016/j.indcr op.2014.11.036

125. M. Delgado, M. Felix, C. Bengoechea, Development of bioplastic materials: from rapeseed oil industry by products to added-value biodegradable biocomposite materials. Ind Crops Prod 125, 401-407 (2018). https://doi.org/10.1016/j.indcrop. 2018.09.013

126. F. Versino, O.V. López, M.A. García, Sunflower oil industry by-product as natural filler of biocomposite foams for packaging applications. J Polym Environ 29, 1869-1879 (2021). https://doi.org/10.1007/s 10924-020-01981-8

127. S. Lammi, N. Le Moigne, D. Djenane et al., Dry fractionation of olive pomace for the development of food packaging biocomposites. Ind Crops Prod 120, 250-261 (2018). https://doi. org/10.1016/j.indcrop.2018.04.052

128. F. Versino, M.A. García, Cassava (Manihot esculenta) starch films reinforced with natural fibrous filler. Ind. Crops. Prod. 58, 305-314 (2014). https://doi.org/10.1016/j.indcrop.2014.04.040

129. F. Versino, M.A. García, Particle size distribution effect on cassava starch and cassava bagasse biocomposites. ACS Sustain Chem Eng 7, 1052-1060 (2019). https://doi.org/10.1021/acssu schemeng. 8 b04700

130. M.A. Berthet, C. Mayer-Laigle, X. Rouau et al., Sorting natural fibres: a way to better understand the role of fibre size polydispersity on the mechanical properties of biocomposites. Compos Part A Appl Sci Manuf 95, 12-21 (2017). https://doi.org/ 10.1016/j.compositesa.2017.01.011

131. K. Georgios, A. Silva, S. Furtado, Applications of Green Composite Materials, in Biodegradable Green Composite, ed. by Kalia S (John Wiley \& Sons Inc, Hoboken, 2016), pp. 312337. https://doi.org/10.1002/9781118911068.ch10

132. S.R. Djafari Petroudy, Physical and Mechanical Properties of Natural Fibers, in Advanced High Strength Natural Fibre Composites in Construction, ed. by Fan M, Fu F (Woodhead Publishing, 2017), pp. 59-83. https://doi.org/10.1016/B978-008-100411-1.00003-0

133. S.K. Ramamoorthy, D. Åkesson, R. Rajan, et al. Mechanical performance of biofibers and their corresponding composites, in Mechanical and Physical Testing of Biocomposites, FibreReinforced Composites and Hybrid Composites, ed. by Jawaid M, Thariq M, Saba N (Woodhead Publishing, 2019), pp. 259292. https://doi.org/10.1016/B978-0-08-102292-4.00014-X

134. M.L. Sánchez, W. Patiño, J. Cárdenas, Physical-mechanical properties of bamboo fibers-reinforced biocomposites: Influence of surface treatment of fibers. J Build Eng 28, 101058 (2020). https://doi.org/10.1016/j.jobe.2019.101058

135. G. Balčiūnas, J. Žvironaitè, S. Vèjelis et al., Ecological, thermal and acoustical insulating composite from hemp shives and sapropel binder. Ind Crops Prod 91, 286-294 (2016). https:// doi.org/10.1016/j.indcrop.2016.06.034

136. M. George, M. Chae, D.C. Bressler, Composite materials with bast fibres: structural, technical, and environmental properties. Prog Mater Sci 83, 1-23 (2016). https://doi.org/10.1016/j. pmatsci.2016.04.002

137. Z.N. Azwa, B.F. Yousif, A.C.A.C. Manalo, W. Karunasena, A review on the degradability of polymeric composites based on natural fibres. Mater Des 47, 424-442 (2013). https://doi.org/ 10.1016/j.matdes.2012.11.025

138. S. Kalia, B.S. Kaith, I. Kaur, Pretreatments of natural fibers and their application as reinforcing material in polymer
composites-A review. Polym Eng Sci 49, 1253-1272 (2009). https://doi.org/10.1002/pen.21328

139. M.M. Kabir, H. Wang, K.T. Lau, F. Cardona, Chemical treatments on plant-based natural fibre reinforced polymer composites: an overview. Compos Part B 43, 2883-2892 (2012). https://doi.org/10.1016/j.compositesb.2012.04.053

140. H.S.S. Shekar, M. Ramachandra, Green composites: a review. Mater Today Proc 5, 2518-2526 (2018). https://doi.org/10. 1016/j.matpr.2017.11.034

141. A. Ferrer, C. Salas, O.J. Rojas, Physical, thermal, chemical and rheological characterization of cellulosic microfibrils and microparticles produced from soybean hulls. Ind Crops Prod 84, 337-343 (2016). https://doi.org/10.1016/j.indcrop.2016.02.014

142. E. de Morais Teixeira, D. Pasquini, A.A.S. Curvelo et al., Cassava bagasse cellulose nanofibrils reinforced thermoplastic cassava starch. Carbohydr Polym 78, 422-431 (2009). https://doi. org/10.1016/j.carbpol.2009.04.034

143. D. Pasquini, E. de Morais Teixeira, A.A. da Silva Curvelo et al., Extraction of cellulose whiskers from cassava bagasse and their applications as reinforcing agent in natural rubber. Ind Crops Prod 32, 486-490 (2010). https://doi.org/10.1016/j.indcrop.2010. 06.022

144. W.N. Gilfillan, L. Moghaddam, W.O.S. Doherty, Preparation and characterization of composites from starch with sugarcane bagasse nanofibres. Cellulose 21, 2695-2712 (2014). https://doi. org/10.1007/s10570-014-0277-4

145. A. Rani, S. Monga, M. Bensal, A. Sharma, Bionanocomposites reinfroced with cellulose nanofibers derived from sugarcane bagasse. Polym. Compos. 37, 915-924 (2016). https://doi.org/ $10.1002 / \mathrm{pc} .23250$

146. F.I. Ditzel, E. Prestes, B.M. Carvalho et al., Nanocrystalline cellulose extracted from pine wood and corncob. Carbohydr Polym 157:1577-1585 (2017).https://doi.org/10.1016/j.carbpol.2016. 11.036

147. A. Khosravi, A. Fereidoon, M.M. Khorasani et al., Soft and hard sections from cellulose-reinforced poly(lactic acid)-based food packaging films: a critical review. Food Packag Shelf Life 23, 100429 (2020). https://doi.org/10.1016/j.fpsl.2019.100429

148. M.P. Arrieta, E. Fortunati, F. Dominici et al., PLA-PHB/cellulose based films: mechanical, barrier and disintegration properties. Polym Degrad Stab 107, 139-149 (2014). https://doi.org/10. 1016/j.polymdegradstab.2014.05.010

149. S. Agustin-Salazar, P. Cerruti, L.Á. Medina-Juárez et al., Lignin and holocellulose from pecan nutshell as reinforcing fillers in poly (lactic acid) biocomposites. Int J Biol Macromol 115, 727736 (2018). https://doi.org/10.1016/j.ijbiomac.2018.04.120

150. R. Jayakumar, M. Prabaharan, P.T. Sudheesh Kumar et al., Biomaterials based on chitin and chitosan in wound dressing applications. Biotechnol Adv 29, 322-337 (2011). https://doi.org/10. 1016/j.biotechadv.2011.01.005

151. A.M. Salaberria, J. Labidi, S.C.M. Fernandes, Chitin nanocrystals and nanofibers as nano-sized fillers into thermoplastic starchbased biocomposites processed by melt-mixing. Chem Eng J 256, 356-364 (2014). https://doi.org/10.1016/j.cej.2014.07.009

152. A.M. Salaberria, R.H. Diaz, J. Labidi, S.C.M. Fernandes, Preparing valuable renewable nanocomposite films based exclusively on oceanic biomass: chitin nanofillers and chitosan. React Funct Polym 89, 31-39 (2015). https://doi.org/10.1016/j.reactfunct polym.2015.03.003

153. G. Sanchez-Olivares, A. Sanchez-Solis, F. Calderas, J. Alongi, Keratin fibres derived from tannery industry wastes for flame retarded PLA composites. Polym Degrad Stab 140, 42-54 (2017). https://doi.org/10.1016/j.polymdegradstab.2017.04.011

154. T. Väisänen, A. Haapala, R. Lappalainen, L. Tomppo, Utilization of agricultural and forest industry waste and residues in natural 
fiber-polymer composites: A review. Waste Manag 54, 62-73 (2016). https://doi.org/10.1016/j.wasman.2016.04.037

155. S. Wong, N. Ngadi, I.M. Inuwa, O. Hassan, Recent advances in applications of activated carbon from biowaste for wastewater treatment: a short review. J Clean Prod 175, 361-375 (2018). https://doi.org/10.1016/j.jclepro.2017.12.059

156. Azeredo HMC de, Nanocomposites for food packaging applications. Food Res Int 42, 1240-1253 (2009). https://doi.org/10. 1016/j.foodres.2009.03.019

157. T.M. Higgins, H. Warren, M. Panhuis, in het, Films, buckypapers and fibers from clay, chitosan and carbon nanotubes. Nanomaterials 1, 3-19 (2011). https://doi.org/10.3390/nano1010003

158. J.T. Martins, A.I. Bourbon, A.C. Pinheiro et al., Biocomposite films based on $\kappa$-carrageenan/locust bean gum blends and clays: physical and antimicrobial properties. Food Bioprocess Technol 6, 2081-2092 (2013). https://doi.org/10.1007/ s11947-012-0851-4

159. B. Caglar, O. Cubuk, E. Demir et al., Characterization of AlFepillared Unye bentonite: a study of the surface acidity and catalytic property. J Mol Struct 1089, 59-65 (2015). https://doi.org/ 10.1016/j.molstruc.2015.02.034

160. N.F. Magalhães, C.T. Andrade, Calcium bentonite as reinforcing nanofiller for thermoplastic starch. J Braz Chem Soc 21, 202-208 (2010). https://doi.org/10.1590/S0103-50532010000200003

161. M.D. Ninago, O.V. López, M. Gabriela Passaretti et al., Mild microwave-assisted synthesis of aluminum-pillared bentonites: thermal behavior and potential applications. J Therm Anal Calorim 129, 1517-1531 (2017). https://doi.org/10.1007/ s10973-017-6304-6

162. R. Garg, M. Kumari, M. Kumar, et al. Green synthesis of calcium carbonate nanoparticles using waste fruit peel extract. Mater. Today Proc. 46:15, 6665-6668 (2021). https://doi.org/10.1016/j. matpr.2021.04.124

163. L.A. Castillo, O.V. López, M.A. García et al., Crystalline morphology of thermoplastic starch/talc nanocomposites induced by thermal processing. Heliyon 5, e01877 (2019). https://doi.org/10. 1016/j.heliyon.2019.e01877

164. S. Ghannam, H. Najm, R. Vasconez, Experimental study of concrete made with granite and iron powders as partial replacement of sand. Sustain Mater Technol 9, 1-9 (2016). https://doi.org/10. 1016/j.susmat.2016.06.001

165. F. Jia, S. Song, Preparation of monolayer muscovite through exfoliation of natural muscovite. RSC Adv 5, 52882-52887 (2015). https://doi.org/10.1039/c5ra07749d

166. M.G. Passaretti, M.D. Ninago, C.I. Paulo et al., Biocomposites based on thermoplastic starch and granite sand quarry waste. J Renew Mater 7, 393-402 (2019). https://doi.org/10.32604/jrm. 2019.04281

167. B.D. Yao, Y.F. Chan, N. Wang, Formation of $\mathrm{ZnO}$ nanostructures by a simple way of thermal evaporation. Appl Phys Lett 81, 757-759 (2002). https://doi.org/10.1063/1.1495878

168. A. Jayachandran, T.R. Aswathy, A.S. Nair, Green synthesis and characterization of zinc oxide nanoparticles using Cayratia pedata leaf extract. Biochem Biophys Rep 26, 100995 (2021). https://doi.org/10.1016/j.bbrep.2021.100995

169. Y. Yin, Formation of hollow nanocrystals through the nanoscale kirkendall effect. Science (80- ) 304, 711-714 (2004). https://doi. org/10.1126/science.1096566

170. J.V. Barth, G. Costantini, K. Kern, Engineering atomic and molecular nanostructures at surfaces. Nanosci Technol Collect Rev Nat J 437, 67-78 (2009). https://doi.org/10.1142/97898 14287005_0008

171. V.V. Pinto, M.J. Ferreira, R. Silva et al., Long time effect on the stability of silver nanoparticles in aqueous medium: effect of the synthesis and storage conditions. Colloids Surf A Physicochem
Eng Asp 364, 19-25 (2010). https://doi.org/10.1016/j.colsurfa. 2010.04.015

172. P. Raveendran, J. Fu, S.L. Wallen, Completely "green" synthesis and stabilization of metal nanoparticles. J Am Chem Soc 125, 13940-13941 (2003). https://doi.org/10.1021/ja029267j

173. G.M. Raghavendra, J. Jung, D. Kim et al., Identification of silver cubic structures during ultrasonication of chitosan AgNO3 solution. Carbohydr Polym 152, 558-565 (2016). https://doi.org/10. 1016/j.carbpol.2016.07.045

174. O.S. Oluwafemi, N. Vuyelwa, M. Scriba, S.P. Songca, Green controlled synthesis of monodispersed, stable and smaller sized starch-capped silver nanoparticles. Mater Lett 106, 332-336 (2013). https://doi.org/10.1016/j.matlet.2013.05.001

175. N. Durán, P.D. Marcato, G.I.H. De Souza et al., Antibacterial effect of silver nanoparticles produced by fungal process on textile fabrics and their effluent treatment. J Biomed Nanotechnol 3, 203-208 (2007). https://doi.org/10.1166/jbn.2007.022

176. A. Martínez-Abad, J.M. Lagarón, M.J. Ocio, Antimicrobial beeswax coated polylactide films with silver control release capacity. Int J Food Microbiol 174, 39-46 (2014). https://doi.org/10. 1016/j.ijfoodmicro.2013.12.028

177. M. Nasrollahzadeh, M.M. Sajadi, F. Babaei, M. Maham, Euphorbia helioscopia Linn as a green source for synthesis of silver nanoparticles and their optical and catalytic properties. J Colloid Interface Sci 450, 374-380 (2015). https://doi.org/10.1016/j.jcis. 2015.03.033

178. M. Nasrollahzadeh, S. Mahmoudi-Gom Yek, N. Motahharifar, M. Ghafori Gorab, Recent developments in the plant-mediated green synthesis of $\mathrm{Ag}$-based nanoparticles for environmental and catalytic applications. Chem Rec 19, 2436-2479 (2019). https:// doi.org/10.1002/tcr.201800202

179. Y. Ren, yu, Yang H, Wang T, Wang C, Green synthesis and antimicrobial activity of monodisperse silver nanoparticles synthesized using Ginkgo Biloba leaf extract. Phys. Lett. A 380:45, 3773-3777 (2016). https://doi.org/10.1016/j.physleta.2016.09. 029

180. W.R. Rolim, M.T. Pelegrino, L.B. de Araújo et al., Green tea extract mediated biogenic synthesis of silver nanoparticles: characterization, cytotoxicity evaluation and antibacterial activity. Appl Surf Sci 463, 66-74 (2019). https://doi.org/10.1016/j. apsusc.2018.08.203

181. G.A. Kahrilas, L.M. Wally, S.J. Fredrick et al., Microwaveassisted green synthesis of silver nanoparticles using orange peel extract. ACS Sustain Chem Eng 2, 367-376 (2014). https://doi. org/10.1021/sc4003664

182. L. Marchiol, A. Mattiello, F. Pošćić et al., In vivo synthesis of nanomaterials in plants: Location of silver nanoparticles and plant metabolism. Nanoscale Res Lett 9, 1-11 (2014). https:// doi.org/10.1186/1556-276X-9-101

183. T. Kathiraven, A. Sundaramanickam, N. Shanmugam, T. Balasubramanian, Green synthesis of silver nanoparticles using marine algae Caulerpa racemosa and their antibacterial activity against some human pathogens. Appl. Nanosci. 5, 499-504 (2015). https://doi.org/10.1007/s13204-014-0341-2

184. F. Ortega, L. Giannuzzi, V.B. Arce, M.A. García, Active composite starch films containing green synthetized silver nanoparticles. Food Hydrocoll 70, 152-162 (2017). https://doi.org/10.1016/j. foodhyd.2017.03.036

185. F. Ortega, M.A. García, V.B. Arce, Nanocomposite films with silver nanoparticles synthesized in situ: effect of corn starch content. Food Hydrocoll 97:. (2019)https://doi.org/10.1016/j.foodh yd.2019.105200

186. F. Ortega, V.B. Arce, M.A. Garcia, Nanocomposite starch-based films containing silver nanoparticles synthesized with lemon juice as reducing and stabilizing agent. Carbohydr Polym 252, 117208 (2021). https://doi.org/10.1016/j.carbpol.2020.117208 
187. M.V. Sujitha, S. Kannan, Green synthesis of gold nanoparticles using Citrus fruits (Citrus limon, Citrus reticulata and Citrus sinensis) aqueous extract and its characterization. Spectrochim Acta - Part A Mol Biomol Spectrosc 102, 15-23 (2013). https:// doi.org/10.1016/j.saa.2012.09.042

188. N. González-Ballesteros, S. Prado-López, J.B. RodríguezGonzález et al., Green synthesis of gold nanoparticles using brown algae Cystoseira baccata: Its activity in colon cancer cells. Colloids Surf B: Biointerfaces 153, 190-198 (2017). https://doi.org/10.1016/j.colsurfb.2017.02.020

189. P. Kumari, A. Meena, Green synthesis of gold nanoparticles from Lawsoniainermis and its catalytic activities following the Langmuir-Hinshelwood mechanism. Colloids Surf A Physicochem Eng Asp 606, 125447 (2020). https://doi.org/10.1016/j. colsurfa.2020.125447

190. P. Clarance, B. Luvankar, J. Sales et al., Green synthesis and characterization of gold nanoparticles using endophytic fungi Fusarium solani and its in-vitro anticancer and biomedical applications. Saudi J Biol Sci 27, 706-712 (2020). https://doi. org/10.1016/j.sjbs.2019.12.026

191. M. Nidhin, K.J. Sreeram, B.U. Nair, Green synthesis of rock salt $\mathrm{CoO}$ nanoparticles for coating applications by complexation and surface passivation with starch. Chem Eng J 185-186, 352-357 (2012). https://doi.org/10.1016/j.cej.2011.11.104

192. J.K. Sharma, P. Srivastava, G. Singh et al., Green synthesis of $\mathrm{Co} 3 \mathrm{O} 4$ nanoparticles and their applications in thermal decomposition of ammonium perchlorate and dye-sensitized solar cells. Mater. Sci. Eng. B 193, 181-188 (2015). https://doi.org/ 10.1016/j.mseb.2014.12.012

193. I. Bibi, N. Nazar, M. Iqbal et al., Green and eco-friendly synthesis of cobalt-oxide nanoparticle: Characterization and photo-catalytic activity. Adv Powder Technol 28, 2035-2043 (2017). https://doi.org/10.1016/j.apt.2017.05.008

194. S.Z. Mohammadi, B. Lashkari, A. Khosravan, Green synthesis of $\mathrm{Co} 3 \mathrm{O} 4$ nanoparticles by using walnut green skin extract as a reducing agent by using response surface methodology. Surf Interfaces 23, 100970 (2021). https://doi.org/10.1016/j.surfin. 2021.100970

195. M. Raeisi, H.Q. Alijani, M. Peydayesh et al., Magnetic cobalt oxide nanosheets: green synthesis and in vitro cytotoxicity. Bioprocess Biosyst Eng 44, 1423-1432 (2021). https://doi.org/ 10.1007/s00449-021-02518-6

196. R.K. Swarnkar, S.C. Singh, R. Gopal, Effect of aging on copper nanoparticles synthesized by pulsed laser ablation in water: Structural and optical characterizations. Bull Mater Sci 34, 1363-1369 (2011). https://doi.org/10.1007/s12034-011-0329-4

197. D. Manoj, R. Saravanan, J. Santhanalakshmi et al., Towards green synthesis of monodisperse $\mathrm{Cu}$ nanoparticles: An efficient and high sensitive electrochemical nitrite sensor. Sensors Actuators B Chem 266, 873-882 (2018). https://doi.org/10. 1016/j.snb.2018.03.141

198. N. Sarwar, Humayoun U. Bin, M. Kumar et al., Citric acid mediated green synthesis of copper nanoparticles using cinnamon bark extract and its multifaceted applications. J Clean Prod 292, 125974 (2021). https://doi.org/10.1016/j.clepro. 2021.125974

199. I. Jahan, F. Erci, I. Isildak, Facile microwave-mediated green synthesis of non-toxic copper nanoparticles using Citrus sinensis aqueous fruit extract and their antibacterial potentials. J Drug Deliv Sci Technol 61, 102172 (2021). https://doi.org/10.1016/j. jddst.2020.102172

200. Z. Wang, Iron complex nanoparticles synthesized by eucalyptus leaves. ACS Sustain Chem Eng 1, 1551-1554 (2013). https://doi. org/10.1021/sc400174a

201. S. Phumying, S. Labuayai, C. Thomas et al., Aloe vera plantextracted solution hydrothermal synthesis and magnetic properties of magnetite (Fe3O4) nanoparticles. Appl Phys A Mater Sci Process 111, 1187-1193 (2013). https://doi.org/10. 1007/s00339-012-7340-5

202. M.J. Rivera-Chaverra, E. Restrepo-Parra, C.D. Acosta-Medina et al., Synthesis of oxide iron nanoparticles using laser ablation for possible hyperthermia applications. Nanomaterials 10, 1-13 (2020). https://doi.org/10.3390/nano10112099

203. V. Mohanasrinivasan, C. Subathra Devi, A. Mehra et al., Biosynthesis of $\mathrm{MgO}$ Nanoparticles Using Lactobacillus Sp. and its Activity Against Human Leukemia Cell Lines HL-60. Bionanoscience 8, 249-253 (2018). https://doi.org/10.1007/ s12668-017-0480-5

204. J. Suresh, G. Pradheesh, V. Alexramani et al., Green synthesis and characterization of hexagonal shaped $\mathrm{MgO}$ nanoparticles using insulin plant (Costus pictus D. Don) leave extract and its antimicrobial as well as anticancer activity. Adv Powder Technol 29, 1685-1694 (2018). https://doi.org/10.1016/j.apt.2018.04.003

205. A.M. Hashem, H. Abuzeid, M. Kaus et al., Green synthesis of nanosized manganese dioxide as positive electrode for lithiumion batteries using lemon juice and citrus peel. Electrochim Acta 262, 74-81 (2018). https://doi.org/10.1016/j.electacta.2018.01. 024

206. G. Rajakumar, A.A. Rahuman, C. Jayaseelan et al., Solanum trilobatum extract-mediated synthesis of titanium dioxide nanoparticles to control Pediculus humanus capitis, Hyalomma anatolicum anatolicum and Anopheles subpictus. Parasitol Res 113, 469-479 (2014). https://doi.org/10.1007/s00436-013-3676-9

207. A.A. Kashale, K.P. Gattu, K. Ghule et al., Biomediated green synthesis of $\mathrm{TiO} 2$ nanoparticles for lithium ion battery application. Compos Part B Eng 99, 297-304 (2016). https://doi.org/10. 1016/j.compositesb.2016.06.015

208. S.P. Goutam, G. Saxena, V. Singh et al., Green synthesis of TiO2 nanoparticles using leaf extract of Jatropha curcas L. for photocatalytic degradation of tannery wastewater. Chem Eng J 336, 386-396 (2018). https://doi.org/10.1016/j.cej.2017.12.029

209. G. Nabi, Ain Q-U-, Tahir MB, et al., Green synthesis of TiO 2 nanoparticles using lemon peel extract: their optical and photocatalytic properties. Int J Environ Anal Chem 00, 1-9 (2020). https://doi.org/10.1080/03067319.2020.1722816

210. L. Guz, L. Fama, R. Candal, S. Goyanes, Size effect of ZnO nanorods on physicochemical properties of plasticized starch composites. Carbohydr Polym 157, 1611-1619 (2017). https:// doi.org/10.1016/j.carbpol.2016.11.041

211. R. Zamiri, B.Z. Azmi, H.A. Ahangar et al., Preparation and characterization of silver nanoparticles in natural polymers using laser ablation. Bull Mater Sci 35, 727-731 (2012). https://doi. org/10.1007/s12034-012-0360-0

212. P. Cheviron, F. Gouanvé, E. Espuche, Green synthesis of colloid silver nanoparticles and resulting biodegradable starch/silver nanocomposites. Carbohydr Polym 108, 291-298 (2014). https:// doi.org/10.1016/j.carbpol.2014.02.059

213. T.C. Prathna, N. Chandrasekaran, A.M. Raichur, A. Mukherjee, Biomimetic synthesis of silver nanoparticles by Citrus limon (lemon) aqueous extract and theoretical prediction of particle size. Colloids Surf B Biointerfaces 82, 152-159 (2011). https:// doi.org/10.1016/j.colsurfb.2010.08.036

214. F. Cheng, J.W. Betts, S.M. Kelly, A.L. Hector, Green synthesis of highly concentrated aqueous colloidal solutions of large starchstabilised silver nanoplatelets. Mater Sci Eng C 46, 530-537 (2015). https://doi.org/10.1016/j.msec.2014.10.041

215. F. Cheng, J.W. Betts, S.M. Kelly et al., Synthesis and antibacterial effects of aqueous colloidal solutions of silver nanoparticles using aminocellulose as a combined reducing and capping reagent. Green Chem 15, 989-998 (2013). https://doi.org/10.1039/ c3gc36831a

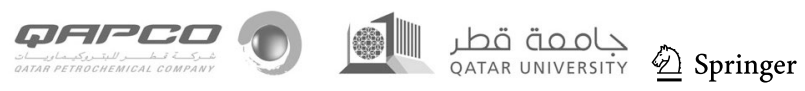


216. V.B. Arce, J.M.J. Santillán, D. Muñetón Arboleda et al., Characterization and stability of silver nanoparticles in starch solution obtained by femtosecond laser ablation and salt reduction. J Phys Chem C 121, 10501-10513 (2017). https://doi.org/10.1021/acs. jpcc.6b12384

217. D. Muñetón Arboleda, J.M.J. Santillán, V.B. Arce et al., A simple and "green" technique to synthesize long-term stability colloidal Ag nanoparticles: Fs laser ablation in a biocompatible aqueous medium. Mater Charact 140, 320-332 (2018). https://doi.org/10. 1016/j.matchar.2018.04.021

218. T.C. Prathna, A.M. Raichur, N. Chandrasekaran, A. Mukherjee, Sunlight irradiation induced green synthesis of stable silver nanoparticles using citrus limon extract. Proc Natl Acad Sci India Sect B - Biol Sci 84, 65-70 (2014). https://doi.org/10.1007/ s40011-013-0193-7

219. O. Masala, R. Seshadri, Synthesis routes for large volumes of nanoparticles. Annu Rev Mater Res 34, 41-81 (2004). https:// doi.org/10.1146/annurev.matsci.34.052803.090949

220. A.S. Abreu, M. Oliveira, A. de Sá et al., Antimicrobial nanostructured starch based films for packaging. Carbohydr Polym 129, 127-134 (2015). https://doi.org/10.1016/j.carbpol.2015.04.021

221. F. Ortega, L. Giannuzzi, V.B. Arce, M.A. García, Active composite starch films containing green synthesized silver nanoparticles. Food Hydrocoll 70, 152-162 (2017). https://doi.org/10.1016/j. foodhyd.2017.03.036

222. A. Slistan-Grijalva, R. Herrera-Urbina, J.F. Rivas-Silva et al., Classical theoretical characterization of the surface plasmon absorption band for silver spherical nanoparticles suspended in water and ethylene glycol. Phys E Low-Dimensional Syst Nanostruct 27, 104-112 (2005). https://doi.org/10.1016/j.physe.2004. 10.014

223. B. Mohapatra, R. Kaintura, J. Singh et al., Biosynthesis of high concentration, stable aqueous dispersions of silver nanoparticles using Citrus limon extract. Adv Mater Lett 6, 228-234 (2015). https://doi.org/10.5185/amlett.2015.5731

224. A.B. Djurišić, Y.H. Leung, Optical Properties of $\mathrm{ZnO}$ Nanostructures. Small 2, 944-961 (2006). https://doi.org/10.1002/ smll.200600134

225. A.M. Nafchi, R. Nassiri, S. Sheibani et al., Preparation and characterization of bionanocomposite films filled with nanorod-rich zinc oxide. Carbohydr Polym 96, 233-239 (2013). https://doi. org/10.1016/j.carbpol.2013.03.055

226. G.-C. Yi, C. Wang, P.W. Il, ZnO nanorods: synthesis, characterization and applications. Semicond Sci Technol 20, S22-S34 (2005). https://doi.org/10.1088/0268-1242/20/4/003

227. L.E. Greene, M. Law, D.H. Tan et al., General route to vertical $\mathrm{ZnO}$ nanowire arrays using textured $\mathrm{ZnO}$ seeds. Nano Lett $\mathbf{5}$, 1231-1236 (2005). https://doi.org/10.1021/n1050788p

228. J.N. Hasnidawani, H.N. Azlina, H. Norita et al., Synthesis of $\mathrm{ZnO}$ nanostructures using sol-gel method. Procedia Chem 19, 211-216 (2016). https://doi.org/10.1016/j.proche.2016.03.095

229. F. Dejene, A. Ali, H. Swart et al., Optical properties of $\mathrm{ZnO}$ nanoparticles synthesized by varying the sodium hydroxide to zinc acetate molar ratios using a Sol-Gel process. Open Phys 9, 1321-1326 (2011). https://doi.org/10.2478/s11534-011-0050-3

230. J. Polte, X. Tuaev, M. Wuithschick et al., Formation mechanism of colloidal silver nanoparticles: analogies and differences to the growth of gold nanoparticles. ACS Nano 6, 5791-5802 (2012). https://doi.org/10.1021/nn301724z

231. A.B. Albeladi, S.A. AL-Thabaiti, Z. Khan, Effect of CTAB on the surface resonance plasmon intensity of silver nanoparticles: stability and oxidative dissolution. J Mol Liq 302, 112565 (2020). https://doi.org/10.1016/j.molliq.2020.112565

232. K. Missoum, M.N. Belgacem, J. Bras, Nanofibrillated cellulose surface modification: a review. Materials (Basel) 6, 1745-1766 (2013). https://doi.org/10.3390/ma6051745
233. M.M. de Souza Lima, R. Borsali, Rodlike cellulose microcrystals: structure, properties, and applications. Macromol. Rapid. Commun. 25:7, 771-787 (2004). https://doi.org/10.1002/marc. 200300268

234. K. Spence, R. Venditti, O. Rojas et al., Water vapor barrier properties of coated and filled microfibrillated cellulose composite films. BioResources 6:4, 4370-4388 (2011). https://doi.org/10. 15376/biores.6.4.4370-4388

235. E. Trovatti, S.C.M. Fernandes, L. Rubatat et al., Pullulannanofibrillated cellulose composite films with improved thermal and mechanical properties. Compos Sci Technol 72, 15561561 (2012). https://doi.org/10.1016/j.compscitech.2012.06. 003

236. A.A. Oun, J.W. Rhim, Preparation and characterization of sodium carboxymethyl cellulose/cotton linter cellulose nanofibril composite films. Carbohydr Polym 127, 101-109 (2015). https://doi.org/10.1016/j.carbpol.2015.03.073

237. M. Fazeli, M. Keley, E. Biazar, Preparation and characterization of starch-based composite films reinforced by cellulose nanofibers. Int. J. Biol. Macromol. 116, 272-280 (2018). https://doi.org/ 10.1016/j.ijbiomac.2018.04.186

238. F.M. Pelissari, M.M. Andrade-Mahecha, P.J. do Amaral Sobral, F.C. Menegalli, Nanocomposites based on banana starch reinforced with cellulose nanofibers isolated from banana peels. J. Colloid. Interface. Sci. 505, 154-167 (2017). https://doi.org/10. 1016/j.jcis.2017.05.106

239. M. Farooq, T. Zou, G. Riviere et al., Strong, ductile, and waterproof cellulose nanofibril composite films with colloidal lignin particles. Biomacromol 20, 693-704 (2019). https://doi.org/10. 1021/acs.biomac.8b01364

240. R. Nasseri, N. Mohammadi, Starch-based nanocomposites: a comparative performance study of cellulose whiskers and starch nanoparticles. Carbohydr. Polym. 106, 432-439 (2014). https:// doi.org/10.1016/j.carbpol.2014.01.029

241. A. Ali, F. Xie, L. Yu et al., Preparation and characterization of starch-based composite films reinfoced by polysaccharide-based crystals. Compos. Part B Eng. 133, 122-128 (2018). https://doi. org/10.1016/j.compositesb.2017.09.017

242. L. Lendvai, A. Apostolov, J. Karger-Kocsis, Characterization of layered silicate-reinforced blends of thermoplastic starch (TPS) and poly(butylene adipate-co-terephthalate). Carbohydr Polym 173, 566-572 (2017). https://doi.org/10.1016/j.carbpol.2017.05. 100

243. K. Wang, W. Wang, R. Ye et al., Mechanical properties and solubility in water of corn starch-collagen composite films: effect of starch type and concentrations. Food Chem 216, 209-216 (2017). https://doi.org/10.1016/j.foodchem.2016.08.048

244. L. Castillo, O.V. López, C. López et al., Thermoplastic starch films reinforced with talc nanoparticles. Carbohydr Polym 95, 664-674 (2013). https://doi.org/10.1016/j.carbpol.2013.03.026

245. M.I.J. Ibrahim, S.M. Sapuan, E.S. Zainudin, M.Y.M. Zuhri, Potential of using multiscale corn husk fiber as reinforcing filler in cornstarch-based biocomposites. Int J Biol Macromol 139, 596-604 (2019). https://doi.org/10.1016/j.ijbiomac.2019.08.015

246. E. Stasi, A. Giuri, F. Ferrari et al., Biodegradable carbon-based ashes/maize starch composite films for agricultural applications. Polymers 12:3, 1-16 (2020). https://doi.org/10.3390/polym12030 524

247. P. Yin, J. Liu, W. Zhou, P. Li, Preparation and properties of corn starch/chitin composite films cross-linked by maleic anhydride. Polymers 12:7, 1606 (2020). https://doi.org/10.3390/polym12071 606

248. L. Calabria, N. Vieceli, O. Bianchi et al., Soy protein isolate/ poly(lactic acid) injection-molded biodegradable blends for slow release of fertilizers. Ind Crops Prod 36, 41-46 (2012). https:// doi.org/10.1016/j.indcrop.2011.08.003 
249. R. Chan, L.T. Lim, S. Barbut, M.F. Marcone, Extrusion and characterization of soy protein film incorporated with soy cellulose microfibers. Int Polym Process 29, 467-476 (2014). https://doi. org/10.3139/217.2866

250. T. Garrido, M. Peñalba, K. de la Caba, P. Guerrero, Injectionmanufactured biocomposites from extruded soy protein with algae waste as a filler. Compos Part B Eng 86, 197-202 (2016). https://doi.org/10.1016/j.compositesb.2015.09.058

251. G. Denavi, D.R. Tapia-Blácido, M.C. Añón et al., Effects of drying conditions on some physical properties of soy protein films. J Food Eng 90, 341-349 (2009). https://doi.org/10. 1016/j.jfoodeng.2008.07.001

252. S. Husseinsyah, C.M. Yeng, A.R. Kassim et al., Kapok huskreinforced soy protein isolate biofilms: tensile properties and enzymatic hydrolysis. BioResources 9, 5636-5651 (2014). https://doi.org/10.15376/biores.9.3.5636-5651

253. I. Siró, D. Plackett, Microfibrillated cellulose and new nanocomposite materials: a review. Cellulose 17, 459-494 (2010). https://doi.org/10.1007/s10570-010-9405-y

254. M. Martelli-Tosi, O.B.G. Assis, N.C. Silva et al., Chemical treatment and characterization of soybean straw and soybean protein isolate/straw composite films. Carbohydr Polym 157, 512-520 (2017). https://doi.org/10.1016/j.carbpol.2016.10.013

255. Y. Zhao, Z. Wang, Q. Zhang et al., Accelerated skin wound healing by soy protein isolate-modified hydroxypropyl chitosan composite films. Int J Biol Macromol 118, 1293-1302 (2018). https://doi.org/10.1016/j.ijbiomac.2018.06.195

256. M.J. Fabra, G. Sánchez, A. López-Rubio, J.M. Lagaron, Microbiological and ageing performance of polyhydroxyalkanoatebased multilayer structures of interest in food packaging. LWT - Food Sci Technol 59, 760-767 (2014). https://doi.org/10. 1016/j.1wt.2014.07.021

257. B. Melendez-Rodriguez, J.L. Castro-Mayorga, M.A.M. Reis et al., Preparation and characterization of electrospun food biopackaging films of poly(3-hydroxybutyrate-co-3-hydroxyvalerate) derived from fruit pulp biowaste. Front Sustain Food Syst 2, 1-16 (2018). https://doi.org/10.3389/fsufs.2018.00038

258. J. Chen, Y. Wang, Z. Yin et al., Morphology and mechanical properties of poly ( $\beta$-hydroxybutyrate)/poly( $\varepsilon$-caprolactone) blends controlled with cellulosic particles. Carbohydr Polym 174, 217-225 (2017). https://doi.org/10.1016/j.carbpol.2017. 06.053

259. X. Jing, Z. Qiu, Effect of low thermally reduced graphene loadings on the crystallization kinetics and morphology of biodegradable poly(3-hydroxybutyrate). Ind Eng Chem Res 51, 13686-13691 (2012). https://doi.org/10.1021/ie3018466

260. E.V. Torres-Tello, J.R. Robledo-Ortíz, Y. González-García et al., Effect of agave fiber content in the thermal and mechanical properties of green composites based on polyhydroxybutyrate or poly(hydroxybutyrate-co-hydroxyvalerate). Ind Crops Prod 99, 117-125 (2017). https://doi.org/10.1016/j.indcrop. 2017.01.035

261. L.M. Araque, T.S. Alves, R. Barbosa, Biodegradation of polyhydroxybutyrate and hollow glass microspheres composite films. J Appl Polym Sci 136, 1-10 (2019). https://doi.org/10. 1002/app.47195

262. M.U. Akbar, F. Rehman, M. Ibrahim, et al., Processing methods of bionanocomposites. In: Zia KM, Jabeen F, Anjum MN, Ikram $\mathrm{S}$ (eds) Micro and Nano Technologies, Bionanocomposites. Elsevier Inc., pp 87-104 (2020)

263. A.S. Scheibe, J.O. de Moraes, J.B. Laurindo, Production and characterization of bags from biocomposite films of starchvegetal fibers prepared by tape casting. J Food Process Eng 37, 482-492 (2014). https://doi.org/10.1111/jfpe.12105

264. C.M.O. Müller, J.B. Laurindo, F. Yamashita, Effect of cellulose fibers addition on the mechanical properties and water vapor barrier of starch-based films. Food Hydrocoll 23, 1328-1333 (2009). https://doi.org/10.1016/j.foodhyd.2008.09.002

265. D. Bondeson, K. Oksman, Polylactic acid/cellulose whisker nanocomposites modified by polyvinyl alcohol. Compos Part A Appl Sci Manuf 38, 2486-2492 (2007). https://doi.org/10.1016/j. compositesa.2007.08.001

266. L.K. Cardon, K.J. Ragaert, R. de Santis, A. Gloria, Design and fabrication methods for biocomposites. In: Biomedical Composites, Second Edi. Elsevier Ltd., pp 17-36 (2017)

267. J. Oliveira de Moraes, A.S. Scheibe, A. Sereno, J.B. Laurindo, Scale-up of the production of cassava starch based films using tape-casting. J Food Eng 119, 800-808 (2013). https://doi.org/ 10.1016/j.jfoodeng.2013.07.009

268. D. Hotza, Review article: Tape Casting. Cerâmica 43, 157-164 (1997)

269. S. Farris, Main Manufacturing Processes for Food Packaging Materials. In: Reference Module in Food Science. Elsevier (2016)

270. M.A. Cader Mhd Haniffa, Y.C. Ching, L.C. Abdullah et al., Review of bionanocomposite coating films and their applications. Polymers 8:7, 1-33 (2016). https://doi.org/10.3390/ polym 8070246

271. K. Spence, R. Venditti, O. Rojas et al., Water vapor barrier properties of coated and filled microfibrillated cellulose composite films. BioResources 6, 4370-4388 (2011). https://doi. org/10.15376/biores.6.4.4370-4388

272. H.Y. Choi, Y.G. Jeong, Microstructures and piezoelectric performance of eco-friendly composite films based on nanocellulose and barium titanate nanoparticle. Compos Part B Eng 168, 58-65 (2019). https://doi.org/10.1016/j.compositesb.2018.12. 072

273. O.V. López, L.A. Castillo, M.A. García et al., Food packaging bags based on thermoplastic corn starch reinforced with talc nanoparticles. Food Hydrocoll 43, 18-24 (2015). https://doi. org/10.1016/j.foodhyd.2014.04.021

274. L.A. Castillo, O.V. López, J. Ghilardi et al., Thermoplastic starch/talc bionanocomposites. Influence of particle morphology on final properties. Food Hydrocoll 51, 432-440 (2015). https://doi.org/10.1016/j.foodhyd.2015.05.030

275. M.G. Passaretti, M.D. Ninago, C. Di Anibal et al., Composite films with UV barrier capacity to minimize flavored waters degradation. Food Packag Shelf Life 21, 100334 (2019). https://doi. org/10.1016/j.fpsl.2019.100334

276. M.G. Passaretti, M.D. Ninago, C.I. Paulo et al., Biocomposites based on thermoplastic starch and granite sand quarry waste. J Renew Mater 7, 393-402 (2019). https://doi.org/10.32604/jrm. 2019.04281

277. G. Sanchez-Olivares, S. Rabe, R. Pérez-Chávez et al., Industrialwaste agave fibres in flame-retarded thermoplastic starch biocomposites. Compos Part B Eng 177, 107370 (2019). https://doi. org/10.1016/j.compositesb.2019.107370

278. S. Jafarzadeh, S.M. Jafari, A. Salehabadi et al., Biodegradable green packaging with antimicrobial functions based on the bioactive compounds from tropical plants and their by-products. Trends Food Sci Technol 100, 262-277 (2020). https://doi.org/ 10.1016/j.tifs.2020.04.017

279. J. Liang, J. Wang, S. Li et al., The size-controllable preparation of chitosan/silver nanoparticle composite microsphere and its antimicrobial performance. Carbohydr Polym 220, 22-29 (2019). https://doi.org/10.1016/j.carbpol.2019.05.048

280. A.M. Youssef, S.M. El-Sayed, Bionanocomposites materials for food packaging applications: concepts and future outlook. Carbohydr Polym 193, 19-27 (2018). https://doi.org/10.1016/j.carbp ol.2018.03.088

281. Dima JB, Sequeiros C, Zaritzky N (2017) Chitosan from marine crustaceans: production, characterization and applications. In:

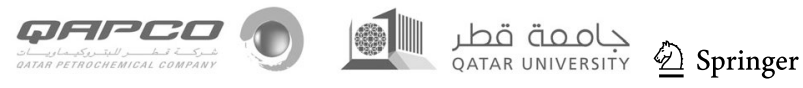


Biological Activities and Application of Marine Polysaccharides. InTech, pp 39-54

282. S.A. Varghese, S. Siengchin, J. Parameswaranpillai, Essential oils as antimicrobial agents in biopolymer-based food packaging - a comprehensive review. Food Biosci 38, 100785 (2020). https:// doi.org/10.1016/j.fbio.2020.100785

283. L. Atarés, A. Chiralt, Essential oils as additives in biodegradable films and coatings for active food packaging. Trends Food Sci Technol 48, 51-62 (2016). https://doi.org/10.1016/j.tifs.2015.12. 001

284. S. Sharma, S. Barkauskaite, A.K. Jaiswal, S. Jaiswal, Essential oils as additives in active food packaging. Food Chem 343, 128403 (2021). https://doi.org/10.1016/j.foodchem.2020.128403

285. W. Lan, S. Wang, M. Chen et al., Developing poly(vinyl alcohol)/ chitosan films incorporate with D-limonene: study of structural, antibacterial, and fruit preservation properties. Int J Biol Macromol 145, 722-732 (2020). https://doi.org/10.1016/j.ijbiomac. 2019.12.230

286. L. Sánchez-González, M. Vargas, C. González-Martínez et al., Characterization of edible films based on hydroxypropylmethylcellulose and tea tree essential oil. Food Hydrocoll 23, 21022109 (2009). https://doi.org/10.1016/j.foodhyd.2009.05.006

287. J.A. do Evangelho, G. da Silva Dannenberg, B. Biduski et al., Antibacterial activity, optical, mechanical, and barrier properties of corn starch films containing orange essential oil. Carbohydr Polym 222, 114981 (2019). https://doi.org/10.1016/j.carbpol. 2019.114981

288. M. Abdollahi, M. Rezaei, G. Farzi, A novel active bionanocomposite film incorporating rosemary essential oil and nanoclay into chitosan. J Food Eng 111, 343-350 (2012). https://doi.org/ 10.1016/j.jfoodeng.2012.02.012

289. L. Sánchez-González, C. González-Martínez, A. Chiralt, M. Cháfer, Physical and antimicrobial properties of chitosan-tea tree essential oil composite films. J Food Eng 98, 443-452 (2010). https://doi.org/10.1016/j.jfoodeng.2010.01.026

290. V.P. Romani, C. Prentice-Hernández, V.G. Martins, Active and sustainable materials from rice starch, fish protein and oregano essential oil for food packaging. Ind Crops Prod 97, 268-274 (2017). https://doi.org/10.1016/j.indcrop.2016.12.026

291. I. Echeverría, M.E. López-Caballero, M.C. Gómez-Guillén et al., Active nanocomposite films based on soy proteins-montmorillonite-clove essential oil for the preservation of refrigerated bluefin tuna (Thunnus thynnus) fillets. Int J Food Microbiol 266, 142-149 (2018). https://doi.org/10.1016/j.ijfoodmicro.2017.10. 003

292. Y. Zhang, L. Zhou, C. Zhang et al., Preparation and characterization of curdlan/polyvinyl alcohol/ thyme essential oil blending film and its application to chilled meat preservation. Carbohydr Polym 247, 116670 (2020). https://doi.org/10.1016/j.carbpol. 2020.116670

293. P. Kanmani, J.W. Rhim, Development and characterization of carrageenan/grapefruit seed extract composite films for active packaging. Int J Biol Macromol 68, 258-266 (2014). https://doi. org/10.1016/j.ijbiomac.2014.05.011

294. S. Estevez-Areco, L. Guz, L. Famá et al., Bioactive starch nanocomposite films with antioxidant activity and enhanced mechanical properties obtained by extrusion followed by thermo-compression. Food Hydrocoll 96, 518-528 (2019). https://doi.org/ 10.1016/j.foodhyd.2019.05.054

295. A. Jayakumar, K.V. H, T.S. S et al., Starch-PVA composite films with zinc-oxide nanoparticles and phytochemicals as intelligent $\mathrm{pH}$ sensing wraps for food packaging application. Int J Biol Macromol 136, 395-403 (2019). https://doi.org/10.1016/j.ijbiomac. 2019.06.018

296. J. Liu, C. Meng, guang, Liu S, et al., Preparation and characterization of protocatechuic acid grafted chitosan films with antioxidant activity. Food Hydrocoll 63, 457-466 (2017). https:// doi.org/10.1016/j.foodhyd.2016.09.035

297. C. Valencia-Sullca, M. Vargas, L. Atarés, A. Chiralt, Thermoplastic cassava starch-chitosan bilayer films containing essential oils. Food Hydrocoll 75, 107-115 (2018). https://doi.org/10. 1016/j.foodhyd.2017.09.008

298. R. Yoksan, S. Chirachanchai, Silver nanoparticle-loaded chitosan-starch based films: fabrication and evaluation of tensile, barrier and antimicrobial properties. Mater. Sci. Eng. C 30:6, 891-897 (2010). https://doi.org/10.1016/j.msec.2010.04.004

299. A.C. Seydim, G. Sarikus-Tutal, E. Sogut, Effect of whey protein edible films containing plant essential oils on microbial inactivation of sliced Kasar cheese. Food Packag Shelf Life 26, 100567 (2020). https://doi.org/10.1016/j.fpsl.2020.100567

300. L.M. Reyes, M. Landgraf, P.J.A. Sobral, Gelatin-based films activated with red propolis ethanolic extract and essential oils. Food Packag Shelf Life 27, 100607 (2021). https://doi.org/10. 1016/j.fpsl.2020.100607

301. Y. Liu, D. Wang, Z. Sun et al., Preparation and characterization of gelatin/chitosan/3-phenylacetic acid food-packaging nanofiber antibacterial films by electrospinning. Int J Biol Macromol 169, 161-170 (2021). https://doi.org/10.1016/j.ijbio mac.2020.12.046

302. M. Li, H. Yu, Y. Xie et al., Fabrication of eugenol loaded gelatin nanofibers by electrospinning technique as active packaging material. LWT 139, 110800 (2021). https://doi.org/10.1016/j. lwt.2020.110800

303. J. Vergara-Figueroa, S. Alejandro-Martin, F. Cerda-Leal, W. Gacitúa, Dual electrospinning of a nanocomposites biofilm: Potential use as an antimicrobial barrier. Mater Today Commun 25, 101671 (2020). https://doi.org/10.1016/j.mtcomm. 2020.101671

304. K.K. Kuorwel, M.J. Cran, J.D. Orbell et al., Review of mechanical properties, migration, and potential applications in active food packaging systems containing nanoclays and nanosilver. Compr Rev Food Sci Food Saf 14, 411-430 (2015). https://doi. org/10.1111/1541-4337.12139

305. J.W. Rhim, H.M. Park, C.S. Ha, Bio-nanocomposites for food packaging applications. Prog Polym Sci 38, 1629-1652 (2013). https://doi.org/10.1016/j.progpolymsci.2013.05.008

306. P. Cheviron, F. Gouanvé, E. Espuche, Effect of silver nanoparticles' generation routes on the morphology, oxygen, and water transport properties of starch nanocomposite films. J Nanoparticle Res 17, 635-645 (2015). https://doi.org/10.1007/ s11051-015-3173-4

307. P. Cheviron, F. Gouanvé, E. Espuche, Preparation, characterization and barrier properties of silver/montmorillonite/starch nanocomposite films. J Memb Sci 497, 162-171 (2016). https:// doi.org/10.1016/j.memsci.2015.09.039

308. J.B. Olivato, J. Marini, F. Yamashita et al., Sepiolite as a promising nanoclay for nano-biocomposites based on starch and biodegradable polyester. Mater Sci Eng C 70, 296-302 (2017). https:// doi.org/10.1016/j.msec.2016.08.077

309. J.W. Rhim, S.I. Hong, H.M. Park, P.K.W. Ng, Preparation and characterization of chitosan-based nanocomposite films with antimicrobial activity. J Agric Food Chem 54, 5814-5822 (2006). https://doi.org/10.1021/jf060658h

310. J.W. Rhim, L.F. Wang, S.I. Hong, Preparation and characterization of agar/silver nanoparticles composite films with antimicrobial activity. Food Hydrocoll 33, 327-335 (2013). https://doi.org/ 10.1016/j.foodhyd.2013.04.002

311. J.W. Rhim, L.F. Wang, Y. Lee, S.I. Hong, Preparation and characterization of bio-nanocomposite films of agar and silver nanoparticles: laser ablation method. Carbohydr Polym 103, 456-465 (2014). https://doi.org/10.1016/j.carbpol.2013.12.075 
312. P. Kanmani, J.W. Rhim, Physical, mechanical and antimicrobial properties of gelatin based active nanocomposite films containing AgNPs and nanoclay. Food Hydrocoll 35, 644-652 (2014). https://doi.org/10.1016/j.foodhyd.2013.08.011

313. P. Kanmani, J.-W. Rhim, Physicochemical properties of gelatin/ silver nanoparticle antimicrobial composite films. Food Chem 148, 162-169 (2014). https://doi.org/10.1016/j.foodchem.2013. 10.047

314. M. Zolfi, F. Khodaiyan, M. Mousavi, M. Hashemi, The improvement of characteristics of biodegradable films made from kefiran-whey protein by nanoparticle incorporation. Carbohydr Polym 109, 118-125 (2014). https://doi.org/10.1016/j. carbpol.2014.03.018

315. A.N. Malathi, A.K. Singh, Antimicrobial activity of rice starch based film reinforced with titanium dioxide ( $\mathrm{TiO} 2$ ) Nanoparticles. Agric Res J 56, 111 (2019). https://doi.org/10.5958/2395146X.2019.00017.6

316. F. Mirjalili, A. Yassini Ardekani, Preparation and characterization of starch film accompanied with $\mathrm{ZnO}$ nanoparticles. J Food Process Eng 40, e12561 (2017). https://doi.org/10.1111/ jfpe. 12561

317. S. Malathi, P. Balashanmugam, T. Devasena, S.N. Kalkura, Enhanced antibacterial activity and wound healing by a novel collagen blended $\mathrm{ZnO}$ nanoparticles embedded niosome nanocomposites. J Drug Deliv Sci Technol 63, 102498 (2021). https://doi.org/10.1016/j.jddst.2021.102498

318. A. Cano, M. Cháfer, A. Chiralt, C. González-Martínez, Development and characterization of active films based on starchPVA, containing silver nanoparticles. Food Packag Shelf Life 10, 16-24 (2016). https://doi.org/10.1016/j.fpsl.2016.07.002

319. M.A. Pérez, E.A. Sanfuentes, N.E. Figueroa et al., Thermoplastic starch/clay nanocomposites loaded with essential oil constituents as packaging for strawberries - in vivo antimicrobial synergy over Botrytis cinerea. Postharvest Biol Technol 129, 29-36 (2017). https://doi.org/10.1016/j.postharvbio.2017.03. 005

320. K.A. Sharifi, S. Pirsa, Biodegradable film of black mulberry pulp pectin/chlorophyll of black mulberry leaf encapsulated with carboxymethylcellulose/silica nanoparticles: investigation of physicochemical and antimicrobial properties. Mater Chem Phys 267, 124580 (2021). https://doi.org/10.1016/j. matchemphys.2021.124580

321. R. Scaffaro, A. Maio, E.F. Gulino, G.D.M. Micale, PLA-based functionally graded laminates for tunable controlled release of carvacrol obtained by combining electrospinning with solvent casting. React Funct Polym 148, 104490 (2020). https://doi. org/10.1016/j.reactfunctpolym.2020.104490

322. L. Atarés, R. Pérez-Masiá, A. Chiralt, The role of some antioxidants in the HPMC film properties and lipid protection in coated toasted almonds. J Food Eng 104, 649-656 (2011). https://doi.org/10.1016/j.jfoodeng.2011.02.005

323. S.A.A. Mohamed, M. El-Sakhawy, M.A.-M. El-Sakhawy, Polysaccharides, protein and lipid -based natural edible films in food packaging: a review. Carbohydr Polym 238, 116178 (2020). https://doi.org/10.1016/j.carbpol.2020.116178

324. C.R. Rech, K.C. da Silva Brabes, B.E. Bagnara e Silva et al., Biodegradation of eugenol-loaded polyhydroxybutyrate films in different soil types. Case Stud Chem Environ Eng 2, 100014 (2020). https://doi.org/10.1016/j.cscee.2020.100014

325. E. Castro-Aguirre, R. Auras, S. Selke et al., Enhancing the biodegradation rate of poly(lactic acid) films and PLA bio-nanocomposites in simulated composting through bioaugmentation. Polym Degrad Stab 154, 46-54 (2018). https://doi.org/10.1016/j. polymdegradstab.2018.05.017

326. S. Salehpour, M. Jonoobi, M. Ahmadzadeh et al., Biodegradation and ecotoxicological impact of cellulose nanocomposites in municipal solid waste composting. Int J Biol Macromol 111, 264-270 (2018). https://doi.org/10.1016/j.jbiomac.2018.01.027

327. L. Ugarte, A. Santamaria-Echart, S. Mastel et al., An alternative approach for the incorporation of cellulose nanocrystals in flexible polyurethane foams based on renewably sourced polyols. Ind Crops Prod 95, 564-573 (2017). https://doi.org/10.1016/j.indcr op.2016.11.011

328. G. Gaidukova, A. Ivdre, A. Fridrihsone et al., Polyurethane rigid foams obtained from polyols containing bio-based and recycled components and functional additives. Ind Crops Prod 102, 133143 (2017). https://doi.org/10.1016/j.indcrop.2017.03.024

329. L.C. Chang, M. Sain, M. Kortschot, Improvement in compressive behavior of alkali-treated wood fibre-reinforced bio-based polyurethane foams. Cell Polym 33, 139-158 (2014). https://doi. org/10.1177/026248931403300302

330. C. Lacoste, M.C. Basso, A. Pizzi et al., Bioresourced pine tannin/ furanic foams with glyoxal and glutaraldehyde. Ind Crops Prod 45, 401-405 (2013). https://doi.org/10.1016/j.indcrop.2012.12. 032

331. C. Lacoste, M. Čop, K. Kemppainen et al., Biobased foams from condensed tannin extracts from Norway spruce (Picea abies) bark. Ind Crops Prod 73, 144-153 (2015). https://doi.org/10. 1016/j.indcrop.2015.03.089

332. C. Lacoste, M.C. Basso, A. Pizzi et al., Natural albumin/tannin cellular foams. Ind Crops Prod 73, 41-48 (2015). https://doi.org/ 10.1016/j.indcrop.2015.03.087

333. A. Martinez de Yuso, M.C. Lagel, A. Pizzi et al., Structure and properties of rigid foams derived from quebracho tannin. Mater Des 63, 208-212 (2014). https://doi.org/10.1016/j.matdes.2014. 05.072

334. A. Arbenz, A. Frache, F. Cuttica, L. Avérous, Advanced biobased and rigid foams, based on urethane-modified isocyanurate from oxypropylated gambier tannin polyol. Polym Degrad Stab 132, 62-68 (2016). https://doi.org/10.1016/j.polymdegradstab.2016. 03.035

335. J. Merle, M. Birot, H. Deleuze et al., New biobased foams from wood byproducts. Mater Des 91, 186-192 (2016). https://doi.org/ 10.1016/j.matdes.2015.11.076

336. J. Zhang, N. Hori, A. Takemura, Optimization of agricultural wastes liquefaction process and preparing bio-based polyurethane foams by the obtained polyols. Ind Crops Prod 138, 111455 (2019). https://doi.org/10.1016/j.indcrop.2019.06.018

337. I. Domingos, J. Ferreira, L. Cruz-Lopes, B. Esteves, Polyurethane foams from liquefied orange peel wastes. Food Bioprod Process 115, 223-229 (2019). https://doi.org/10.1016/j.fbp.2019.04.002

338. T. Vincent, C. Vincent, L. Dumazert et al., Fire behavior of innovative alginate foams. Carbohydr Polym 250, 116910 (2020). https://doi.org/10.1016/j.carbpol.2020.116910

339. M. Cregut, M. Bedas, M.J. Durand, G. Thouand, New insights into polyurethane biodegradation and realistic prospects for the development of a sustainable waste recycling process. Biotechnol Adv 31, 1634-1647 (2013). https://doi.org/10.1016/j.biotechadv. 2013.08.011

340. J. Guan, K.L. Fujimoto, M.S. Sacks, W.R. Wagner, Preparation and characterization of highly porous, biodegradable polyurethane scaffolds for soft tissue applications. Biomaterials 26, 3961-3971 (2005). https://doi.org/10.1016/j.biomaterials.2004. 10.018

341. Y.C. Kuo, S.C. Hung, S. Hsu, hui, The effect of elastic biodegradable polyurethane electrospun nanofibers on the differentiation of mesenchymal stem cells. Colloids Surf B Biointerfaces 122, 414-422 (2014). https://doi.org/10.1016/j.colsurfb.2014.07.017

342. G.B. Kim, J. Guo, J. Hu, et al., Novel Applications of Urethane/ Urea Chemistry in the Field of Biomaterials. In: Cooper SL, Guan J (eds) Advances in Polyurethane Biomaterials. Elsevier Ltd, pp 115-147 (2016)

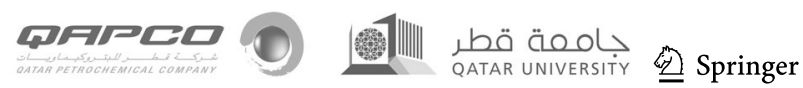


343. X. Zhang, K.G. Battiston, J.E. McBane, et al., Design of biodegradable polyurethanes and the interactions of the polymers and their degradation by-products within in vitro and in vivo environments. In: Advances in Polyurethane Biomaterials. Elsevier, pp 75-114 (2016)

344. M. Kuranska, A. Prociak, Porous polyurethane composites with natural fibres. Compos Sci Technol 72, 299-304 (2012). https:// doi.org/10.1016/j.compscitech.2011.11.016

345. S. Członka, M.F. Bertino, K. Strzelec, Rigid polyurethane foams reinforced with industrial potato protein. Polym Test 68, 135-145 (2018). https://doi.org/10.1016/j.polymertesting.2018.04.006

346. S. Członka, M.F. Bertino, K. Strzelec et al., Rigid polyurethane foams reinforced with solid waste generated in leather industry. Polym Test 69, 225-237 (2018). https://doi.org/10.1016/j.polym ertesting.2018.05.013

347. E.G. de Moraes, L. Sangiacomo, N.P. Stochero et al., Innovative thermal and acoustic insulation foam by using recycled ceramic shell and expandable styrofoam (EPS) wastes. Waste Manag 89, 336-344 (2019). https://doi.org/10.1016/j.wasman.2019.04.019

348. F. Giuliani, F. Autelitano, E. Garilli, A. Montepara, Expanded polystyrene (EPS) in road construction: twenty years of Italian experiences. Transp Res Procedia 45, 410-417 (2020). https:// doi.org/10.1016/j.trpro.2020.03.033

349. A. Gallego-Schmid, J.M.F. Mendoza, A. Azapagic, Environmental impacts of takeaway food containers. J Clean Prod 211, 417-427 (2019). https://doi.org/10.1016/j.jclepro.2018.11.220

350. A. Dsouza, G.W. Price, M. Dixon, T. Graham, A conceptual framework for incorporation of composting in closed-loop urban controlled environment agriculture. Sustain 13, 1-28 (2021). https://doi.org/10.3390/su13052471

351. A.E. Schwarz, T.N. Ligthart, D. Godoi Bizarro et al., Plastic recycling in a circular economy; determining environmental performance through an LCA matrix model approach. Waste Manag 121, 331-342 (2021). https://doi.org/10.1016/j.wasman.2020.12. 020

352. E. Setyowati, Eco-building material of styrofoam waste and sugar industry fly-ash based on nano-technology. Procedia Environ Sci 20, 245-253 (2014). https://doi.org/10.1016/j.proenv.2014.03. 031

353. A. Milling, A. Mwasha, H. Martin, Exploring the full replacement of cement with expanded polystyrene (EPS) waste in mortars used for masonry construction. Constr Build Mater 253, 119158 (2020). https://doi.org/10.1016/j.conbuildmat.2020. 119158

354. W. Nhuapeng, W. Thamjaree, Fabrication and mechanical properties of hybrid composites between pineapple fiber/styrofoam particle/paper tissue. Mater Today Proc 17, 1444-1450 (2019). https://doi.org/10.1016/j.matpr.2019.06.166

355. S. Dixit, V.L. Yadav, Optimization of polyethylene/polypropylene/alkali modified wheat straw composites for packaging application using RSM. J Clean Prod 240, 118228 (2019). https://doi. org/10.1016/j.jclepro.2019.118228

356. A. Dixit, S.D. Pang, S.H. Kang, J. Moon, Lightweight structural cement composites with expanded polystyrene (EPS) for enhanced thermal insulation. Cem Concr Compos 102, 185-197 (2019). https://doi.org/10.1016/j.cemconcomp.2019.04.023

357. H. Xu, P. Xu, D. Wang et al., A dimensional stable hydrogel-born foam with enhanced mechanical and thermal insulation and fireretarding properties via fast microwave foaming. Chem Eng J 399, 125781 (2020). https://doi.org/10.1016/j.cej.2020.125781

358. F. Razza, F.D. Innocenti, A. Dobon et al., Environmental profile of a bio-based and biodegradable foamed packaging prototype in comparison with the current benchmark. J Clean Prod 102, 493-500 (2015). https://doi.org/10.1016/j.jclepro.2015.04.033

359. C.M. Machado, P. Benelli, I.C. Tessaro, Study of interactions between cassava starch and peanut skin on biodegradable foams.
Int J Biol Macromol 147, 1343-1353 (2020). https://doi.org/10. 1016/j.ijbiomac.2019.10.098

360. A. Georges, C. Lacoste, E. Damien, Effect of formulation and process on the extrudability of starch-based foam cushions. Ind Crops Prod 115, 306-314 (2018). https://doi.org/10.1016/j.indcr op.2018.02.001

361. C. Chiarathanakrit, S.A. Riyajan, K. Kaewtatip, Transforming fish scale waste into an efficient filler for starch foam. Carbohydr Polym 188, 48-53 (2018). https://doi.org/10.1016/j.carbp ol.2018.01.101

362. K. Kaewtatip, C. Chiarathanakrit, S.A. Riyajan, The effects of egg shell and shrimp shell on the properties of baked starch foam. Powder Technol 335, 354-359 (2018). https://doi.org/ 10.1016/j.powtec.2018.05.030

363. J.P. Cruz-Tirado, R. Vejarano, D.R. Tapia-Blácido et al., Biodegradable foam tray based on starches isolated from different Peruvian species. Int J Biol Macromol 125, 800-807 (2019). https://doi.org/10.1016/j.ijbiomac.2018.12.111

364. S. Chaireh, P. Ngasatool, K. Kaewtatip, Novel composite foam made from starch and water hyacinth with beeswax coating for food packaging applications. Int J Biol Macromol 165, 13821391 (2020). https://doi.org/10.1016/j.ijbiomac.2020.10.007

365. N.A. Abu Hassan, S. Ahmad, R.S. Chen, D. Shahdan, Cells analyses, mechanical and thermal stability of extruded polylactic acid/kenaf bio-composite foams. Constr Build Mater 240, 117884 (2020). https://doi.org/10.1016/j.conbuildmat.2019. 117884

366. N. Kaisangsri, O. Kerdchoechuen, N. Laohakunjit, Characterization of cassava starch based foam blended with plant proteins, kraft fiber, and palm oil. Carbohydr Polym 110, 70-77 (2014). https://doi.org/10.1016/j.carbpol.2014.03.067

367. M. Mitrus, L. Moscicki, Extrusion-cooking of starch protective loose-fill foams. Chem Eng Res Des 92, 778-783 (2014). https://doi.org/10.1016/J.CHERD.2013.10.027

368. K. Pornsuksomboon, B.B. Holló, K.M. Szécsényi, K. Kaewtatip, Properties of baked foams from citric acid modified cassava starch and native cassava starch blends. Carbohydr Polym 136, 107-112 (2016). https://doi.org/10.1016/j.carbpol. 2015.09.019

369. B.F. Bergel, L.M. da Luz, R.M.C. Santana, Comparative study of the influence of chitosan as coating of thermoplastic starch foam from potato, cassava and corn starch. Prog Org Coat 106, 27-32 (2017). https://doi.org/10.1016/j.porgcoat.2017.02.010

370. B.F. Bergel, L.M. da Luz, R.M.C. Santana, Effect of poly(lactic acid) coating on mechanical and physical properties of thermoplastic starch foams from potato starch. Prog Org Coat 118, 91-96 (2018). https://doi.org/10.1016/j.porgcoat.2018.01.029

371. B.F. Bergel, S. Dias Osorio, L.M. da Luz, R.M.C. Santana, Effects of hydrophobized starches on thermoplastic starch foams made from potato starch. Carbohydr Polym 200, 106114 (2018). https://doi.org/10.1016/j.carbpol.2018.07.047

372. J.P. Cruz-Tirado, R. Siche, A. Cabanillas et al., Properties of baked foams from oca (Oxalis tuberosa) starch reinforced with sugarcane bagasse and asparagus peel fiber. Procedia Eng 200, 178-185 (2017). https://doi.org/10.1016/j.proeng.2017.07.026

373. K. Bocz, T. Tábi, D. Vadas et al., Characterisation of natural fibre reinforced PLA foams prepared by supercritical $\mathrm{CO} 2$ assisted extrusion. Express Polym Lett 10, 771-779 (2016). https://doi.org/10.3144/expresspolymlett.2016.71

374. J. Guan, M.A. Hanna, Functional properties of extruded foam composites of starch acetate and corn cob fiber. Ind Crops Prod 19, 255-269 (2004). https://doi.org/10.1016/j.indcrop.2003.10. 007

375. J. Guan, K.M. Eskridge, M.A. Hanna, Acetylated starch-polylactic acid loose-fill packaging materials. Ind Crop Prod 22, 109-123 (2005). https://doi.org/10.1016/j.indcrop.2004.06.004 
376. M.M. Hassan, N. Tucker, M.J. Le Guen, Thermal, mechanical and viscoelastic properties of citric acid-crosslinked starch/cellulose composite foams. Carbohydr Polym 230, 115675 (2020). https://doi.org/10.1016/j.carbpol.2019.115675

377. N. Kaisangsri, O. Kerdchoechuen, N. Laohakunjit, Biodegradable foam tray from cassava starch blended with natural fiber and chitosan. Ind Crops Prod 37, 542-546 (2012). https://doi. org/10.1016/j.indcrop.2011.07.034

378. N. Hendrawati, A.A. Wibowo, R.D. Chrisnandari, R. Adawiyah, Biodegradable foam tray based on sago starch with beeswax as coating agent. IOP Conf Ser Mater Sci Eng 1073, 012006 (2021). https://doi.org/10.1088/1757-899x/1073/1/ 012006

379. N. Soykeabkaew, C. Thanomsilp, O. Suwantong, A review: starch-based composite foams. Compos Part A Appl Sci Manuf 78, 246-263 (2015). https://doi.org/10.1016/j.compositesa. 2015.08.014

380. E. Richards, R. Rizvi, A. Chow, H. Naguib, Biodegradable composite foams of PLA and PHBV using subcritical CO 2. J Polym Environ 16, 258-266 (2008). https://doi.org/10.1007/ s10924-008-0110-y

381. R. Pantani, V. Volpe, G. Titomanlio, Foam injection molding of poly(lactic acid) with environmentally friendly physical blowing agents. J Mater Process Technol 214, 3098-3107 (2014). https://doi.org/10.1016/J.JMATPROTEC.2014.07.002

382. V. Peinado, L. García, Á. Fernández, P. Castell, Novel lightweight foamed poly(lactic acid) reinforced with different loadings of functionalised Sepiolite. Compos Sci Technol 101, 17-23 (2014). https://doi.org/10.1016/j.compscitech.2014.06.025

383. A. Lopez-Gil, F. Silva-Bellucci, D. Velasco et al., Cellular structure and mechanical properties of starch-based foamed blocks reinforced with natural fibers and produced by microwave heating. Ind Crops Prod 66, 194-205 (2015). https://doi.org/10. 1016/j.indcrop.2014.12.025

384. G. Coste, C. Negrell, S. Caillol, From gas release to foam synthesis, the second breath of blowing agents. Eur Polym J 140, 110029 (2020). https://doi.org/10.1016/j.eurpolymj.2020.110029

385. A. Szczurek, V. Fierro, A. Pizzi et al., A new method for preparing tannin-based foams. Ind Crops Prod 54, 40-53 (2014). https://doi.org/10.1016/j.indcrop.2014.01.012

386. N. Le Moigne, M. Sauceau, M. Benyakhlef et al., Foaming of poly(3-hydroxybutyrate-co-3-hydroxyvalerate)/organo-clays nano-biocomposites by a continuous supercritical $\mathrm{CO} 2$ assisted extrusion process. Eur Polym J 61, 157-171 (2014). https://doi. org/10.1016/j.eurpolymj.2014.10.008

387. T. Kuang, J. Ju, Z. Yang et al., A facile approach towards fabrication of lightweight biodegradable poly (butylene succinate)/ carbon fiber composite foams with high electrical conductivity and strength. Compos Sci Technol 159, 171-179 (2018). https:// doi.org/10.1016/j.compscitech.2018.02.021

388. B. Grignard, J.M. Thomassin, S. Gennen et al., CO2-blown microcellular non-isocyanate polyurethane (NIPU) foams: from bio- and $\mathrm{CO} 2$-sourced monomers to potentially thermal insulating materials. Green Chem. 18, 2206-2215 (2016). https://doi. org/10.1039/c5gc02723c

389. J.M. Julien, J.C. Quantin, J.C. Bénézet et al., Chemical foaming extrusion of poly(lactic acid) with chain-extenders: physical and morphological characterizations. Eur Polym J 67, 40-49 (2015). https://doi.org/10.1016/j.eurpolymj.2015.03.011

390. J.B. Engel, A. Ambrosi, I.C. Tessaro, Development of biodegradable starch-based foams incorporated with grape stalks for food packaging. Carbohydr Polym 225, 115234 (2019). https://doi. org/10.1016/j.carbpol.2019.115234

391. A. Ameli, D. Jahani, M. Nofar et al., Development of high void fraction polylactide composite foams using injection molding: mechanical and thermal insulation properties. Compos Sci
Technol 90, 88-95 (2014). https://doi.org/10.1016/j.compscitech.2013.10.019

392. D.K.M. Matsuda, A.E.S. Verceheze, G.M. Carvalho et al., Baked foams of cassava starch and organically modified nanoclays. Ind Crops Prod 44, 705-711 (2013). https://doi.org/10.1016/j.indcr op.2012.08.032

393. S. Polat, M.-K. Uslu, A. Aygün, M. Certel, The effects of the addition of corn husk fibre, kaolin and beeswax on cross-linked corn starch foam. J Food Eng 116, 267-276 (2013). https://doi. org/10.1016/j.jfoodeng.2012.12.017

394. C. Zhang, F. Li, J. Li et al., A new biodegradable composite with open cell by combining modified starch and plant fibers. Mater. Des. 120, 222-229 (2017). https://doi.org/10.1016/j.matdes. 2017.02.027

395. W. Nansu, S. Ross, G. Ross, S. Mahasaranon, Effect of crosslinking agent on the physical and mechanical properties of a composite foam based on cassava starch and coconut residue fiber. Mater Today Proc 17, 2010-2019 (2019). https://doi.org/10. 1016/j.matpr.2019.06.249

396. J. Zhou, J. Song, R. Parker, Structure and properties of starchbased foams prepared by microwave heating from extruded pellets. Carbohydr Polym 63, 466-475 (2006). https://doi.org/10. 1016/j.carbpol.2005.09.019

397. J. Zhou, J. Song, R. Parker, Microwave-assisted moulding using expandable extruded pellets from wheat flours and starch. Carbohydr Polym 69, 445-454 (2007). https://doi.org/10.1016/j.carbp ol.2007.01.001

398. H. Chanvrier, L. Chaunier, G. Della Valle, D. Lourdin, Flow and foam properties of extruded maize flour and its biopolymer blends expanded by microwave. Food Res Int 76, 567-575 (2015). https://doi.org/10.1016/j.foodres.2015.07.019

399. Y. Deng, J.M. Catchmark, Insoluble starch composite foams produced through microwave expansion. Carbohydr Polym 111, 864-869 (2014). https://doi.org/10.1016/j.carbpol.2014.04.090

400. M. Darder, C.R.S. Matos, P. Aranda et al., Bionanocomposite foams based on the assembly of starch and alginate with sepiolite fibrous clay. Carbohydr Polym 157, 1933-1939 (2017). https:// doi.org/10.1016/J.CARBPOL.2016.11.079

401. X.Y. Chen, A. Romero, A. Paton-Carrero, et al., Functionalized graphene-reinforced foams based on polymer matrices: processing and applications. In: Functionalized Graphene Nanocomposites and Their Derivatives: Synthesis, Processing and Applications. Elsevier Inc., pp 121-155 (2018)

402. S. Polat, M.-K. Uslu, A. Aygün, M. Certel, The effects of the addition of corn husk fibre, kaolin and beeswax on cross-linked corn starch foam. J. Food Eng. 116:2, 267-276 (2013). https:// doi.org/10.1016/j.jfoodeng.2012.12.017

403. K. Kaewtatip, V. Tanrattanakul, W. Phetrat, Preparation and characterization of kaolin/starch foam. Appl Clay Sci 80-81, 413-416 (2013). https://doi.org/10.1016/j.clay.2013.07.011

404. C. Chiarathanakrit, J. Mayakun, A. Prathep, K. Kaewtatip, Comparison of the effects of calcified green macroalga (Halimeda macroloba Decaisne) and commercial $\mathrm{CaCO}_{3}$ on the properties of composite starch foam trays. Int. J. Biol Macromol. 121, 71-76 (2019). https://doi.org/10.1016/j.ijbiomac.2018.09.191

405. J.B. Engel, C.L. Luchese, I.C. Tessaro, How are the properties of biocomposite foams influenced by the substitution of cassava starch for its residual sources? Food Hydrocoll 118, 106790 (2021). https://doi.org/10.1016/j.foodhyd.2021.106790

406. D. Yin, J. Mi, H. Zhou et al., Fabrication of branching poly (butylene succinate)/cellulose nanocrystal foams with exceptional thermal insulation. Carbohydr Polym 247, 116708 (2020). https://doi.org/10.1016/j.carbpol.2020.116708

407. M.S. Firouz, K. Mohi-Alden, M. Omid, A critical review on intelligent and active packaging in the food industry: Research 
and development. Food Res Int 141, 110113 (2021). https://doi. org/10.1016/j.foodres.2021.110113

408. J. Yang, M. Shen, Y. Luo et al., Advanced applications of chitosan-based hydrogels: from biosensors to intelligent food packaging system. Trends Food Sci Technol 110, 822-832 (2021). https://doi.org/10.1016/j.tifs.2021.02.032

409. I. Echeverría, M.E. López-Caballero, M.C. Gómez-Guillén et al., Active nanocomposite films based on soy proteins-montmorillonite-clove essential oil for the preservation of refrigerated bluefin tuna (Thunnus thynnus) fillets. Int J Food Microbiol 266, 142-149 (2018). https://doi.org/10.1016/j.jjfoodmicro.2017.10. 003

410. Y. Xu, N. Rehmani, L. Alsubaie et al., Tapioca starch active nanocomposite films and their antimicrobial effectiveness on ready-to-eat chicken meat. Food Packag Shelf Life 16, 86-91 (2018). https://doi.org/10.1016/j.fpsl.2018.02.006

411. W. Li, C. Zhang, H. Chi et al., Development of Antimicrobial Packaging Film Made from Poly(Lactic Acid) Incorporating Titanium Dioxide and Silver Nanoparticles. Molecules 22, 1170 (2017). https://doi.org/10.3390/molecules22071170

412. X. Zhai, Z. Li, J. Zhang et al., Natural Biomaterial-Based Edible and $\mathrm{pH}-$ Sensitive Films Combined with Electrochemical Writing for Intelligent Food Packaging. J Agric Food Chem 66, 1283612846 (2018). https://doi.org/10.1021/acs.jafc.8b04932

413. G. Göksen, M.J. Fabra, H.I. Ekiz, A. López-Rubio, Phytochemical-loaded electrospun nanofibres as novel active edible films: Characterization and antibacterial efficiency in cheese slices. Food Control 112, 107133 (2020). https://doi.org/10.1016/j. foodcont.2020.107133

414. J. Cai, D. Zhang, R. Zhou et al., Hydrophobic Interface Starch Nanofibrous Film for Food Packaging: From Bioinspired Design to Self-Cleaning Action. J Agric Food Chem 69, 5067-5075 (2021). https://doi.org/10.1021/acs.jafc.1c00230

415. E. Díaz-Montes, J. Yáñez-Fernández, R. Castro-Muñoz, Dextran/ chitosan blend film fabrication for bio-packaging of mushrooms (Agaricus bisporus). J Food Process Preserv 45, 1-12 (2021). https://doi.org/10.1111/jfpp.15489

416. N. Noshirvani, B. Ghanbarzadeh, R. Rezaei Mokarram, M. Hashemi, Novel active packaging based on carboxymethyl cellulose-chitosan-ZnO NPs nanocomposite for increasing the shelf life of bread. Food Packag Shelf Life 11, 106-114 (2017). https:// doi.org/10.1016/j.fps1.2017.01.010

417. V. Kanikireddy, K. Varaprasad, M.S. Rani et al., Biosynthesis of CMC-Guar gum-Ag0 nanocomposites for inactivation of food pathogenic microbes and its effect on the shelf life of strawberries. Carbohydr Polym 236, 116053 (2020). https://doi.org/10. 1016/j.carbpol.2020.116053

418. F. Versino, M. Urriza, M.A. García, Cassava-based biocomposites as fertilizer controlled-release systems for plant growth improvement. Ind Crops Prod 144, 112062 (2020). https://doi. org/10.1016/j.indcrop.2019.112062

419. L. Sartore, G. Vox, E. Schettini, Preparation and performance of novel biodegradable polymeric materials based on hydrolyzed proteins for agricultural application. J Polym Environ 21, 718725 (2013). https://doi.org/10.1007/s10924-013-0574-2

420. L. Sartore, E. Schettini, F. Bignotti et al., Biodegradable plant nursery containers from leather industry wastes. Polym Compos 39, 2743-2750 (2018). https://doi.org/10.1002/pc.24265

421. J. Rivadeneira, M. Audisio, A. Gorustovich, Films based on soy protein-agar blends for wound dressing: Effect of different biopolymer proportions on the drug release rate and the physical and antibacterial properties of the films. J Biomater Appl 32, 1231-1238 (2018). https://doi.org/10.1177/0885328218756653

422. A.M. Abdel-Mohsen, D. Pavliňák, M. Čileková et al., Electrospinning of hyaluronan/polyvinyl alcohol in presence of in-situ silver nanoparticles: Preparation and characterization. Int J Biol
Macromol 139, 730-739 (2019). https://doi.org/10.1016/j.ijbio mac.2019.07.205

423. L. Dejob, B. Toury, S. Tadier et al., Electrospinning of in situ synthesized silica-based and calcium phosphate bioceramics for applications in bone tissue engineering: a review. Acta Biomater 123, 123-153 (2021). https://doi.org/10.1016/j.actbio.2020.12. 032

424. J. Lamarra, M.N. Calienni, S. Rivero, A. Pinotti, Electrospun nanofibers of poly(vinyl alcohol) and chitosan-based emulsions functionalized with cabreuva essential oil. Int J Biol Macromol 160, 307-318 (2020). https://doi.org/10.1016/j.ijbiomac.2020. 05.096

425. H.-M. Wang, Y.-T. Chou, Z.-H. Wen et al., Novel Biodegradable Porous Scaffold Applied to Skin Regeneration. PLoS ONE 8, e56330 (2013). https://doi.org/10.1371/journal.pone.0056330

426. A. Jamal, L. Shahzadi, S. Ahtzaz et al., Identification of anticancer potential of doxazocin: Loading into chitosan based biodegradable hydrogels for on-site delivery to treat cervical cancer. Mater Sci Eng C 82, 102-109 (2018). https://doi.org/10.1016/j. msec.2017.08.054

427. A. Dasari, J. Quirós, B. Herrero et al., Antifouling membranes prepared by electrospinning polylactic acid containing biocidal nanoparticles. J Memb Sci 405-406, 134-140 (2012). https://doi. org/10.1016/j.memsci.2012.02.060

428. J. Miao, H. Liu, Y. Li, X. Zhang, Biodegradable Transparent Substrate Based on Edible Starch-Chitosan Embedded with Nature-Inspired Three-Dimensionally Interconnected Conductive Nanocomposites for Wearable Green Electronics. ACS Appl Mater Interfaces 10, 23037-23047 (2018). https://doi.org/10. 1021/acsami.8b04291

429. H. Sharififard, shahraki ZH, Rezvanpanah E, Rad SH, A novel natural chitosan/activated carbon/iron bio-nanocomposite: Sonochemical synthesis, characterization, and application for cadmium removal in batch and continuous adsorption process. Bioresour Technol 270, 562-569 (2018). https://doi.org/10. 1016/j.biortech.2018.09.094

430. M. Maryami, M. Nasrollahzadeh, E. Mehdipour, S.M. Sajadi, Preparation of the $\mathrm{Ag} / \mathrm{RGO}$ nanocomposite by use of Abutilon hirtum leaf extract: a recoverable catalyst for the reduction of organic dyes in aqueous medium at room temperature. Int $\mathrm{J}$ Hydrogen Energy 41, 21236-21245 (2016). https://doi.org/10. 1016/j.ijhydene.2016.09.130

431. A.M. Metak, F. Nabhani, S.N. Connolly, Migration of engineered nanoparticles from packaging into food products. LWT - Food Sci Technol 64, 781-787 (2015). https://doi.org/10.1016/j.lwt. 2015.06.001

432. B. Carla, A. Ale, M.F. Simoniello et al., Genotoxicity and oxidative stress in fish after a short-term exposure to silver nanoparticles. Ecol Indic 76, 230-239 (2017). https://doi.org/10.1016/j. ecolind.2017.01.018

433. C. Bidian, G.A. Filip, L. David et al., The impact of silver nanoparticles phytosynthesized with Viburnum opulus L extract on the ultrastrastructure and cell death in the testis of offspring arts. Food Chem Toxicol 150, 112053 (2021). https://doi.org/ 10.1016/j.fet.2021.112053

434. D. Briassoulis, A. Giannoulis, Evaluation of the functionality of bio-based plastic mulching films. Polym Test 67, 99-109 (2018). https://doi.org/10.1016/j.polymertesting.2018.02.019

435. Y. Yang, P. Li, J. Jiao et al., Renewable sourced biodegradable mulches and their environment impact. Sci Hortic (Amsterdam) 268, 109375 (2020). https://doi.org/10.1016/j.scienta.2020. 109375

436. D. Briassoulis, M. Hiskakis, E. Babou et al., Experimental investigation of the quality characteristics of agricultural plastic wastes regarding their recycling and energy recovery potential. 
Waste Manag 32, 1075-1090 (2012). https://doi.org/10.1016/j. wasman.2012.01.018

437. P. Siwek, I. Domagała-Świątkiewicz, P. Bucki, M. Puchalski, Biodegradable agroplastics in 21st century horticulture. Polimery/Polymers 64, 480-486 (2019). https://doi.org/10. 14314/polimery.2019.7.2

438. M. Yin, Y. Li, H. Fang, P. Chen, Biodegradable mulching film with an optimum degradation rate improves soil environment and enhances maize growth. Agric Water Manag 216, 127-137 (2019). https://doi.org/10.1016/j.agwat.2019.02.004

439. Y. Chae, Y.J. An, Current research trends on plastic pollution and ecological impacts on the soil ecosystem: a review. Environ Pollut 240, 387-395 (2018). https://doi.org/10.1016/j. envpol.2018.05.008

440. Z. Steinmetz, C. Wollmann, M. Schaefer et al., Plastic mulching in agriculture. Trading short-term agronomic benefits for long-term soil degradation? Sci Total Environ 550, 690-705 (2016). https://doi.org/10.1016/j.scitotenv.2016.01.153

441. F. Touchaleaume, L. Martin-Closas, H. Angellier-Coussy et al., Performance and environmental impact of biodegradable polymers as agricultural mulching films. Chemosphere 144, 433-439 (2016). https://doi.org/10.1016/j.chemosphere. 2015.09.006

442. L. Sartore, E. Schettini, L. de Palma et al., Effect of hydrolyzed protein-based mulching coatings on the soil properties and productivity in a tunnel greenhouse crop system. Sci Total Environ 645, 1221-1229 (2018). https://doi.org/10.1016/j.scito tenv.2018.07.259

443. G. Vox, E. Schettini, Evaluation of the radiometric properties of starch-based biodegradable films for crop protection. Polym Test 26, 639-651 (2007). https://doi.org/10.1016/j.polymertes ting.2007.03.010

444. A.P. Bilck, M.V.E. Grossmann, F. Yamashita, Biodegradable mulch films for strawberry production. Polym Test 29, 471-476 (2010). https://doi.org/10.1016/j.polymertesting.2010.02.007

445. F. Versino, M.A. García, Materiales eco-compatibles reforzados a base de almidón de mandioca para aplicaciones agronómicas. Matéria (Rio Janeiro) 23, 11 (2018). https://doi.org/10.1590/ s1517-707620180002.0545

446. P. Rychter, M. Kot, K. Bajer et al., Utilization of starch films plasticized with urea as fertilizer for improvement of plant growth. Carbohydr Polym 137, 127-138 (2016). https://doi.org/ 10.1016/j.carbpol.2015.10.051

447. B. Immirzi, G. Santagata, G. Vox, E. Schettini, Preparation, characterisation and field-testing of a biodegradable sodium alginatebased spray mulch. Biosyst Eng 102, 461-472 (2009). https://doi. org/10.1016/j.biosystemseng.2008.12.008

448. G. Scarascia-Mugnozza, E. Schettini, G. Vox et al., Mechanical properties decay and morphological behaviour of biodegradable films for agricultural mulching in real scale experiment. Polym Degrad Stab 91, 2801-2808 (2006). https://doi.org/10.1016/j. polymdegradstab.2006.02.017

449. P. Johnston, G. Freischmidt, C.D. Easton et al., Hydrophobichydrophilic surface switching properties of nonchain extended poly(urethane)s for use in agriculture to minimize soil water evaporation and permit water infiltration. J Appl Polym Sci 134, 1-12 (2017). https://doi.org/10.1002/app.44756

450. U. de Corato, I. de Bari, E. Viola, M. Pugliese, Assessing the main opportunities of integrated biorefining from agro-bioenergy co/by-products and agroindustrial residues into high-value added products associated to some emerging markets: a review. Renew Sustain Energy Rev 88, 326-346 (2018). https://doi.org/ 10.1016/j.rser.2018.02.041

451. L. Sartore, F. Bignotti, S. Pandini et al., Green composites and blends from leather industry waste. Polym. Compos. 37:12, 3416-3422 (2016). https://doi.org/10.1002/pc.23541
452. E. Schettini, L. Sartore, M. Barbaglio, G. Vox, Hydrolyzed protein based materials for biodegradable spray mulching coatings. Acta Hortic 952, 359-366 (2012). https://doi.org/10.17660/ ActaHortic.2012.952.45

453. H. Kono, Characterization and properties of carboxymethyl cellulose hydrogels crosslinked by polyethylene glycol. Carbohydr Polym 106, 84-93 (2014). https://doi.org/10.1016/j.carbpol. 2014.02.020

454. K. Baccaro, M. Degorgue, M. Lucca et al., Calidad de agua para consumo humano y riego en muestras del cintrurón hortícola de Mar del Plata. RIA Rev Investig Agropecu Inst Nac Tecnol Agropecu Argentina 35, 95-110 (2006)

455. M. Fernández-Pérez, F.J. Garrido-Herrera, E. González-Pradas, Alginate and lignin-based formulations to control pesticides leaching in a calcareous soil. J Hazard Mater 190, 794-801 (2011). https://doi.org/10.1016/j.jhazmat.2011.03.118

456. H. Hazrati, M.J. Saharkhiz, M. Niakousari, M. Moein, Natural herbicide activity of Satureja hortensis L. essential oil nanoemulsion on the seed germination and morphophysiological features of two important weed species. Ecotoxicol Environ Saf 142, 423-430 (2017). https://doi.org/10.1016/j.ecoenv.2017.04.041

457. A.M. Al-Enizi, M.M. Zagho, A.A. Elzatahry, Polymer-based electrospun nanofibers for biomedical applications. Nanomaterials 8, 1-22 (2018). https://doi.org/10.3390/nano8040259

458. T.G. Sahana, P.D. Rekha, Biopolymers: applications in wound healing and skin tissue engineering. Mol Biol Rep 45, 28572867 (2018). https://doi.org/10.1007/s11033-018-4296-3

459. S. Hamdan, I. Pastar, S. Drakulich et al., Nanotechnology-driven therapeutic interventions in wound healing: potential uses and applications. ACS Cent Sci 3, 163-175 (2017). https://doi.org/ 10.1021/acscentsci.6b00371

460. P. Kujath, A. Michelsen, Wounds - from physiology to wound dressing. Dtsch Aerzteblatt Online 105:. (2008).https://doi.org/ 10.3238/arztebl.2008.0239

461. E. Pinho, G. Soares, Functionalization of cotton cellulose for improved wound healing. J Mater Chem B 6, 1887-1898 (2018). https://doi.org/10.1039/c8tb00052b

462. K. Varaprasad, T. Jayaramudu, V. Kanikireddy et al., Alginatebased composite materials for wound dressing application:a mini review. Carbohydr Polym 236, 116025 (2020). https://doi.org/10. 1016/j.carbpol.2020.116025

463. I. Kalashnikova, S. Das, S. Seal, Nanomaterials for wound healing: scope and advancement. Nanomedicine 10, 2593-2612 (2015). https://doi.org/10.2217/nnm.15.82

464. K.T. Shalumon, K.H. Anulekha, S.V. Nair et al., Sodium alginate/ poly(vinyl alcohol)/nano $\mathrm{ZnO}$ composite nanofibers for antibacterial wound dressings. Int J Biol Macromol 49, 247-254 (2011). https://doi.org/10.1016/j.ijbiomac.2011.04.005

465. C. Chen, L. Liu, T. Huang et al., Bubble template fabrication of chitosan/poly(vinyl alcohol) sponges for wound dressing applications. Int J Biol Macromol 62, 188-193 (2013). https://doi.org/ 10.1016/j.ijbiomac.2013.08.042

466. D. Brett, A review of collagen and collagen-based wound dressings. Wounds 20:12, 347-356 (2008). https://pubmed.ncbi.nlm. nih.gov/25941895/

467. S.M. Keshk, Bacterial cellulose production and its industrial applications. J Bioprocess Biotech 04. (2014).https://doi.org/ 10.4172/2155-9821.1000150

468. M. Litwiniuk, A. Krejner, M.S. Speyrer et al., Hyaluronic acid in inflammation and tissue regeneration. Wounds 28:3, 78-88 (2016). https://pubmed.ncbi.nlm.nih.gov/26978861/

469. T. Dai, M. Tanaka, Y.Y. Huang, M.R. Hamblin, Chitosan preparations for wounds and burns: antimicrobial and wound-healing effects. Expert. Rev. Anti. Infect. Ther. 9:7, 857-879 (2011). https://doi.org/10.1586/eri.11.59

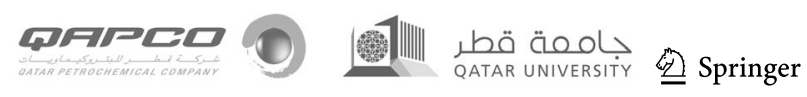


470. M. Zagho, E. Hussein, A. Elzatahry, Recent overviews in functional polymer composites for biomedical applications. Polymers 10:7, 739 (2018). https://doi.org/10.3390/polym10070739

471. C.J. Pérez-Guzmán, R. Castro-Muñoz, A review of zein as a potential biopolymer for tissue engineering and nanotechnological applications. Processes 8, 1-21 (2020). https://doi.org/10. 3390/pr8111376

472. R. Gauvin, Y.C. Chen, J.W. Lee et al., Microfabrication of complex porous tissue engineering scaffolds using 3D projection stereolithography. Biomaterials 33, 3824-3834 (2012). https:// doi.org/10.1016/j.biomaterials.2012.01.048

473. N. Iqbal, A.S. Khan, A. Asif et al., Recent concepts in biodegradable polymers for tissue engineering paradigms: a critical review. Int Mater Rev 64, 91-126 (2019). https://doi.org/10.1080/09506 608.2018.1460943

474. S. Khan, M. Ul-Islam, M. Ikram et al., Preparation and structural characterization of surface modified microporous bacterial cellulose scaffolds: a potential material for skin regeneration applications in vitro and in vivo. Int. J. Biol. Macromol. 117, 1200-1210 (2018). https://doi.org/10.1016/j.ijbiomac.2018.06.044

475. P. Song, C. Zhou, H. Fan et al., Novel 3D porous biocomposite scaffolds fabricated by fused deposition modeling and gas foaming combined technology. Compos Part B Eng 152, 151-159 (2018). https://doi.org/10.1016/j.compositesb.2018.06.029

476. N. Sarwar, H.U. Bin, M. Kumar et al., Citric acid mediated green synthesis of copper nanoparticles using cinnamon bark extract and its multifaceted applications. J Clean Prod 292, 125974 (2021). https://doi.org/10.1016/j. clepro.2021.125974

477. M. Faigón, Desarrollan telas antivirales para barbijos de uso social. In: CONICET. (2020). https://www.conicet.gov.ar/desar rollan-telas-antivirales-para-barbijos-de-uso-social/. Accessed 14 May 2021

478. L. Wu, S. Huang, J. Zheng et al., Synthesis and characterization of biomass lignin-based PVA super-absorbent hydrogel. Int J Biol Macromol 140, 538-545 (2019). https://doi.org/10.1016/j. ijbiomac.2019.08.142

479. C. Goldhahn, M. Schubert, T. Lüthi et al., Wood-gelatin biocomposite membranes with tunable flux. ACS Sustain Chem Eng 8, 7205-7213 (2020). https://doi.org/10.1021/acssuschem eng.0c01856

480. E. Gontarek-Castro, R. Castro-Muñoz, M. Lieder, New insights of nanomaterials usage toward superhydrophobic membranes for water desalination via membrane distillation: a review Crit. Rev. Environ. Sci. Technol. 0:1, 46. (2021). https://doi.org/10.1080/ 10643389.2021.1877032

481. R. Castro-Muñoz, Breakthroughs on tailoring pervaporation membranes for water desalination: a review. Water Res 187, 116428 (2020). https://doi.org/10.1016/j.watres.2020.116428

482. R. Castro-Muñoz, F. Galiano, V. Fíla et al., Mixed matrix membranes (MMMs) for ethanol purification through pervaporation: current state of the art. Rev Chem Eng 35, 565-590 (2019). https://doi.org/10. 1515/revce-2017-0115

483. R. Castro-Muñoz, F. Galiano, A. Figoli, Recent advances in pervaporation hollow fiber membranes for dehydration of organics. Chem. Eng. Res. Des. 1, 68-85 (2020). https://doi.org/10.1016/j. cherd.2020.09.028

484. R. Castro-Muñoz, Pervaporation: The emerging technique for extracting aroma compounds from food systems. J Food Eng 253, 27-39 (2019). https://doi.org/10.1016/j.jfoodeng.2019.02.013

485. R. Castro-Muñoz, M.Z. Ahmad, A. Cassano, Pervaporation-aided processes for the selective separation of aromas, fragrances and essential (AFE) solutes from agro-food products and wastes. Food Rev Int 00, 1-27 (2021). https://doi.org/10.1080/87559 129.2021.1934008

486. A. Msahel, F. Galiano, M. Pilloni et al., Exploring the effect of iron metal-organic framework particles in polylactic acid membranes for the azeotropic separation of organic/organic mixtures by pervaporation. Membranes (Basel) 11, 65 (2021). https://doi.org/10.3390/membranes11010065

487. C. Ursino, R. Castro-Muñoz, E. Drioli et al., Progress of nanocomposite membranes for water treatment. Membranes (Basel) 8, 18 (2018). https://doi.org/10.3390/membranes8020018

488. R. Castro-Muñoz, J. González-Valdez, New trends in biopolymerbased membranes for pervaporation. Molecules 24, 1-17 (2019). https://doi.org/10.3390/molecules24193584

489. M. Hasan, D.A. Gopakumar, V. Arumughan et al., Robust superhydrophobic cellulose nanofiber aerogel for multifunctional environmental applications. Polymers 11:3, 1-14 (2019). https://doi. org/10.3390/polym11030495

490. Y. Monroy, S. Rivero, M.A. García, Sustainable panels design based on modified cassava starch bioadhesives and wood processing byproducts. Ind Crops Prod 137, 171-179 (2019). https:// doi.org/10.1016/j.indcrop.2019.04.062

491. Y. Monroy, P. Seré, S. Rivero, M.A. García, Sustainable panels based on starch bioadhesives: an insight into structural and tribological performance. Int J Biol Macromol 148, 898-907 (2020). https://doi.org/10.1016/j.ijbiomac.2020.01.205

492. J. Miao, H. Liu, Y. Li, X. Zhang, Biodegradable transparent substrate based on edible starch-chitosan embedded with nature-inspired three-dimensionally interconnected conductive nanocomposites for wearable green electronics. ACS Appl Mater Interfaces 10, 23037-23047 (2018). https://doi.org/10.1021/ acsami.8b04291

493. A. Kafy, K.K. Sadasivuni, A. Akther et al., Cellulose/graphene nanocomposite as multifunctional electronic and solvent sensor material. Mater Lett 159, 20-23 (2015). https://doi.org/10.1016/j. matlet.2015.05.102

494. K.K. Sadasivuni, A. Kafy, H.C. Kim et al., Reduced graphene oxide filled cellulose films for flexible temperature sensor application. Synth Met 206, 154-161 (2015). https://doi.org/10. 1016/j.synthmet.2015.05.018

495. D. Ponnamma, Q. Guo, I. Krupa et al., Graphene and graphitic derivative filled polymer composites as potential sensors. Phys Chem Chem Phys 17, 3954-3981 (2015). https://doi.org/10. 1039/c4cp04418e

496. S. Thiangtham, J. Runt, N. Saito, H. Manuspiya, Fabrication of biocomposite membrane with microcrystalline cellulose (MCC) extracted from sugarcane bagasse by phase inversion method. Cellulose 27, 1367-1384 (2020). https://doi.org/10.1007/ s10570-019-02866-3

497. S. Spierling, E. Knüpffer, H. Behnsen et al., Bio-based plastics - a review of environmental, social and economic impact assessments. J Clean Prod 185, 476-491 (2018). https://doi.org/10. 1016/j.jclepro.2018.03.014

498. R. Shogren, D. Wood, W. Orts, G. Glenn, Plant-based materials and transitioning to a circular economy. Sustain Prod Consum 19, 194-215 (2019). https://doi.org/10.1016/j.spc.2019.04.007

499. M. Lima, C.A. da Silva Junior, T.D. Pelissari et al., Sugarcane: brazilian public policies threaten the Amazon and Pantanal biomes. Perspect Ecol Conserv 18, 210-212 (2020). https://doi. org/10.1016/j.pecon.2020.06.002

500. H. Schaumberg, Aboriginal conceptions of the forest in the soy era: frontiers of deforestation in the Argentine Chaco. Curr Opin Environ Sustain 43, 99-105 (2020). https://doi.org/10.1016/j. cosust.2020.04.007

501. H. van der Ven, C. Rothacker, B. Cashore, Do eco-labels prevent deforestation? Lessons from non-state market driven governance in the soy, palm oil, and cocoa sectors. Glob Environ Chang 52, 141-151 (2018). https://doi.org/10.1016/j.gloenvcha.2018.07. 002

502. M. Vigil, M. Pedrosa-Laza, J. Alvarez Cabal, F. Ortega-Fernández, Sustainability analysis of active packaging for the fresh cut 
vegetable industry by means of attributional \& consequential life cycle assessment. Sustainability 12, 7207 (2020). https://doi.org/ $10.3390 / \mathrm{su} 12177207$

503. G. Bishop, D. Styles, P.N.L. Lens, Environmental performance comparison of bioplastics and petrochemical plastics: a review of life cycle assessment (LCA) methodological decisions. Resour Conserv Recycl 168, 105451 (2021). https://doi.org/10.1016/j. resconrec.2021.105451

504. C.R. Álvarez-Chávez, S. Edwards, R. Moure-Eraso, K. Geiser, Sustainability of bio-based plastics: general comparative analysis and recommendations for improvement. J Clean Prod 23, 47-56 (2012). https://doi.org/10.1016/j.jclepro.2011.10.003
505. S. Hackenberg, A. Scherzed, M. Kessler et al., Silver nanoparticles: evaluation of DNA damage, toxicity and functional impairment in human mesenchymal stem cells. Toxicol Lett 201, 27-33 (2011). https://doi.org/10.1016/j.toxlet.2010.12.001

506. Z. Yu, W. Wang, F. Kong et al., Cellulose nanofibril/silver nanoparticle composite as an active food packaging system and its toxicity to human colon cells. Int J Biol Macromol 129, 887-894 (2019). https://doi.org/10.1016/j.ijbiomac.2019.02.084

507. F. Vilaplana, E. Strömberg, S. Karlsson, Environmental and resource aspects of sustainable biocomposites. Polym Degrad Stab 95, 2147-2161 (2010). https://doi.org/10.1016/j.polymdegra dstab.2010.07.016 